INSTITUTO DE PESQUISAS ENERGÉTICAS E NUCLEARES

Autarquia Associada à Universidade de São Paulo

\title{
Modernização de máquina de ensaio de fluência para estudo da liga Ti-6Al-4V
}

\section{EWERTON LUIZ COSTADELLE}

Dissertação apresentada como parte dos requisitos para obtenção do Grau de Mestre em Ciências na Área de Tecnologia Nuclear - Materiais

Orientador:

Prof. Dr. Antonio Augusto Couto 
INSTITUTO DE PESQUISAS ENERGÉTICAS E NUCLEARES

Autarquia Associada à Universidade de São Paulo

\section{Modernização de máquina de ensaio de fluência}

para estudo da liga Ti-6AI-4V

Versão Corrigida

\section{EWERTON LUIZ COSTADELLE}

Dissertação apresentada como parte dos requisitos para obtenção do Grau de Mestre em Ciências na Área de Tecnologia Nuclear - Materiais

Orientador:

Prof. Dr. Antonio Augusto Couto

São Paulo

2019 
Autorizo a reprodução e divulgação total ou parcial deste trabalho, para fins de estudo e pesquisa, desde que citada a fonte

Como citar:

COSTADELLE, E. L. Modernização de máquina de ensaio de fluência para estudo da liga Ti-6Al-4V. 2019. 78 f. Dissertação (Mestrado em Tecnologia Nuclear), Instituto de Pesquisas Energéticas e Nucleares, IPEN-CNEN/SP, São Paulo. Disponível em: 21/10/2019

Ficha catalográfica elaborada pelo Sistema de geração automática da Biblioteca IPEN/USP, com os dados fornecidos pelo(a) autor(a)

Costadelle, Ewerton Luiz

Modernização de máquina de ensaio de fluência para estudo da liga Ti-6Al-4V / Ewerton Luiz Costadelle; orientador

Antonio Augusto Couto. -- São Paulo, 2019.

$78 \mathrm{f}$.

Dissertação (Mestrado) - Programa de Pós-Graduação em Tecnologia Nuclear (Materiais) -- Instituto de Pesquisas Energéticas e Nucleares, São Paulo, 2019.

1. modernização. 2. instrumentação. 3. fluência. 4. caracterização. 5. titânio. I. Couto, Antonio Augusto, orient. II. Título. 


\section{AGRADECIMENTOS}

Agradeço ao COSMOS por permitir que tantas coisas maravilhosas ocorressem na minha vida, inclusive o fechamento do ciclo que compreende a entrada, a passagem e finalização deste curso. Aos meus pais, Jaime Costadelle e Luzia Gerlack Costadelle, que sempre me apoiaram em minhas decisões. À minha esposa, Larissa Nogueira, pelo apoio e tempo cedido. Ao Prof. Dr. Nelson Batista Duarte, pelo empréstimo das ferramentas. À Dra. Gisele Fabiane Costa Almeida, que tanto compartilhou seus conhecimentos e experiências. Aos amigos que tive o prazer de conhecer durante esta jornada, que muito compartilharam vivências e motivação. Ao Instituto Federal de Rondônia por incentivar a capacitação de seus colaboradores. A todos aqueles que contribuíram de forma direta ou indireta para a realização deste trabalho, em especial ao meu orientador, Prof. Dr. Antonio Augusto Couto, pelo empenho, dedicação e, principalmente, paciência. 
"Um mecânico vulgar pode praticar aquilo que Ihe foi ensinado ou viu ser feito, mas se ele estiver em erro, não sabe como desvendá-lo e corrigi-lo, e se você tirá-lo de sua rota, ele fica imóvel; enquanto que aquele capaz de refletir profunda e judiciosamente sobre figuras, força e movimento, nunca está em descanso, até superar todos os obstáculos" Isaac Newton 


\section{RESUMO}

COSTADELLE, E. L. Modernização de máquina de ensaio de fluência para estudo da liga Ti-6Al-4V. 2019. 78 f. Dissertação (Mestrado em Tecnologia Nuclear), Instituto de Pesquisas Energéticas e Nucleares, IPEN-CNEN/SP, São Paulo.

Este trabalho teve como objetivo desenvolver um conjunto de modernização para um equipamento de ensaio de fluência da marca The Electronic and Mechanical Engineering Co. Ltd. (EMEC), de propriedade do IPEN. Para tanto, obteve características mecânicas. Além disso, modelou e simulou o comportamento do dispositivo de aplicação de tração. Este estudo também desenvolveu um dispositivo eletrônico de baixo custo baseado na plataforma Arduino para registrar a deformação e controlar a temperatura da amostra em torno de $\pm 2^{\circ} \mathrm{C}$. Para validar os resultados, foram realizados ensaios em amostras do mesmo lote. Tanto no equipamentos EMEC quanto em outros dois modelos diferentes, eles eram um Zwick (fabricado em 2015 e pertencente à UPM) e um Mayes (modernizado há cerca de 20 anos e pertencente ao DCTA). No EMEC a taxa de fluência estacionária para a liga Ti6Al4V foi de $2,71 \times 10^{-4} s^{-1}$ e tempo total até a ruptura foi de $619 s$, no Zwick estes valores foram de $2,85 \times 10^{-4} s^{-1}$ e $615 s$, respectivamente, e no Mayes, $5,04 \times 10^{-4} s^{-1}$ e $321 s$.

Palavras chave: modernização, instrumentação, fluência, caracterização, titânio 


\begin{abstract}
COSTADELLE, E. L. Creep-test machine modernization for Ti-6Al-4V alloy study. 2019. 78 f. Dissertação (Mestrado em Tecnologia Nuclear), Instituto de Pesquisas Energéticas e Nucleares, IPEN-CNEN/SP, São Paulo.
\end{abstract}

This work aimed to develop a modernization suite for The Electronic and Mechanical Engineering Co. Ltd. (EMEC) creep-test equipment that is the property of IPEN. Therefore, it obtained mechanical characteristics. Also, it modelled and simulated the behaviour of the traction application device. This study also developed a low-cost electronic device based on the Arduino platform to, record the deformation and control the specimen temperature around $\pm 2{ }^{\circ} \mathrm{C}$ during the test. To validate the results, it performed tests on samples from the same batch. Both in EMEC equipment and two other different models, they were a Zwick (manufactured in 2015 and belonging to UPM) and a Mayes (modernized about 20 years ago and belonging to DCTA). At EMEC the steady-state creep rate for Ti6Al4V alloy was $2.71 \times 10^{-4} s^{-1}$ and creep total time to rupture was $619 \mathrm{~s}$, at Zwick these values were $2.85 \times 10^{-4} \mathrm{~s}^{-1}$ and $615 s$, respectively, and in Mayes, 5,04 $\times 10^{-4} s^{-1}$ and $321 s$.

Keywords: retrofit, instrumentation, creep, characterization, titanium 


\section{LISTA DE FIGURAS}

Figura 1 - Estágios de deformação por fluência e taxas de deformação. .................18

Figura 2 - Esquemático de um equipamento de ensaio de fluência .......................20

Figura 3 - Conjunto de milivoltimetro, termopar e compensação de junção. ............22

Figura 4 - Tensão do termopar produzida por cada tipo em função da temperatura 23

Figura 5 - Esquema de um LVDT, com o núcleo em diferentes posições. 26

Figura 6 - Esquema representativo de um número decimal. .27

Figura 7 - Esquema de um forno controlado por um dispositivo digital ...................32

Figura 8 - Diagrama de blocos de um sistema retroalimentado ............................32

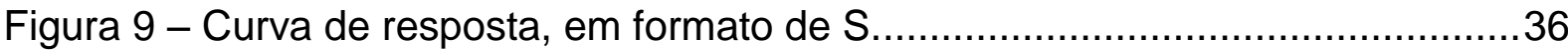

Figura 10 - Oscilação sustentada com período crítico (segundos)........................37

Figura 11 - Diagrama de corpo-livre de um braço de alavanca. ...........................40

Figura 12 - Fluxograma de ações para a modernização do equipamento EMEC. ...43

Figura 13 - Algoritmo de análise do braço de alavanca....................................44

Figura 14 - Rotina produzida no SciLab para análise do braço de alavanca...........45

Figura 15 - Relé de estado sólido........................................................46

Figura 16 - Placa ADC para termopar tipo K. ..............................................46

Figura 17 - Placa Arduino Nano com conexão de bornes parafusados ...................47

Figura 18 - Configuração do ensaio de indutância do TD-43. .............................49

Figura 19 - Dimensões e formato do corpos de prova......................................51

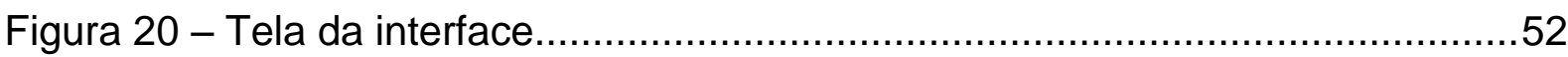

Figura 21 - Distribuição das zonas de aquecimento do forno............................54

Figura 22 - Vistas frontal e lateral do equipamento EMEC, pertencente ao IPEN...55

Figura 23 - Esquemático do mecanismo de força ...........................................56

Figura 24 - Tração na amostra, em função do alongamento.................................57

Figura 25 - Curva de aquecimento e resfriamento nas três zonas do forno. ............59

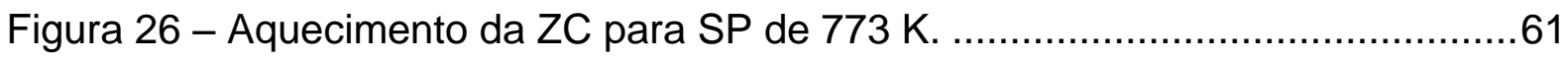

Figura 27 - Recorte de 500s no aquecimento da ZC para SP de $773 \mathrm{~K} \ldots \ldots \ldots \ldots \ldots . . . . . .61$

Figura 28 - Curva de aquecimento durante ensaio de fluência com SP de 873 K....62

Figura 29 - Indutâncias do TD-43 em função do deslocamento do núcleo. 
Figura 30 - Simulação da resposta em função do deslocamento. ...........................63

Figura 31 - Leitura do ADC em função do deslocamento real ..................................64

Figura 32 - Curva da deformação em função do tempo (EMEC).............................64

Figura 33 - Imagem do equipamento Zwick, pertencente à UPM..........................66

Figura 34 - Oscilação da força provocado pelo equipamento Zwick .......................66

Figura 35 - Curva da deformação em função do tempo (Zwick) .............................67

Figura 36 - Imagem do equipamento Mayes, pertencente ao DCTA.......................68

Figura 37 - Temperatura durante o ensaio em função do tempo.............................69

Figura 38 - Recorte de um registro de alongamento ...........................................70

Figura 39 - Curva da deformação em função do tempo (Mayes) ............................70

Figura 40 - Sobreposição das curvas de deformação em função do tempo ..............71 


\section{LISTA DE TABELAS}

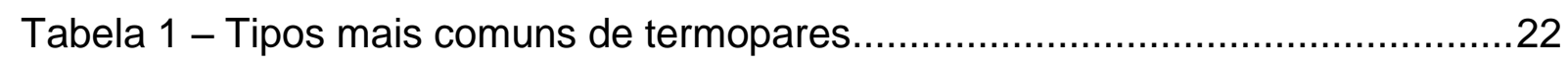

Tabela 2 - Regra de ZN para sintonia pelo método de malha aberta .......................35

Tabela 3 - Regra de ZN para sintonia pelo método de malha fechada ....................37

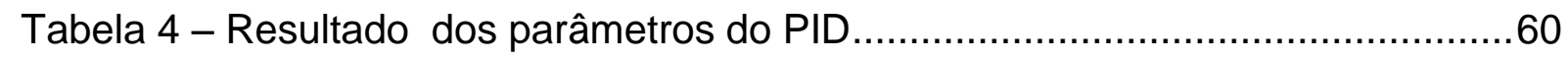

Tabela 5 - Parâmetros obtidos com os ensaios nos diferentes equipamentos..........71 


\title{
LISTA DE SÍMBOLOS E ABREVIATURAS
}

\author{
$\delta \quad$ Alongamento \\ $\varepsilon \quad$ Deformação \\ $\theta \quad$ Ângulo de rotação \\ $\sigma \quad$ Tração normal \\ $\tau_{a} \quad$ Constante de tempo de aquecimento \\ $\tau_{r} \quad$ Constante de tempo de resfriamento \\ $\phi \quad$ Ângulo formado por dois vetores \\ $\Omega \quad$ Ohm (resistência elétrica) \\ AC Corrente alternada (alternating current) \\ ADC Conversor de Analógico para Digital (Analog to Digital Converter) \\ Al Alumínio (elemento químico) \\ AMR Divisão de Materiais \\ B Barra \\ CCTM Centro de Ciência e Tecnologia de Materiais \\ $\mathrm{Cl} \quad$ Circuito integrado \\ $\mathrm{Cr} \quad$ Cromo (elemento químico) \\ CSV Texto separado por vírgulas (Comma-separated values). \\ DC Corrente Contínua \\ DCTA Departamento de Ciência e Tecnologia Aeroespacial \\ EMEC The Electronic and Mechanical Engineering Co. Ltd. \\ $\overrightarrow{F_{1}} \quad$ Força-peso (vetor de posição) \\ $\overrightarrow{F_{2}} \quad$ Força no braço menor da alavanca \\ $\mathrm{Fe} \quad$ Ferro (elemento químico)
}


H Histerese

${ }^{2} \mathrm{C} \quad$ Circuito Inter-integrado (Inter-Integrated Circuit).

IAE Instituto de Aeronáutica e Espaço

IDE Ambiente de Desenvolvimento Integrado (Integrated Development Environment)

IPEN Instituto de Pesquisas Energéticas e Nucleares

IPT Instituto de Pesquisas Tecnológicas

$I_{x, y} \quad$ Junta inferior (coordenada cartesiana)

K Kelvin (temperatura)

kHz Quilo hertz (frequência)

kN Quilo-newton

$\mathrm{Kp} \quad$ Proporcional

$L_{0} \quad$ Comprimento inicial

LEME Laboratório de Ensaios Mecânicos

LVDT Transformador Diferencial Variável Linear (Linear Variable Differential Transformer)

MIMO Sistema de múltiplas entradas com múltiplas saídas (multiple input multiple output)

mm Milímetro

$\overrightarrow{M_{o}} \quad$ Momento em relação a origem

$\mathrm{MPa} \quad$ Megapascal

$\mathrm{mV} \quad$ Milivolt

ND Conjunto de ruídos (noise data)

$\mathrm{Ni} \quad$ Níquel (elemento químico)

$\mathrm{Nm} \quad$ Newton-metro (torque)

o Origem (coordenada cartesiana)

PC Computador pessoal (Personal computer) 
PID Proporcional-integral-derivativo (controle)

$P_{x, y} \quad$ Eixo de força potente (coordenada cartesiana)

$\mathrm{RD} \quad$ Conjunto de dados brutos (raw data)

RMS Valor eficaz ou valor quadrático médio (Root Mean Square)

$R_{x, y} \quad$ Eixo de força resistente (coordenada cartesiana)

S Segundo (tempo)

SD Dados alisados (smoothed data).

SP Entrada Programada (Set Point)

SPI Interface de comunicação de dados em série síncrona (Serial Peripheral Interface)

SSR Relé de estado sólido (Solid State Relay)

$t \quad$ Tempo

Td Tempo derivativo (constante)

$\mathrm{Ti}$ Tempo integral (constante), Titânio (elemento)

$T_{\max } \quad$ Temperatura máxima

TPC Termopar da zona central

TPI Termopar da zona inferior

TPS Termopar da zona superior

$\overrightarrow{T_{R I}} \quad$ Tração do ponto $\mathrm{R}$ em relação a I

V Vanádio (elemento químico), volt (tensão elétrica)

Vpp Tensão de pico-a-pico (corrente alternada)

W Watt (potência elétrica)

ZC Zona central

Zl Zona inferior

ZS Zona superior 


\section{SUMÁRIO}

Página

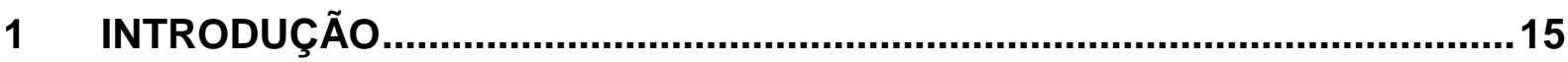

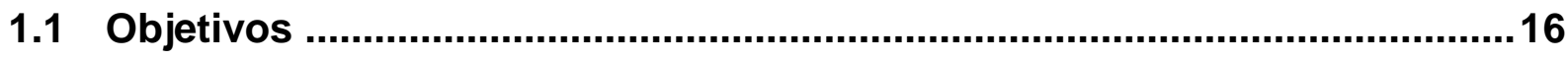

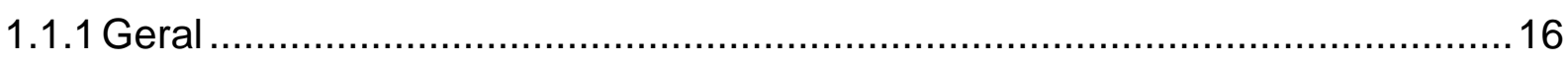

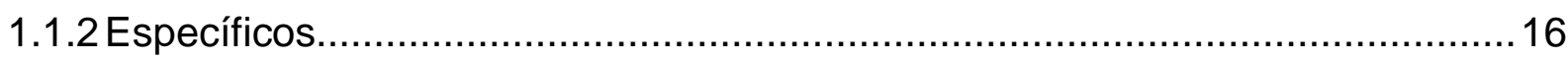

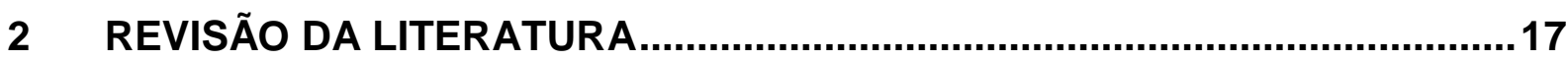

2.1 Avaliação das taxas de fluência ..................................................................18

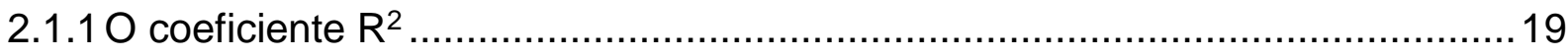

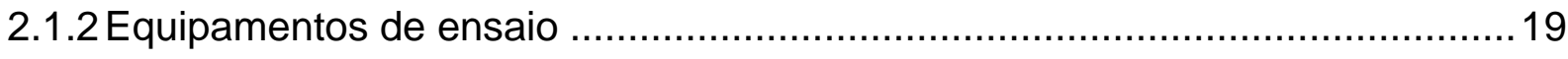

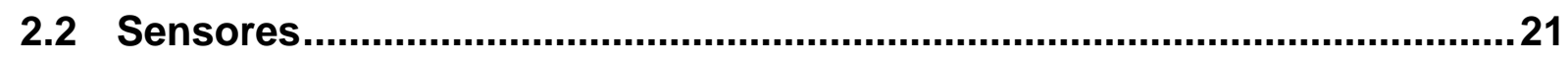

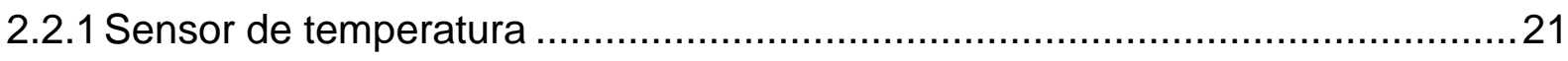

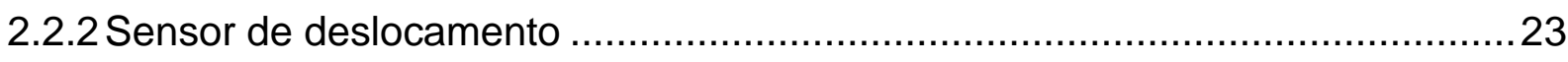

2.3 Conversão de analógico para digital ........................................................26

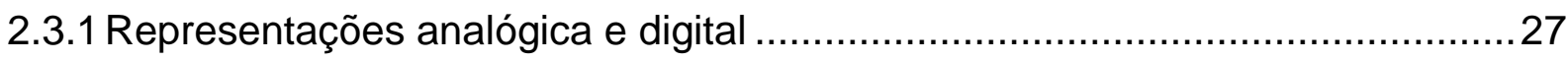

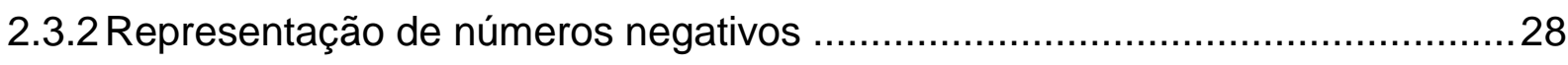

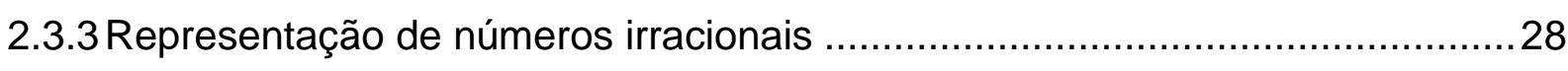

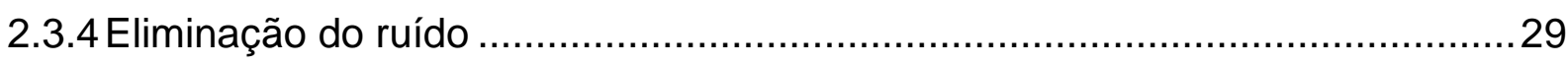

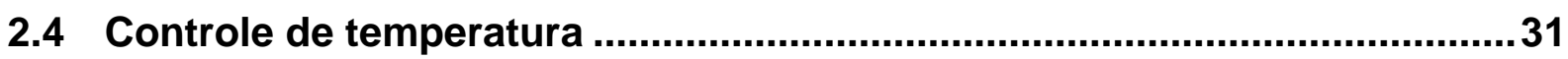

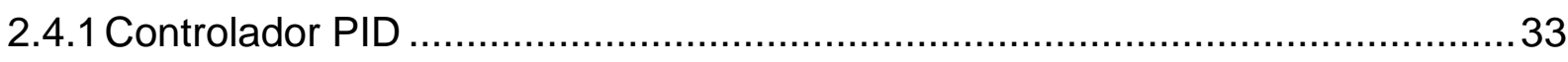

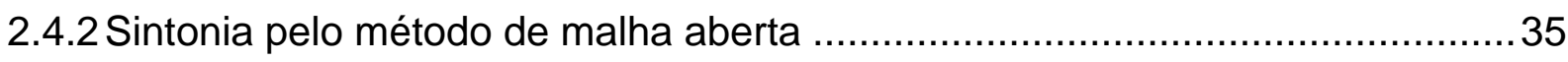

2.4.3 Sintonia pelo método de malha fechada ........................................................ 35

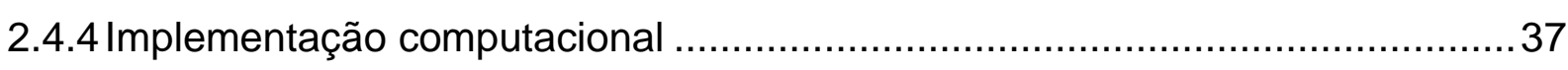

2.5 Modelagem do braço de alavanca ............................................................. 


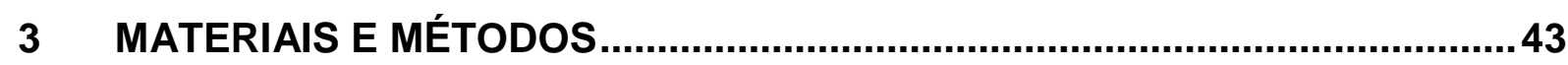

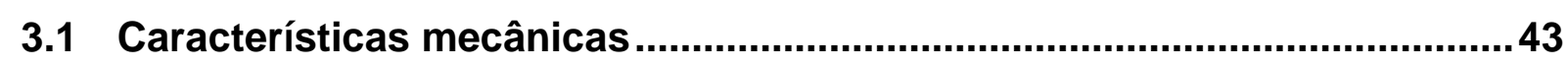

3.1.1 Análise numérica do braço de alavanca ...................................................... 44

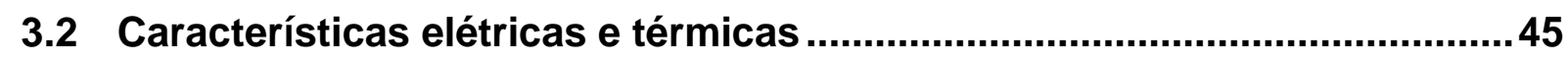

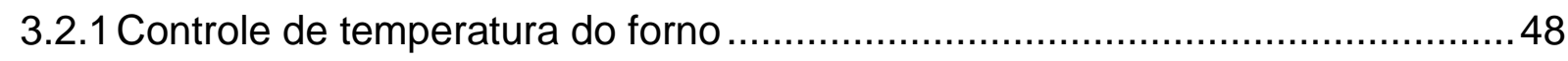

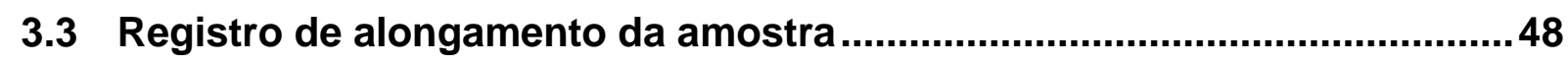

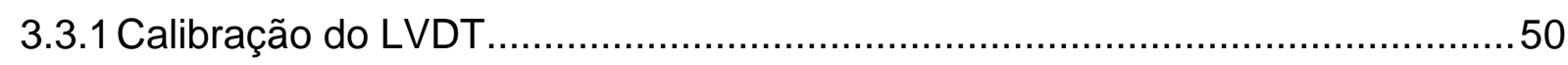

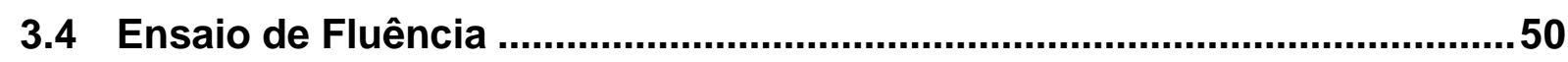

3.4.1 Instalação do conjunto de modernização no equipamento EMEC .....................51

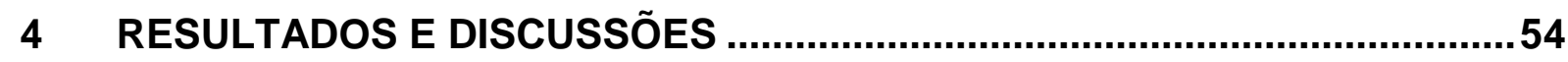

4.1 Processo de modernização do equipamento EMEC (IPEN) ........................54

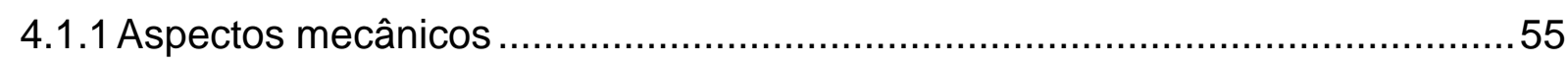

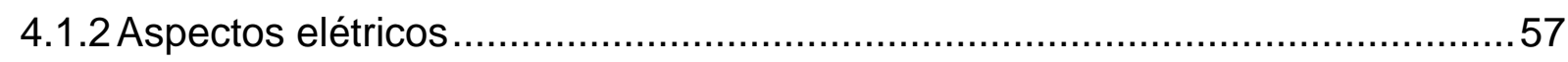

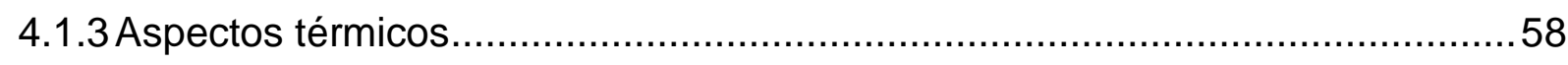

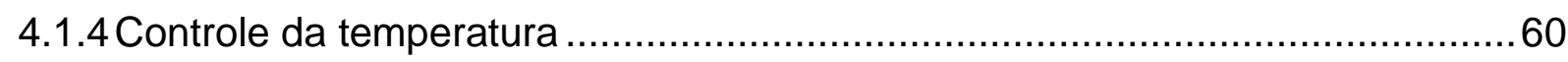

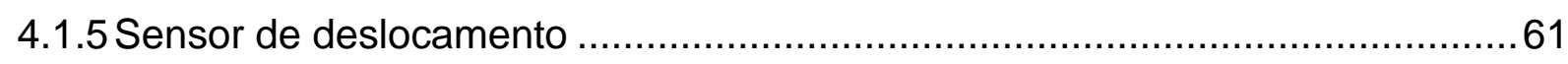

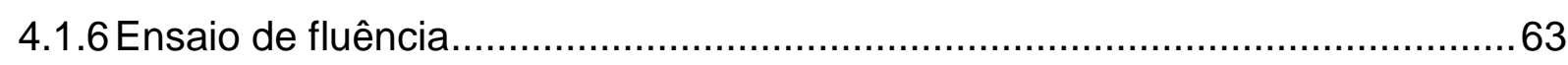

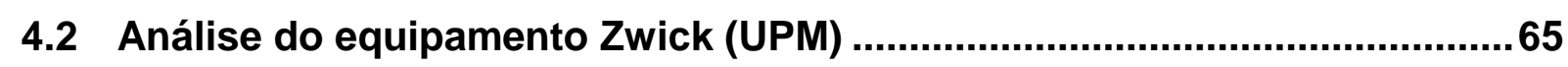

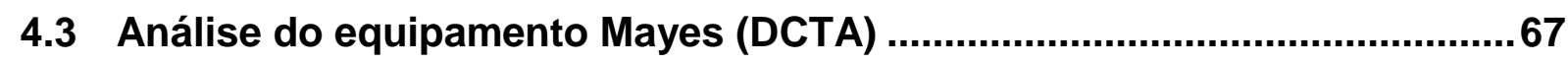

4.4 Comparação entre os resultados dos ensaios............................................70

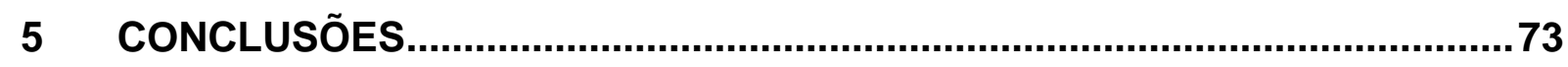

REFERÊNCIAS BIBLIOGRÁFICAS...........................................................75 


\section{INTRODUÇÃO}

O desenvolvimento de um produto requer atenção à sua confiabilidade. Não obstante, o mercado tem exigido redução no preço, peso e volume das máquinas e equipamentos. Nesta dicotomia, busca-se evitar o superdimensionamento dos componentes, uma vez que a negligência na atribuição das margens de segurança provoca efeitos na contramão do que se espera (JUVINALL e MARSHEK, 2012).

A resposta de uma peça é previsível quando o comportamento mecânico do material que a compõe é conhecida para uma condição de esforço. A fim de obter estas características, amostras de materiais são analisadas em um processo denominado ensaio, que consiste em aplicar condições esforços pré-estabelecidas em amostras de materiais com o propósito de determinar suas reações, definindo os parâmetros de projeto capazes de prever falhas (GARCIA, SPIN e SANTOS, 2012). Os danos mais conhecidos são as fraturas e as deformações indesejadas.

Os dispositivos também estão sujeitos a combinações de fatores externos, que, mesmo abaixo da zona de deformação permanente, podem ocasionar problemas com o uso prolongado. A combinação da elevação da tensão com a elevação de temperatura acelera uma avaria, geralmente uma fratura, provocada por um fenômeno denominado fluência (CALLISTER, 2007). Conceitualmente fluência é a deformação permanente, dependente do tempo, em um sólido sujeito a uma carga constante (AMERICAN SOCIETY FOR TESTING AND MATERIALS, 2011). É uma reação macroscópica ocasionada pela movimentação das discordâncias na microestruturas da matéria que compõe este corpo. O calor contribui para esta movimentação em nível atômico. A elevação da temperatura provoca, além do aumento da deformação instantânea, por dilatação, a elevação nas taxas de fluência no estado estacionário (AMERICAN SOCIETY FOR TESTING AND MATERIALS, 1996).

O Centro de Ciência e Tecnologia de Materiais (CCTM) do Instituto de Pesquisas Energéticas e Nucleares (IPEN) possui um equipamento para o ensaio da de fluência. Esta máquina foi doada inoperante ao IPEN pelo Departamento de Ciência e Tecnologia Aeroespacial (DCTA). 
Este trabalho está organizado da seguinte maneira, no Capítulo 2 é apresentado o referencial teórico utilizado, bem como são descritas os memoriais de cálculo que fundamentam as análises. No Capítulo 3 é apresentado o material utilizado neste projeto, bem como são descritas as técnicas de ensaios e análises utilizadas. O Capítulo 4 reserva os resultados e as discussões. O Capítulo 5 apresenta as conclusões.

\section{$1.1 \quad$ Objetivos}

\subsubsection{Geral}

Neste contexto, o objetivo geral deste trabalho foi modernizar a máquina de ensaio de fluência, através de controle eletrônico da temperatura, coleta automatizada das variáveis, que facilitem a obtenção de gráficos, e produzam resultados confiáveis de ensaio.

\subsubsection{Específicos}

Para tanto, algumas etapas precisaram ser concluídas, quais sejam:

- Analisar outros equipamentos semelhantes.

- Levantar as características mecânicas do equipamento EMEC

- Obter características elétricas e térmicas do forno

- Controlar a temperatura dentro do limite de $\pm 2{ }^{\circ} \mathrm{C}$

- Registrar o alongamento da amostra

- Ensaiar uma liga metálica, em condições disponíveis na literatura

- Comparar os resultados com os outros equipamentos 


\section{REVISÃO DA LITERATURA}

Conceitualmente "fluência é a deformação permanente, dependente do tempo, em um sólido sujeito a uma carga constante" (AMERICAN SOCIETY FOR TESTING AND MATERIALS, 2011). O ensaio de fluência consiste na aplicação de uma carga de tração uniaxial estática sobre uma amostra entre 0,4 e 0,7 da temperatura absoluta de fusão. No decorrer do teste o corpo sofre deformação que, quando plotada em função do tempo, produz uma curva caracterizada por três regiões. Na primeira região existe uma resposta quase instantânea, seguida de uma diminuição da taxa de deformação com o tempo. A segunda região é onde a deformação aumenta linearmente com o tempo. Esta região é chamada de estado estacionário ou estágio de fluência secundária e, do ponto de vista prático, é a mais importante. Já a terceira região é chamada de estágio de fluência terciária, onde a taxa de deformação aumenta rapidamente com o tempo, até a ocorrência da falha catastrófica. Tipicamente, a resistência à fluência de um sólido é estimada pelo cálculo da taxa de deformação secundária e avaliada como função da carga ou tensão aplicada. A elevação da temperatura, da tensão, ou ambas, resulta no aumento da deformação instantânea e nas taxas de fluência no estado estacionário, além da diminuição no tempo para falha (GARCIA, SPIN e SANTOS, 2012; CALLISTER, 2007; AMERICAN SOCIETY FOR TESTING AND MATERIALS, 2011; AMERICAN SOCIETY FOR TESTING AND MATERIALS, 1996; FROST e ASHBY, 1982).

Segundo a U.S. Army Test and Evaluation Command (1968), a maioria dos dispositivos de carga aplicam a força de pesos-mortos à amostra através de braços de alavanca. Geralmente estes dispositivos não tem a capacidade de compensar as mudanças na área da seção transversal da amostra, porém, é satisfatório para testes de fluência de longo tempo e para testes de fluência onde a deformação total antes da ruptura seja pequena. Para testes de fluência de curta duração ou testes de fluência de tensão constantes, faz-se necessária uma máquina de carregamento com capacidade de carga variável. A tensão aplicada deve ser medida com uma precisão de um por cento e deve-se evitar a torção ou flexão na amostra. A excentricidade pode ser evitada utilizando hastes longas ou juntas flexíveis. 
Em suas pesquisas com a liga Ti-6Al-4V, Reis (2005) utilizou uma solução proprietária, um equipamento modernizado por uma empresa privada, a BSW Tecnologia, Industrial e Comércio Ltda, pertencente ao Laboratório de Ensaios Mecânicos (LEME) da Divisão de Materiais (AMR) do Instituto de Aeronáutica e Espaço (IAE) do Departamento de Ciência e Tecnologia Aeroespacial (DCTA), localizado em São José dos Campos, SP.

\subsection{Avaliação das taxas de fluência}

A fluência dos materiais é classicamente associada à plasticidade dependente do tempo sob uma tensão fixa e em uma temperatura elevada, geralmente superior a metade da temperatura absoluta de fusão. Na Figura 1 são delineadas três regiões: fluência primária, que denota a porção em que a taxa de fluência diminui com o aumento da deformação. Em seguida aparece o estágio de fluência secundária, ou estado estacionário, em que há uma taxa de deformação quase constante. Nesse ponto o comportamento pode ser descrito por uma reta tangente. A fluência terciária é caracterizada pela elevação repentina da taxa de deformação e ocorre pela cavitação ou aumento de rachaduras, que culmina na ruptura. $O$ início deste terceiro estágio é marcado pela divergência entre o valor observado e o descrito pela reta tangente (KASSNER, 2009).

Figura 1 - Estágios de deformação por fluência e taxas de deformação.

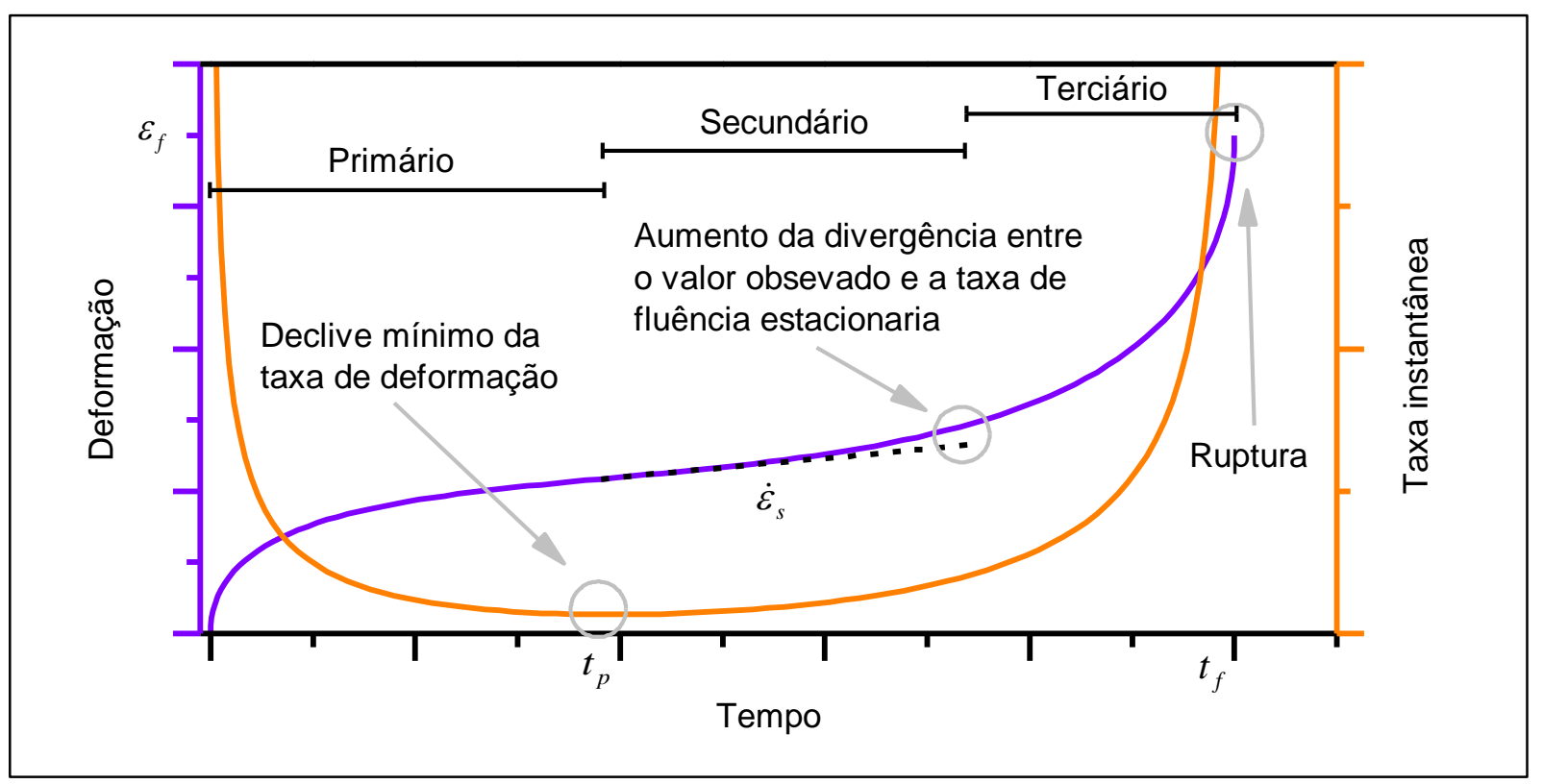

Fonte: autor da dissertação. 
Para avaliar o estado estacionário, alguns parâmetros devem ser registrados, seu início o ocorre após o tempo de fluência primária $\left(t_{p}\right)$. Registra-se, também a taxa de fluência secundária $\left(\dot{\varepsilon}_{s}\right)$, dada pelo coeficiente de inclinação da reta tangente, o tempo final de fratura $\left(t_{f}\right)$ e a deformação de fratura $\left(\varepsilon_{f}\right)$.

De fato, como é selecionada a menor taxa, há uma tendência da curva divergir da reta tangente. Normalmente utiliza-se um coeficiente de determinação da reta de forma que pelo menos $99 \%$ dos pontos estejam próximos à reta.

\subsubsection{O coeficiente $R^{2}$}

Segundo (LARSON e FARBER, 2010), uma das formas de avaliar a qualidade do ajuste de um modelo pode ser feita através do coeficiente de determinação da reta $\left(R^{2}\right)$. Basicamente, este coeficiente indica quanto o modelo foi capaz de explicar os dados coletados. O coeficiente de determinação é dado pela Equação (1):

$$
R^{2}=1-\frac{\sum_{i=1}^{n}\left(y_{i}-\bar{y}\right)^{2}}{\sum_{i=1}^{n}\left(y_{i}-\hat{y}_{i}\right)^{2}}
$$

onde:

$n$ é o número de observações;

$y_{i}$ é o valor observado;

$\bar{y}$ é a média das observações; e

$\hat{y}_{i}$ é o valor estimado.

$\mathrm{O} R^{2}$ é, portanto, uma medida descritiva da qualidade do ajuste obtido. Em geral é referido como a quantidade de variabilidade nos dados que é explicada pelo modelo linear empregado. Desta maneira, quando este coeficiente tende a ficar menor que $99,9 \%$ entende-se que iniciou-se o estágio terciário de fluência.

\subsubsection{Equipamentos de ensaio}

Os procedimentos de ensaio são padronizados pelas normas ASTM E139 e ISO 204. Usualmente empregam-se corpos de prova cilíndricos submetidos a solicitação uniaxial. Os ensaios são classificados como ruptura por fluência, fluência à carga constante, fluência à tensão constante e ensaio de relaxação. 
$\mathrm{Na}$ ruptura por fluência, avalia-se o efeito da temperatura na capacidade de suportar cargas por tempos longos. Mede-se o tempo necessário para a ruptura dos corpos de prova. Os ensaios de fluência sob carga constante e tensão constante são empregados quanto é necessário conhecer a curva de fluência. Neste último caso, mede-se a variação de comprimento do corpo de prova durante o ensaio. Já no ensaio de relaxação a deformação é mantida constante e mede-se a variação da força necessária.

As máquinas convencionais utilizam um sistema de alavanca e peso morto para a aplicação de carga constante, como a apresentada na Figura 2. Estes equipamentos, ainda, capturam a temperatura do corpo de prova, através do contato direto de um termopar e o alongamento, através de um sensor de deslocamento linear.

Figura 2 - Esquemático de um equipamento de ensaio de fluência

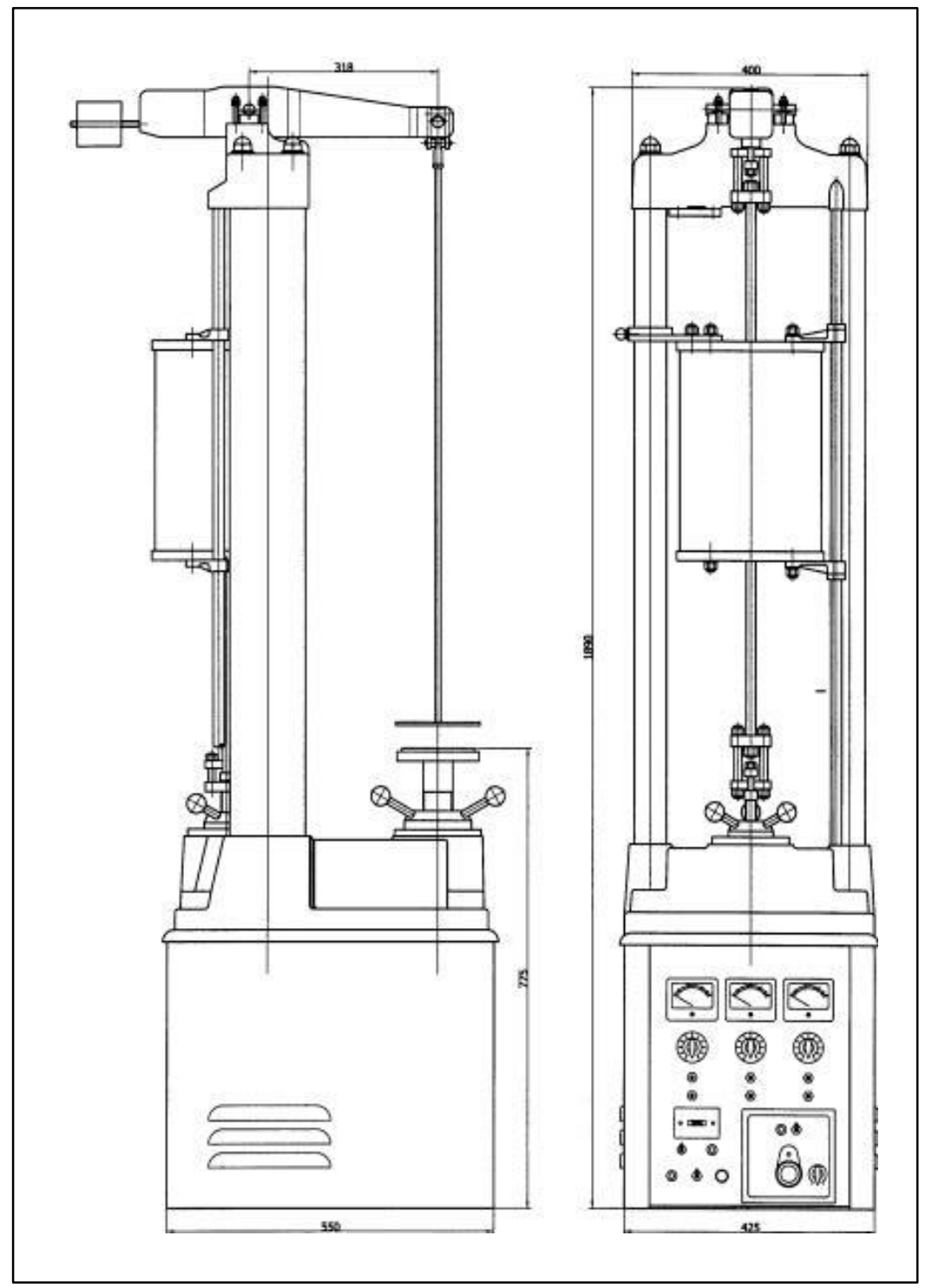

Fonte: Reis (2005) 


\subsection{Sensores}

Para que o controlador e registrador possa interpretar as grandezas físicas, seja de temperatura ou de deslocamento, é necessário que os sensores convertam essa grandeza física em uma grandeza elétrica, geralmente uma tensão. Nesse sentido, a saída do sensor é apenas uma representação da grandeza física e pode assumir valores contínuos dentro de um intervalo definido.

\subsubsection{Sensor de temperatura}

Decerto que os ensaios de fluência na liga Ti-6Al-4V são realizados em temperaturas que podem chegar a $800^{\circ} \mathrm{C}$, a medição desta grandeza se restringe aos termopares. Abdelaziz (2012) definiu estes sensores como a junção de dois condutores de materiais diferentes em um circuito em que, caso haja diferença de temperatura entre as junções, o fenômeno termoelétrico denominado efeito seebeck suscita a circulação de corrente elétrica neste circuito. Factualmente, ocorre porque cada material possui um potencial eletroquímico diferente e a difusão de elétrons é desigual. Ou seja, os elétrons livres são diferentes em cada um dos condutores. Este efeito foi descoberto em 1821 pelo físico alemão Thomas Johann Seebeck.

Desta maneira, em um termopar normatizado e conhecendo-se a temperatura em um junta de referência, chamada de junção fria, é possível medir a temperatura da outra extremidade verificando-se a tensão elétrica e comparando com os dados tabelados para a junta de medida. Esta tensão está na ordem de milivolts (TICIANELLI e GONZALEZ, 1998).

Há duas possibilidade de obter a referência. A primeira e menos utilizada por questões práticas é manter a junção fria em uma temperatura no ponto de fusão do gelo $\left(0^{\circ} \mathrm{C}\right)$, como mostrado na Figura 3 . Outra maneira é utilizar outro método de medição para determinar a temperatura ambiente e realizar a compensação de junção fria, somando-se os valores obtidos. Segundo Melo (2010) é possível prolongar seus terminais utilizando-se de um cabo de compensação para liga-lo a um aparelho de medição eletrônica. 
Figura 3 - Conjunto de milivoltimetro, termopar e compensação de junção.

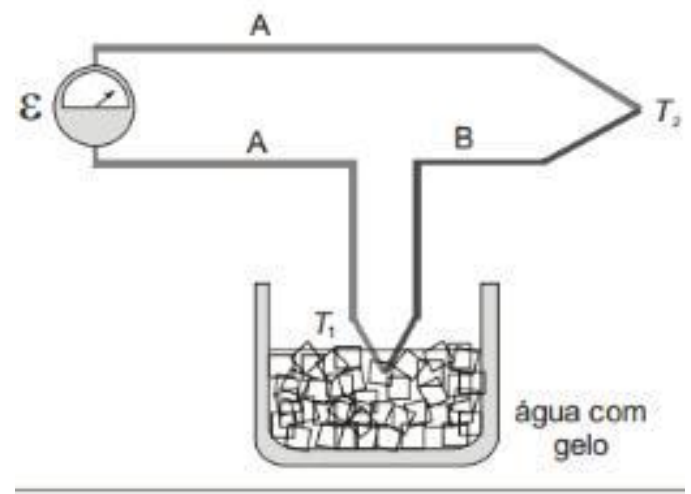

Fonte: Melo (2010)

Durante a seleção do termopar deve-se buscar a adequação à aplicação desejada, tomando-se por base as características dos tipos disponíveis, dentre as quais pode-se destacar a faixa de temperaturas de trabalho, a exatidão e a confiabilidade das leituras naquela faixa. Na Tabela 1 é apresentado um resumo dos tipos de termopares mais comuns.

Tabela 1 - Tipos mais comuns de termopares

\begin{tabular}{clcc}
\hline Tipo & Composição & $\begin{array}{c}\text { Faixa } \\
(\mathrm{K})\end{array}$ & $\begin{array}{c}\text { Sensibilidade } \\
(\mu \mathrm{V} / \mathrm{K})\end{array}$ \\
\hline K & Cromel e Alumel & 73 a 1523 & 41 \\
E & Cromel e Constantan & 73 a 1173 & 68 \\
J & Ferro e Constantan & 233 a 1023 & 51 \\
N & Nicrosil e Nisil & 3 a 1573 & - \\
R & Platina e Ródio-Platina & 573 a 1873 & 7 \\
S & Platina e Ródio-Platina & 573 a 1873 & 7 \\
B & Platina e Ródio-Platina & 573 a 2073 & 10 \\
T & Cobre e Constantan & 3 a 673 & 40 \\
C & Tungstênio e Rênio & 273 a 2593 & - \\
M & Niquel e Niquel-Molibidênio & 273 a 1673 & - \\
\hline
\end{tabular}

Fonte: OMEGA Engineering (2019) 
$\mathrm{Na}$ Figura 4 são apresentadas as curvas de tensão características (em milivolts) dos tipos mais comuns de termopares em função da diferença de temperatura entre as junções.

Figura 4 - Tensão do termopar produzida por cada tipo em função da temperatura

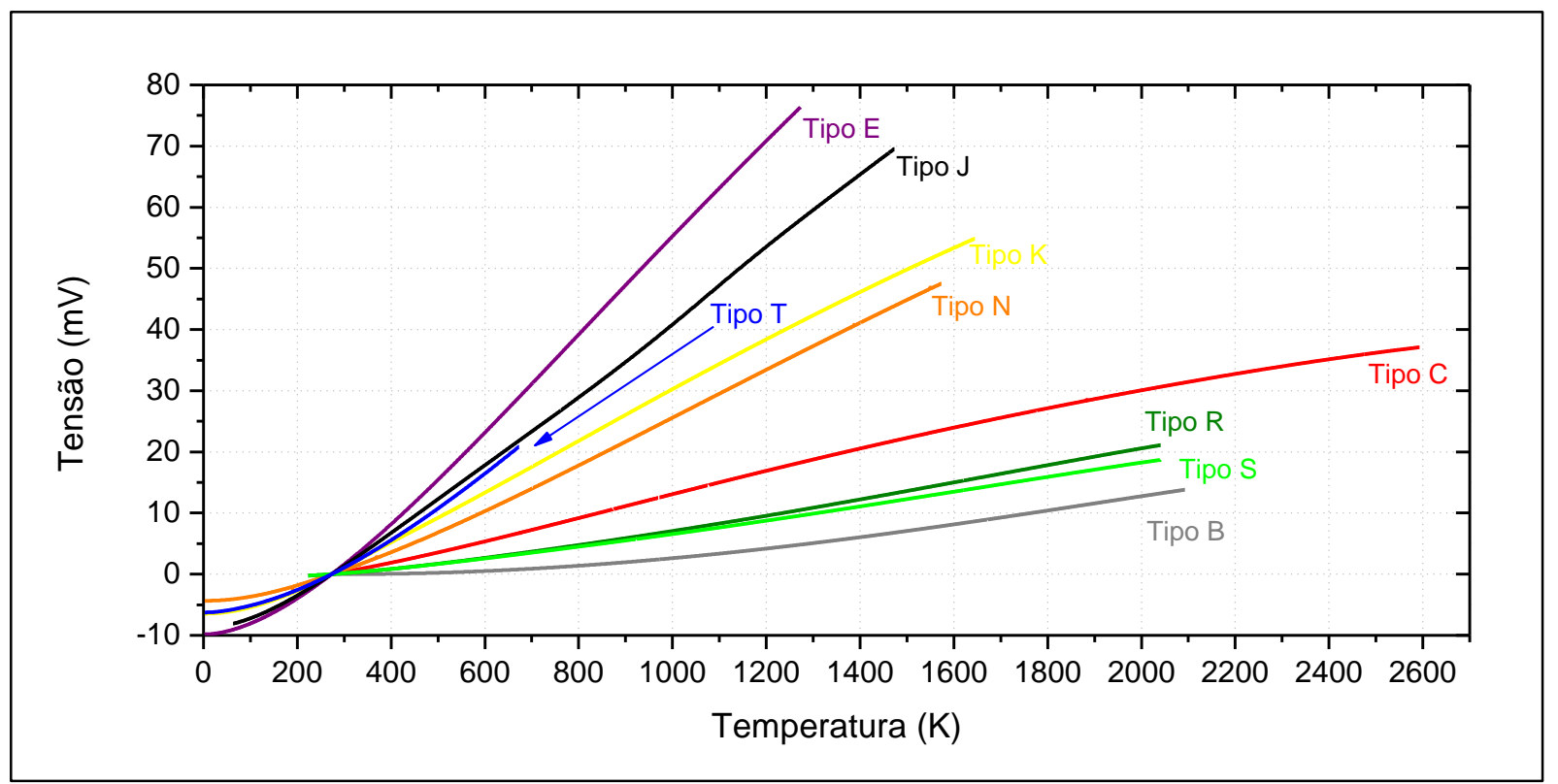

Fonte: National Institute of Standards and Technology (2008 ) - Elaboração do autor

\subsubsection{Sensor de deslocamento}

Segundo Dieter (1961), a deformação $(\varepsilon)$ é a relação entre o alongamento $(\delta)$ e o comprimento inicial da amostra $\left(L_{0}\right)$. E, como o método mais comum do ensaio de fluência consiste na obtenção de uma curva da deformação, ou de sua primeira derivada $(\dot{\varepsilon})$, em função do tempo $(t)$. Faz-se necessário medir o alongamento da amostra.

Outra vez, as temperaturas elevadas são complicadores do processo de medição. E, com a finalidade de reproduzir deformação no lado externo do forno, são empregadas hastes extensométricas, de modo que um sensor possa capturar a deformação sem sofrer os efeitos térmicos. Os extensômetros devem ser fabricados em material com baixo coeficiente de dilatação e resistente ao aquecimento, a fim de evitar que as leituras sejam comprometidas.

Um dos sensores mais utilizado para medir o deslocamento linear é o Transformador Diferencial Variável Linear (LVDT - Linear Variable Differential Transformer) e possui inúmeras vantagens em relação à alternativa usual, que são os 
transdutores potenciométricos. Dentre as quais, pode-se citar a medição com baixíssimo atrito, vida mecânica infinita, excelente resolução e ótima repetibilidade (AL-SHARIF, KILANI, et al., 2011).

Segundo Boylestad (2012), o princípio de um transformador está no acoplamento entre dois enrolamentos. Quando excitada com uma corrente alternada, a bobina primária produz um campo magnético variante no tempo que, por meio de um núcleo, induz outra corrente na bobina secundária. De modo que surge uma tensão alternada no secundário $\left(v_{S}\right)$. Esta tensão depende do produto da impedância $\left(z_{s}\right)$ pela corrente $\left(i_{s}\right)$ no secundário, como demonstrado na Equação (2).

$$
v_{s}=z_{s} \cdot i_{s}
$$

Em primeiro lugar, a impedância é o módulo de um número complexo em que a resistência elétrica $(r)$ é a parte real e a reatância $\left(x_{L}\right)$, neste caso indutiva, representa a parte imaginária. Assim, a Equação (3) demonstra a formulação a fim de obtê-la.

$$
z=\sqrt{x_{L}^{2}+r^{2}}
$$

Por sua vez, a reatância indutiva, que é a oposição a passagem de corrente dependente da velocidade angular $(\omega)$ da tensão alternada e pode ser representada pela Equação (4).

$$
x_{L}=L \cdot \omega
$$

Além disso, a velocidade angular é diretamente proporcional à frequência, como demostrado na Equação (5).

$$
\omega=2 \cdot \pi \cdot f
$$

E, a corrente no secundário é diretamente proporcional a corrente no enrolamento primário e inversamente proporcional a um fator de transformação $(a)$, como demonstrado na Equação (6). 


$$
i_{s}=\frac{i_{p}}{a}
$$

De maneira análoga às Equações (2) à (5), pode-se relacionar a corrente no enrolamento primário com a sua indutância, tensão e frequência de excitação.

De todo modo, em um acoplamento magnético ideal, a relação de transformação entre dois indutores é dada pelo quociente das suas indutâncias, como exibido na Equação (7).

$$
a=\frac{L_{s}}{L_{p}}
$$

\subsubsection{LVDT}

De outro ponto de vista, os LVDTs, que também são baseados no princípio da indução mútua, possuem um enrolamento primário e dois secundários, como exibido na Comercialmente, os LVDTs estão disponíveis para cobrir faixas de $\pm 0,25$ $\mathrm{mm}$ a $\pm 75 \mathrm{~mm}$. Eles são sensíveis o suficiente para serem usados para responder a deslocamentos abaixo de $0,5 \mu \mathrm{m}$. E podem ser encontrados em faixas de temperatura operacional que vão de $8 \mathrm{~K}$ a $873 \mathrm{~K}$. Estes sensores também estão disponíveis em projetos resistentes a radiação para operação em reatores nucleares. Para um LVDT típico de $\pm 25 \mathrm{~mm}$, a tensão de alimentação recomendada é de $4 \mathrm{~V}$ a $6 \mathrm{~V}$, com uma frequência nominal de $5 \mathrm{kHz}$, e uma não-linearidade máxima de $1 \%$ da escala total . Sua sensibilidade nominal determina o valor da tensão de saída para cada $1 \mathrm{~V}$ na excitação, quando em seu deslocamento nominal.

Figura 5. Os secundários são construídos para serem semelhantes, senão idênticos. Quando o núcleo está na posição central, ambos possuem a mesma indutância e, quando há excitação no primário, a mesma tensão elétrica. (DRUMEA, VASILE, et al., 2006). Desta maneira, a diferença entre as tensões nos dois secundários é zero e por esta razão este ponto central é chamado de null-point. Com a mudança de posição do êmbolo ferromagnético (núcleo), a força eletromotriz induzida nos secundários deixa de ser simétrica, provocando diferença de tensão ente eles. 
Comercialmente, os LVDTs estão disponíveis para cobrir faixas de $\pm 0,25 \mathrm{~mm}$ a $\pm 75 \mathrm{~mm}$. Eles são sensíveis o suficiente para serem usados para responder a deslocamentos abaixo de $0,5 \mu \mathrm{m}$. E podem ser encontrados em faixas de temperatura operacional que vão de $8 \mathrm{~K}$ a $873 \mathrm{~K}$. Estes sensores também estão disponíveis em projetos resistentes a radiação para operação em reatores nucleares. Para um LVDT típico de $\pm 25 \mathrm{~mm}$, a tensão de alimentação recomendada é de $4 \mathrm{~V}$ a $6 \mathrm{~V}$, com uma frequência nominal de $5 \mathrm{kHz}$, e uma não-linearidade máxima de $1 \%$ da escala total (EREN, 1999). Sua sensibilidade nominal determina o valor da tensão de saída para cada $1 \mathrm{~V}$ na excitação, quando em seu deslocamento nominal.

Figura 5 - Esquema de um LVDT, com o núcleo em diferentes posições.

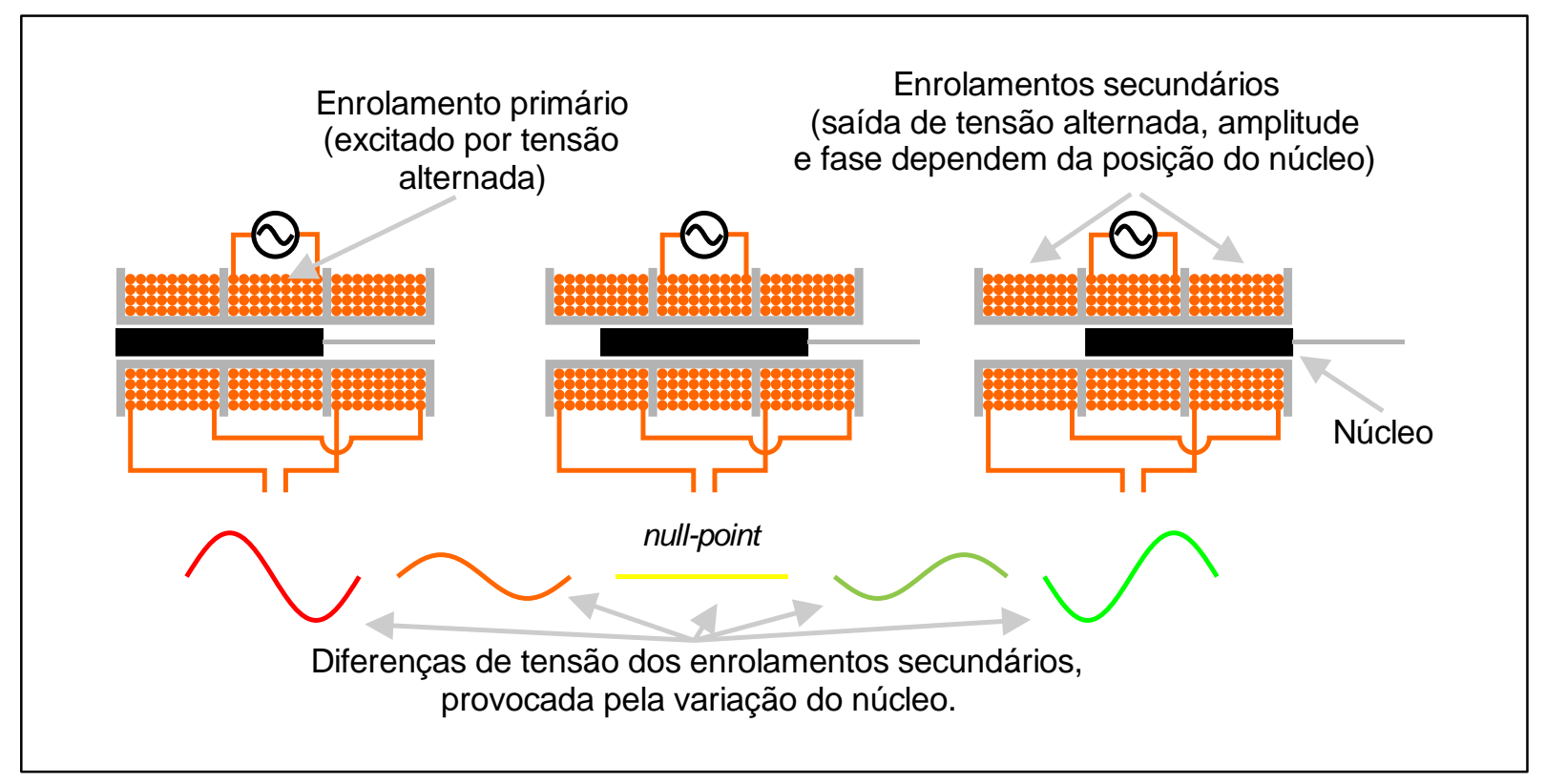

Fonte: Powell (2013) - adaptado

Desta maneira, os LVDTs demandam um equipamento eletrônico adicional, capaz de produzir a tensão de excitação e de medir a diferença da tensão induzida. Este dispositivo é chamado de condicionador de sinais e, geralmente, relacionam o deslocamento a uma tensão contínua.

\subsection{Conversão de analógico para digital}

Como os controladores atuais são digitais, a tensão elétrica de saída dos sensores ou condicionadores, que são analógicos, precisam ser convertidas para grandezas digitais, que por essência são valores numéricos limitados. De forma geral, um Conversor de Analógico para Digital (ADC - Analog to Digital Converter) 
transforma amostras de um sinal contínuo em um valor finito. Estes fatores limitantes, intrínsecos do ADC, promovem uma discretização dos sinais e, por consequência, os valores intermediários aos degraus previamente estabelecidos são ignorados (OPPENHEIM, WILLSKY e NAWAB, 2010).

Nesse processo de conversão, chama-se de quantização a definição de qual é o valor que cada degrau discreto possui. A quantidade de dígitos binários disponíveis para armazenar esse valor determinam a resolução do ADC. De modo que, um conversor com maior número de bits produz resultados com aproximações menores.

\subsubsection{Representações analógica e digital}

Segundo Tocci (2011), os primórdios humanos utilizaram seus dedos para contar. Tanto é que a palavra digitus significa dedo em latim. Porém, foi o agrupamento de números de dez em dez e a consequente representação em unidades, dezenas e centenas, entre outros, que culminou no sistema de numeração decimal. Este modo de representação multiplica o valor de um símbolo pelo peso da sua posição. De modo que os algarismos mais à esquerda são os mais significativos (MSD - Most Significant Digit) e à direita menos (LSD - Less Significant Digit). Na Figura 6 é possível visualizar um esquema representativo do número "2019”, em que a posição do "2" Ihe confere a maior significância. Neste exemplo, o peso total do dígito mais à esquerda é 2 mil, este valor foi obtido pela multiplicação do algarismo pela potência de dez elevado à sua posição, enquanto o LSD vale apenas 9.

Figura 6 - Esquema representativo de um número decimal.

\begin{tabular}{|cccc|}
\hline milhar & centena & dezena & unidade \\
2 & 0 & 1 & 9 \\
$\times 10^{3}$ & $\times 10^{2}$ & $\times 10^{1}$ & $\times 10^{0}$ \\
MSD & & & LSD \\
\hline
\end{tabular}

Fonte: autor da dissertação

De forma similar, os computadores digitais representam um conjunto de números pelos sinais elétricos que são capazes de interpretar. Na maioria destes dispositivos este conjunto é formado pela informação desligado e ligado, que foram expressos matematicamente pelos algarismos 0 e 1, respectivamente. Neste sistema binário a menor informação possível é chamada de bit - uma redução da expressão 
em língua inglesa binary digit. De modo que a quantidade de símbolos para representar estados definem a base do sistema, neste caso 2. Quando trata-se do conjunto de números naturais (inteiros positivos), a posição indica a significância. De modo que um número de $n$ bits é capaz de representar $2^{n}$ valores distintos. De maneira análoga a utilizada no sistema decimal, há uma descrição para o bit mais significativo (MSB) e para o menos significativo (LSB).

\subsubsection{Representação de números negativos}

Por outro lado não há uma maneira direta de representar números binários negativos. Porém em todas as alternativas disponíveis a magnitude do maior número representado é comprometida para armazenar o sinal. Dentre as várias técnicas, uma delas é subtrair uma tendência, ou bias, definido previamente. Para exemplificar, um número de 10 bits com bias de 511 pode representar números inteiros entre -511 e +512. Outro método empregado é o complemento de 2 , no qual a operação "NÃOlógico" (NAND - not and), inverte os valores, ou seja, os 0s são substituídos por 1s e os $1 \mathrm{~s}$ por 0s. Posteriormente soma-se o número 1 ao valor. Esta técnica é empregada basicamente porque facilita a operação de subtração utilizando apenas operações lógicas. Desta maneira o número é armazenado em um formato que contribui para melhoria de desempenho em operações futuras.

\subsubsection{Representação de números irracionais}

Uma vez que as limitações construtivas permitem armazenar apenas um conjunto finito de valores, os computadores digitais são capazes de armazenar apenas números inteiros ou a combinação de alguns números em um racional. $\mathrm{E}$, neste sentido, a representação de um número irracional sempre será a partir de um arredondamento para um racional.

Uma alternativa para reduzir os erros é o emprego de um número de ponto flutuante, que segundo a IEEE Computer Society (2008), é um formato de representação numérica finita que possui três componentes: um sinal, um expoente e uma mantissa. A precisão desta representação é definida pelo número máximo de dígitos significativos que podem ser representados, ou o número de dígitos para o qual um resultado é arredondado. 
Por conseguinte, a informação em ponto flutuante de precisão simples possui 32 bits dos quais o bit mais à esquerda representa o sinal, 0 para positivo e 1 para negativo. Os próximos 8 bits representam o expoente de uma potência de 2 e é um número inteiro que possui um bias de 127. Esta potência multiplica uma mantissa de 23 bits. Se comparado com um racional, formado por dois inteiros, a representação por ponto flutuante é capaz de armazenar um espectro maior de valores.

\subsubsection{Eliminação do ruído}

A conversão de um valor contínuo em degraus, por si só, provoca ruídos. Adicionalmente os cabos e conexões estão sujeitos às interferências eletromagnéticas, térmicas, entre outras, de forma que os ruídos estão sempre presentes. Muitas vezes, para eliminar ou diminuir algum ruído indesejável em um sinal, é necessário filtrá-lo. Essa filtragem pode ser analógica, quando o sinal contínuo é tratado antes da conversão, ou após ela, por um filtro digital. E este último é implementado através de programação e é comum quando se trabalha com sinais provenientes do ADC (GRAY e NEUHOFF, 1998).

Segundo Scandelari (2013) o filtro de média móvel é obtido calculando-se a média de um conjunto de valores, sempre se adicionando um novo valor ao conjunto e se descartando o mais velho. Não é apenas uma média de um conjunto isolado de valores é representado na Equação (8).

$$
y(k)=\frac{1}{m} \cdot \sum_{n=0}^{m-1} x(k-n)
$$

onde:

$x(k)$ é a leitura atual da variável de entrada,

$y(k)$ é a saída e

$m$ é a janela do filtro.

A quantidade de ruído reduzida é igual a raiz quadrada do número de pontos, ou janela, do filtro. Ao utilizar coeficientes fixos, o filtro de média móvel produz um filtro passa baixa suave, reduzindo os sinais de alta frequência. Caso se deseje outro tipo de filtragem, será necessário a multiplicação com valores fracionários, o que exigirá o 
uso de ponto flutuante no programa. Isso pode ser um problema para microcontroladores de 8 bits pelo consumo maior de memória e da limitada capacidade de processamento da CPU.

É possível implementar um filtro média móvel com um algoritmo rápido, uma vez que a implementação por convolução é lenta. Seja um filtro média móvel com janela $m=7$. Dois pontos de saída adjacentes são calculados da seguinte forma:

$$
\begin{aligned}
& y^{\prime}(51)=\frac{y(47)+y(48)+y(49)+y(50)+y(51)+y(52)+y(53)}{7} \\
& y^{\prime}(52)=\frac{y(48)+y(49)+y(50)+y(51)+y(52)+y(53)+y(54)}{7}
\end{aligned}
$$

Uma vez que os pontos $y(48) \cdots y(53)$ aparecem em $y^{\prime}(51)$ e $y^{\prime}(52)$, a melhor maneira para calcular $y^{\prime}(53)$ é:

$$
y^{\prime}(53)=y^{\prime}(52)+\frac{y(55)-y(48)}{7}
$$

Mesmo assim, armazenar janelas com número elevado de dados pode exigir Processadores ou Controladores Digital de Sinais (DSP, Digital Signal Processors ou DSC, Digital Signal Controllers). Uma alternativa é acrescentar uma malha de realimentação ao filtro. De modo que este elo de recursão simplifique a construção. $\mathrm{Na}$ Equação (12) é exibido um filtro digital de Média Móvel Exponencial (EMA Exponential Moving Average), em que um fator $\alpha$ atribui pesos entre a leitura atual e as média anterior.

$$
y(k)=\alpha \cdot x(k)+(1-\alpha) \cdot y(k-1)
$$

Se considerar $\beta=(1-\alpha)$ e aplicar a transformada $Z$ obtém-se a Equação (13).

$$
Y(Z)=\alpha \cdot X(Z)+\beta \cdot Y(Z) \cdot Z^{-1}
$$


Ao dividir $Y(Z)$ pela Equação (13), é possível obter o função de transferência $\left(G(Z)=\frac{Y(Z)}{X(Z)}\right)$, exibida na Equação (14).

$$
G(Z)=\frac{\alpha}{\beta \cdot\left(\frac{1}{\beta}-z^{-1}\right)}
$$

De modo que, a Equação (15) representa o sistema de primeira ordem deste filtro.

$$
G(Z)=\frac{\alpha z}{z-\beta}
$$

\subsection{Controle de temperatura}

Segundo a U.S. Army Test and Evaluation Command (1968), o forno elétrico e o dispositivo regulador de temperatura são os itens mais importantes do equipamento de ensaio de fluência. $O$ aquecedor do forno geralmente consiste em fio de níquel-cromo ( $\mathrm{NiCr}$ ) enrolado em um tubo refratário. Os enrolamentos são próximos, de modo que os gradientes de temperatura ao longo da amostra possam ser reduzidos. Uma cobertura isolante é colocada em torno do forno para conservar energia e evitar flutuações de temperatura.

De modo geral, os processos térmicos são difíceis de controlar, uma vez que apresentam resposta excessivamente lenta, o resultado disto é a variabilidade da temperatura real dentro do forno. Outro complicador é que na prática os aquecedores elétricos não respondem linearmente às suas entradas e mudam suas características físicas em função do tempo (OGATA, 2010; LIYING e GUOSHU, 2008).

Ogata (2010) descreve o processo simplificado de controle digital da temperatura de um forno elétrico. No qual um termopar coleta o sinal analógico referente a temperatura e um ADC transforma a temperatura em um dado digital, que o controlador é capaz de interpretar. Este último compara o valor lido com o inserido na Entrada Programada (SP - Set Point) e atua ligando e desligando o aquecedor, a fim de manter a temperatura dentro de níveis pré-estabelecidos. Na Figura 7 é 
mostrado o esquema para controle digital de um forno com aquecimento por intermédio de um resistor elétrico.

Figura 7 - Esquema de um forno controlado por um dispositivo digital

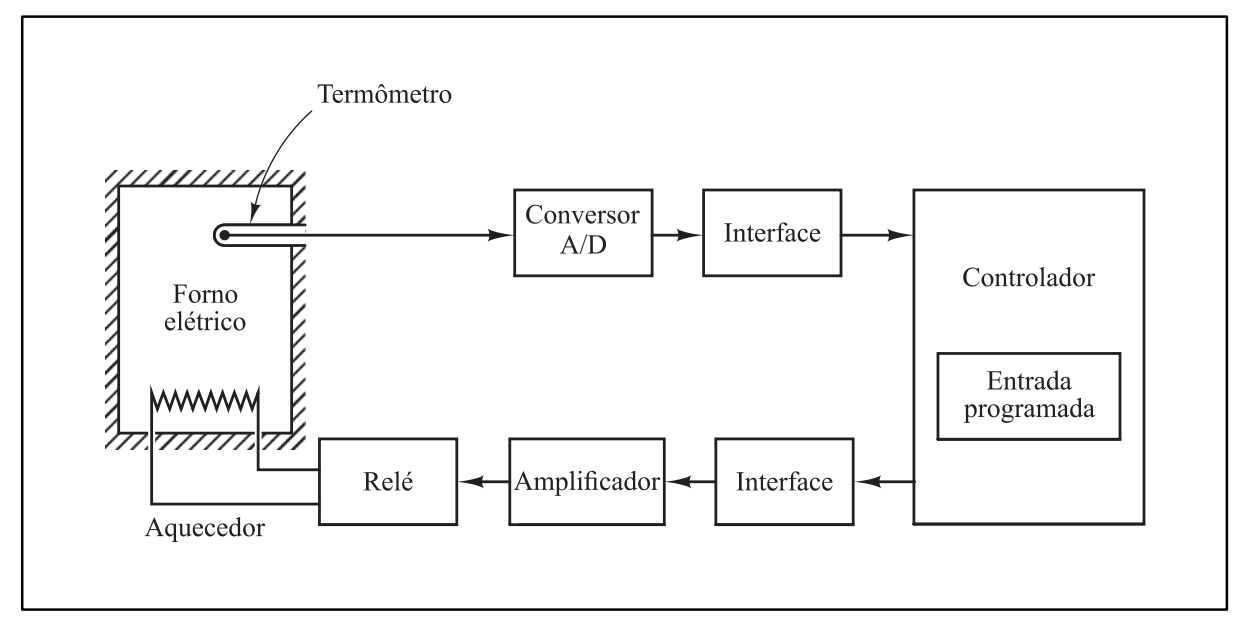

Fonte: Ogata (2010) - adaptado

Este modelo pode ser simplificado em um diagramas de blocos, como mostrado na Figura 8. O valor da temperatura é a saída do processo $(y(t))$, esta mesma saída realimenta o sistema. Através de um bloco somador é realizada a subtração entre o valor lido e o set point $(r(t))$. O resultado desta última operação, o erro $(e(t))$, que alimenta o controlador. A saída do controlador $(u(t))$ atua no processo na tentativa de eliminar o erro da variável manipulada no estado estacionário (DORF e BISHOP, 2001).

Figura 8 - Diagrama de blocos de um sistema retroalimentado

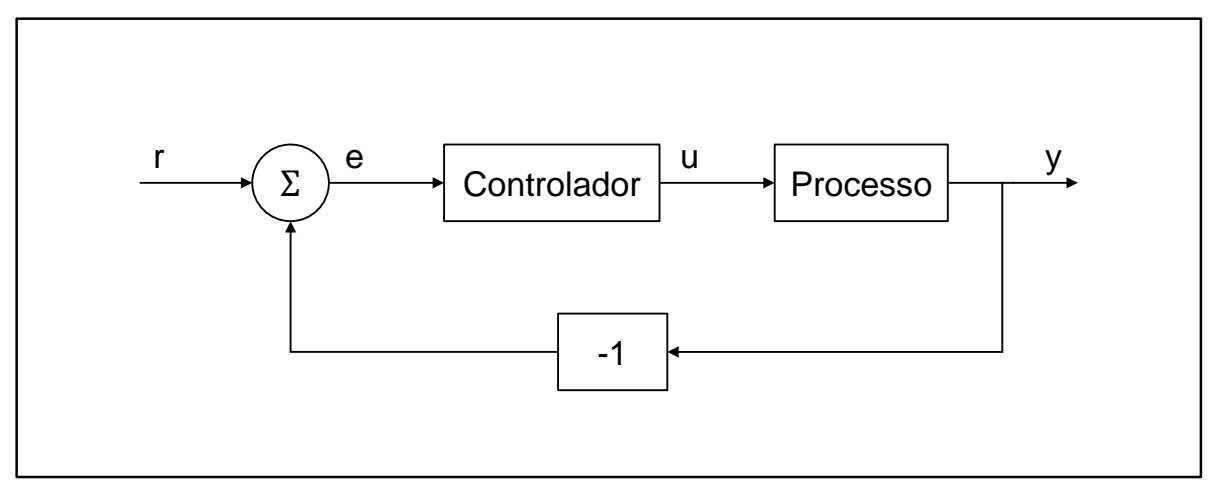

Fonte: Åström e Hägglund (2006) - adaptado 


\subsubsection{Controlador PID}

Dentre os diversos modelos de controladores, o Proporcional-IntegralDerivativo (PID) é a solução mais comum para problemas práticos. Há relatos de que controladores com ação proporcional e integral tenham sido utilizados em moinhos de vento e motores a vapor. Porém, o formato atual emergiu com os controladores pneumáticos na década de 1930. O desenvolvimento foi acelerado quando, a partir dos anos 1980, surgiram as implementações do microprocessador (ÅSTRÖM e HÄGGLUND, 2006).

O controle proporcional ocorre quando sua saída possui um valor proporcional ao erro de maneira que:

$$
u(t)=K_{p} \cdot e(t)
$$

$\mathrm{Na}$ Equação (16), $K$ é uma constante de proporcionalidade, também conhecida como ganho proporcional. Neste caso, há uma tendência de eliminação do erro, porém, muito lenta. Para elevar o tempo de resposta é necessário aumentar o ganho e isto pode causar a instabilidade no sistema. Pode-se adicionar a influência da taxa de variação do erro, multiplicada por outra constante $\left(k_{d}\right)$. A fim de estabilizar um sistema com ganho proporcional elevado, em menor intervalo de tempo, de modo que:

$$
u(t)=K_{p} \cdot e(t)+k_{d} \cdot \frac{d e(t)}{d t}
$$

a porção diferencial atua no processo antes de haver um sobressinal. De certa maneira, este termo tem a capacidade de prever erros futuros. No entanto sempre haverá alguma oscilação, de maneira que a saída do sistema nunca será estacionária. Para evitar este efeito, é possível, ainda, utilizar a soma de todos os erros passados. Isto posto, uma porção integral é capaz de estabilizar o sistema no estado estacionário, desta maneira:

$$
u(t)=K_{p} \cdot e(t)+k_{i} \int_{-\infty}^{0} e(t) d t+k_{d} \cdot \frac{d e(t)}{d t}
$$


Se considerar:

$$
k_{i}=K_{p} / T_{i}
$$

e

$$
k_{d}=K_{p} \cdot T_{d}
$$

O modelo matemático de um controlador PID contínuo, em função do tempo, é apresentado na Equação (21).

$$
u(t)=K_{p}\left(e(t)+\frac{1}{T_{i}} \int_{-\infty}^{0} e(t) d t+T_{d} \cdot \frac{d e(t)}{d t}\right)
$$

Os métodos em resposta de frequência e de lugar das raízes são a essência da Teoria Clássica do Controle (DORF e BISHOP, 2001). De modo que, alternativamente, esta equação é descrita como uma função de transferência $(G(s))$ no domínio de Laplace na Equação (22).

$$
G_{c}(s)=\frac{U(s)}{E(s)}=K_{p}\left(1+\frac{1}{T_{i} \cdot s}+T_{d} \cdot s\right)
$$

As constantes de ganho proporcional $\left(K_{p}\right)$, tempo integral ou reset-time $\left(T_{i}\right)$ e tempo derivativo $\left(T_{d}\right)$ são conhecidos por parâmetros do PID e podem ser obtidos pelos métodos heurísticos de Ziegler-Nichols (1942) de malhas aberta ou fechada. Teixeira \& Jota (2007), Gwak \& Masada (2008), Beifei (2009), Nayak et al. (2012), Kumar et al. (2013) e Xie \& Long (2015) propuseram metodologias de PID modificadas, que objetivavam minimizar a variabilidade na temperatura de fornos nos mais diversos processos. Todos são baseados nos métodos de sintonia de ZieglerNichols $(Z N)$ e implementação computacional conforme descrito por Åström e Hägglund (2006). 


\subsubsection{Sintonia pelo método de malha aberta}

O método malha aberta é operacionalizado provocando um salto no processo e sua resposta é armazenada. A reta tangente ao ponto de inflexão da curva determina duas variáveis, $L$ e $T$, conforme exibido na Figura 9. Esta curva pode ser aproximada em um sistema de primeira ordem com atraso de transporte, como exibido na Equação (23).

$$
G(s)=\frac{K_{p} \cdot e^{-L s}}{T \cdot s+1}
$$

Ziegler e Nichols sugeriram escolher os valores dos parâmetros de acordo com a Tabela 2.

Tabela 2 - Regra de ZN para sintonia pelo método de malha aberta

\begin{tabular}{c|ccc}
\hline Tipo de controlador & $K_{p}$ & Parâmetro & $T_{d}$ \\
\hline P & $T / L$ & $T_{i}$ & 0 \\
PI & $0,9 \cdot T / L$ & $T / 0,3$ & 0 \\
PID & $1,2 \cdot T / L$ & $2 L$ & $0,5 \cdot L$ \\
\hline
\end{tabular}

Fonte: Ogata (2010)

\subsubsection{Sintonia pelo método de malha fechada}

Por outro lado, no método de malha fechada, utilizando-se de um controle proporcional $\left(T_{i}=\infty, T_{d}=0\right)$ o $K_{p}$ é elevado até o valor crítico $\left(K_{c r}\right)$ no qual a saída exibe uma oscilação constante, como mostrado na 
Figura 9 - Curva de resposta, em formato de S.

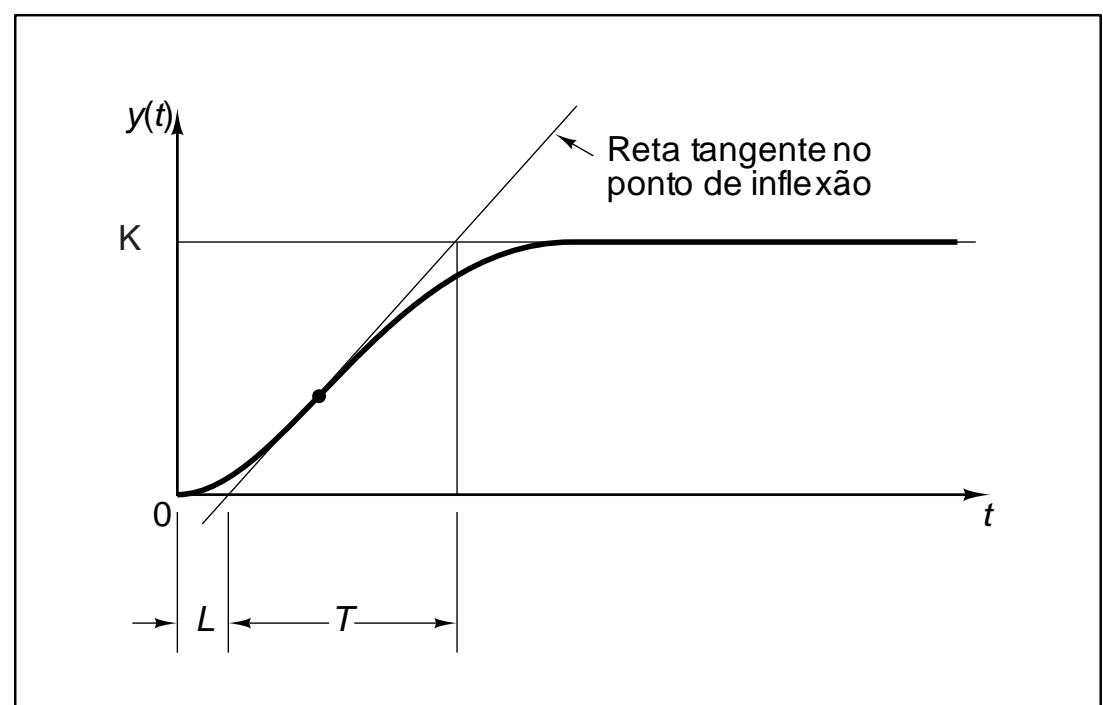

Fonte: Ogata - adaptado

Figura 10. A partir do $K_{c r}$ e do período crítico $\left(P_{c r}\right)$, utiliza-se a regra exibido na Tabela 3, para determinar os parâmetros do PID.

Figura 9 - Curva de resposta, em formato de S.

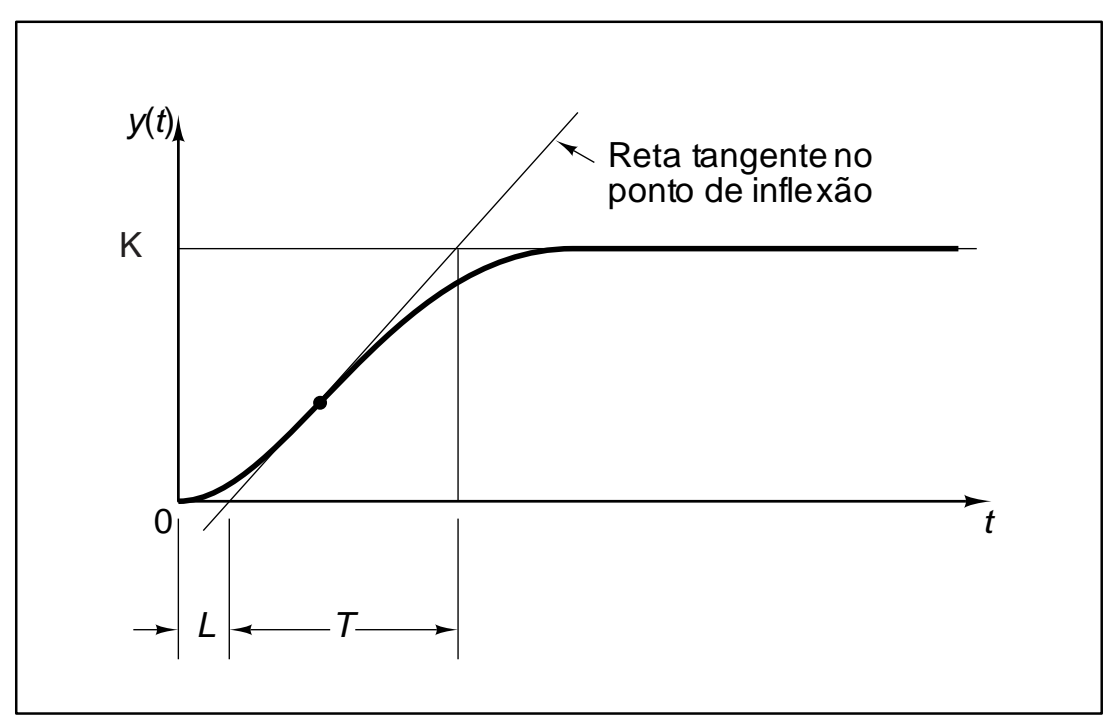

Fonte: Ogata (2010) - adaptado 
Figura 10 - Oscilação sustentada com período crítico (segundos).

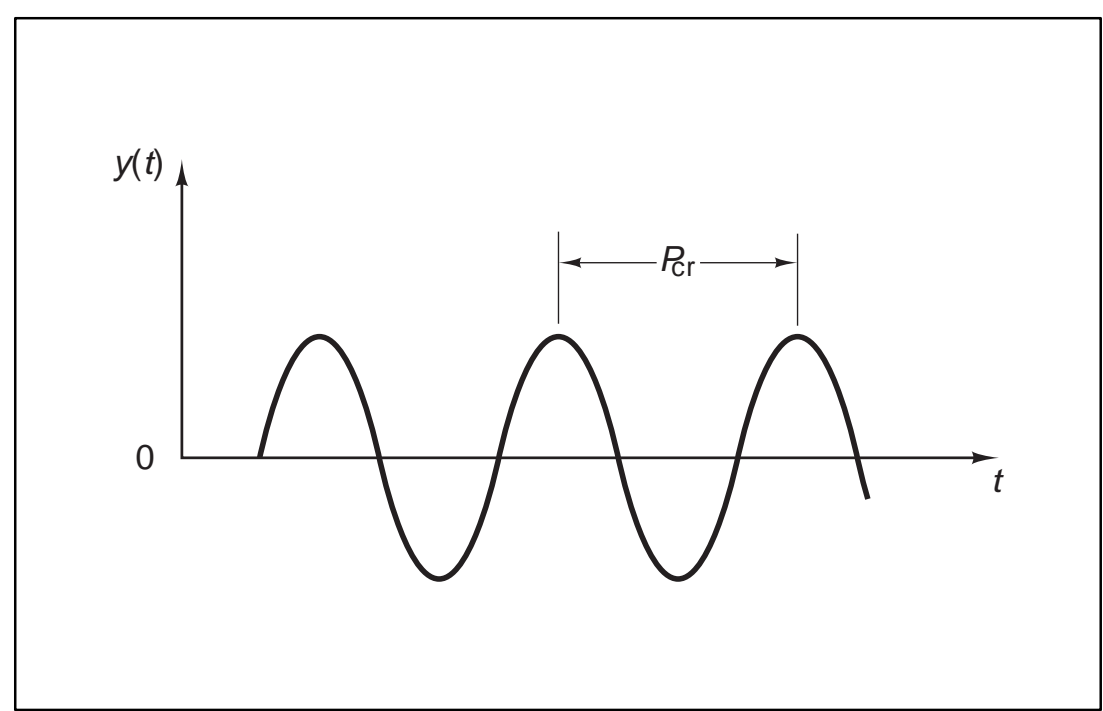

Fonte: Ogata (2010) - adaptado

Tabela 3 - Regra de ZN para sintonia pelo método de malha fechada

\begin{tabular}{c|ccc}
\hline Tipo de controlador & $K_{c}$ & Parâmetro & $T_{d}$ \\
\hline P & $0,5 \cdot K_{c r}$ & $\infty$ & 0 \\
PI & $0,45 \cdot K_{c r}$ & $\frac{P_{c r}}{1,2}$ & 0 \\
PID & $0,6 \cdot K_{c r}$ & $0,5 \cdot P_{c r}$ & $0,125 \cdot P_{c r}$ \\
\hline
\end{tabular}

Fonte: Ogata (2010)

\subsubsection{Implementação computacional}

A vantagem do controlador digital em relação aos reguladores de temperatura mais antigos é a possibilidade da aplicação de técnicas avançadas de controle de aquecimento do forno, com o objetivo de manter a temperatura dentro dos limites 
estabelecidos, sem alterações substanciais. Uma vez que, diversos autores (BARBOZA., MOURA NETO e SILVA, 2004; BARBOZA, 2001) afirmam que cada vez mais, o projeto de componentes exige sofisticações tecnológicas nos estudos dos materiais utilizados e aprimoramentos nos ensaios. Neste mesmo sentido, a American Society For Testing And Materials (2011), que é referência mundial para ensaio de materiais, definiu procedimentos de teste de fluência em materiais metálicos através da norma ASTM E139-11. Este documento limita a temperatura a variações, durante o ensaio, de $2 \mathrm{~K}$, para testes abaixo de $1273 \mathrm{~K}$.

Para tanto, algumas considerações são necessárias devido ao fato de que os sinais são amostrados em instâncias de tempo discretas. No ciclo de trabalho os microprocessadores e microcontroladores digitais, geralmente, aguardam a interrupção do clock, leem a entrada analógica, calculam o sinal de controle, ajustam a saída do controlador, atualizam as variáveis de controle e voltam ao início do processo. Cada instância $(k)$ de tempo possui uma duração $(T)$, de modo que serão executadas nos instantes $\left(t_{k}\right)$ definidos. A instância anterior é denotada por $(k-1)$ e a posterior por $(k+1)$. Nesse sentido, a porção proporcional $(P(t))$ da Equação $(21)$ pode ser discretizada conforme exibido na Equação (24)

$$
P(k)=K_{p} \cdot e(k)
$$

A porção integral,

$$
I(t)=K_{p} \cdot \frac{1}{T_{i}} \int_{-\infty}^{0} e(t) d t
$$

pode ser integrada pela aproximação de Tusting (método dos trapézios),

$$
I(k+1)=I(k)+\frac{K_{p}}{T_{i}} \cdot\left[T \cdot \frac{e(k+1)+e(k)}{2}\right]
$$

simplificando, torna-se:

$$
I(k)=I(k-1)+\frac{K_{p} \cdot T \cdot[e(k)+e(k-1)]}{2 \cdot T_{i}}
$$


A porção derivativa,

$$
D(t)=K_{p} \cdot T_{d} \cdot \frac{d e(t)}{d t}
$$

discretizado, torna-se:

$$
D(k)=K_{p} \cdot T_{d} \cdot[e(k)-e(k-1)]
$$

\subsection{Modelagem do braço de alavanca}

Sob a perspectiva de Mello et al. (2006) no desenvolvimento de um produto, o ponto crítico é a formulação de especificações. Para tanto, são necessárias atividades de pesquisa, desenvolvimento e conhecimentos técnicos a fim de solucionar a complexidade demandada. Segundo Kim (1997), a engenharia reversa é uma metodologia útil para implementação de melhorias em produtos, através de uma combinação de aquisição explícita de conhecimento e inferência heurística. O paradigma de reprodução e modificação é um método efetivo de reprojeto, que tem como ponto de partida outro produto com conceitos ou características técnicas melhores e já aplicados e testados no mercado. Desta maneira, não é apenas uma cópia, é, portanto, o aperfeiçoamento de um produto já existente. $E$, na busca da compreensão do funcionamento dos equipamentos existentes, modelou-se o dispositivo de aplicação de carga.

A alavanca é um dos primeiros mecanismos conhecidos. Máquina simples, que amplifica a força aplicada de uma extremidade à outra (NORTON, 2010). O ponto de apoio é chamado de fulcro. Onde aplica-se a força é chamado de potente e onde está a carga de resistente. Um modelo matemático pode ser elaborado, a fim de estimar o comportamento do mecanismo e as forças que atuam sobre ele. Na Figura 11 é apresentado o esquema de uma alavanca, que se considerar o fulcro como origem $(O)$ de um sistema de posicionamento cartesiano, as coordenadas dos centros dos eixos de forças potente $\left(P_{x, y}\right)$ e resistente $\left(R_{x, y}\right)$ a representação dos vetores de posição utilizados na modelagem do mecanismo em que a força-peso $\left(\overrightarrow{F_{1}}\right)$ aplicada no braço maior provoca a tração uniaxial em uma barra $(B)$, acoplada por articulações 
entre o ponto $R_{x, y}$ e uma junta inferior $\left(I_{x, y}\right)$. Deste modo, o alongamento da amostra ( $\delta$ ) é a própria variação de $B$.

Figura 11 - Diagrama de corpo-livre de um braço de alavanca.

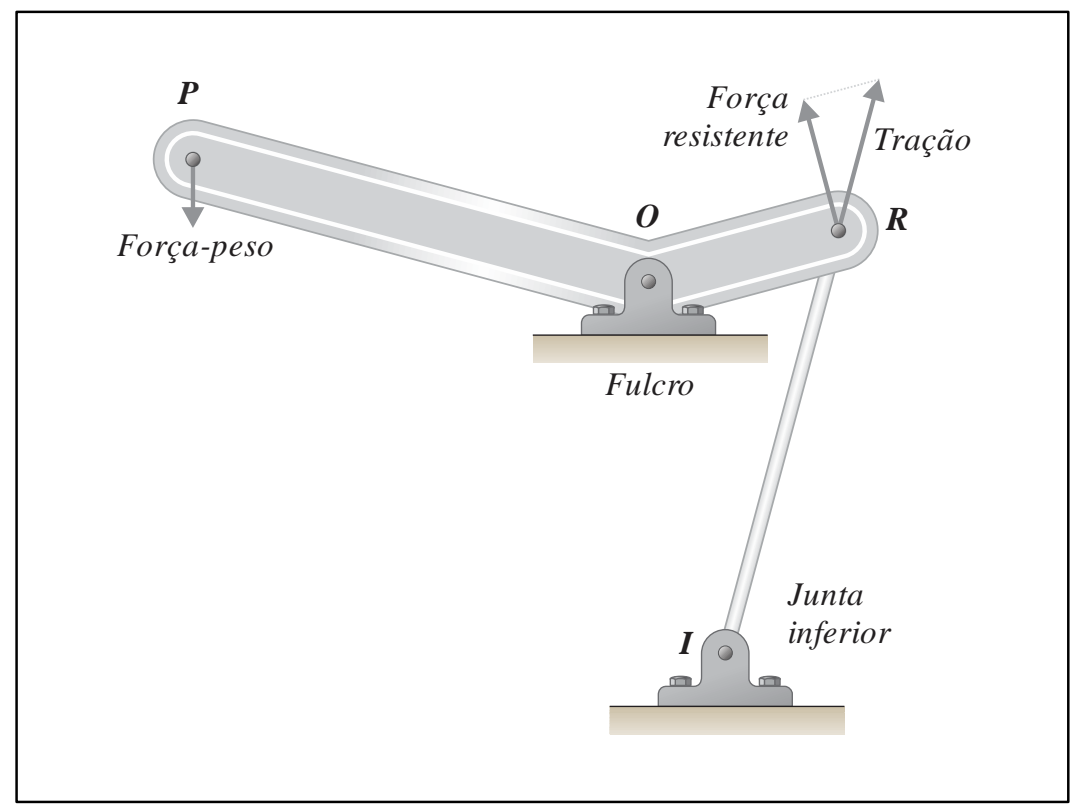

Fonte: autor da dissertação

Ao acrescentar cota nula $(z=0)$ nas coordenadas dos vetores $\vec{P}, \vec{R}$ e $\vec{I}$, transforma-se o sistema em um modelo tridimensional e, desta maneira, pode-se relacionar o momento em relação a origem $\left(\overrightarrow{M_{o}}\right)$ pelo produto vetorial demonstrado na Equação (30).

$$
\overrightarrow{M_{O}}=\vec{P} \times \overrightarrow{F_{1}}
$$

De forma análoga, a força no braço menor da alavanca $\left(\overrightarrow{F_{2}}\right)$ é um vetor perpendicular ao vetor posição $\vec{R}$ e, seu módulo, é um escalar definido na Equação (31).

$$
\left|\overrightarrow{F_{2}}\right|=\frac{\left|\overrightarrow{M_{O}}\right|}{|\vec{R}|}
$$


Também, pode-se determinar a direção e sentido pelo produto dos vetores unitários paralelos à $\overrightarrow{M_{O}}$ e $\vec{R}$ :

$$
\overrightarrow{F_{2}}=\left|\overrightarrow{F_{2}}\right| \cdot \widehat{M_{O}} \times \hat{R}
$$

Isolando $\left|\overrightarrow{M_{O}}\right|$ na Equação (31) e substituindo o resultado no vetor unitário $\widehat{M}_{O}$ da Equação (32) obtém-se módulo, direção e sentido de $\overrightarrow{F_{2}}$, conforme Equação (33).

$$
\overrightarrow{F_{2}}=\frac{\overrightarrow{M_{O}} \times \vec{R}}{|\vec{R}|^{2}}
$$

Sabe-se que $\overrightarrow{F_{2}}$ é a projeção ortogonal da tração do ponto $R_{x, y, z}$ em relação a $I_{x, y, z}\left(\overrightarrow{T_{R I}}\right)$ na direção de $\vec{B}$ e que há um ângulo $(\phi)$ formado pelos dois vetores, de maneira que é possível determinar o cosseno deste ângulo, como executado na Equação (34).

$$
\cos \phi=\left(\frac{\left\langle\overrightarrow{F_{2}}, \overrightarrow{T_{R I}}\right\rangle}{\left|\overrightarrow{F_{2}}\right| \cdot\left|\overrightarrow{T_{R I}}\right|}\right)
$$

Ao considerar que $\overrightarrow{T_{R I}}$ e $\vec{B}$ são paralelos, a fim de obter o $\cos \phi$, pode-se substituir um pelo outro sem prejuízos:

$$
\cos \phi=\left(\frac{\left\langle\overrightarrow{F_{2}}, \vec{B}\right\rangle}{\left|\overrightarrow{F_{2}}\right| \cdot|\vec{B}|}\right)
$$

Portanto, a tração normal $(\sigma)$ na amostra, que é o escalar $\left|\overrightarrow{T_{P I}}\right|$, pode ser encontrado na relação exibida na Equação (36).

$$
\sigma=\frac{\left|\overrightarrow{F_{2}}\right|}{\cos \phi}
$$

Ou ainda, ao substituir a Equação (35) em (36), a tração na amostra é determinada na Eq. (37). 


$$
\sigma=\frac{\left|\overrightarrow{F_{2}}\right|^{2} \cdot|\vec{B}|}{\left\langle\overrightarrow{F_{2}}, \vec{B}\right\rangle}
$$

Com o tempo, a alteração na dimensão $B$, provocado pelo alongamento da amostra, produz uma rotação $(\theta)$ no braço. As novas posições dos pontos, sujeitos à rotação, podem ser alcançadas através da rotação em torno do eixo perpendicular à transformação. Assim, segundo Spong (2006), a matriz de rotação, com valores de ângulos positivos para o sentido anti-horário, em Z é apresentada na Equação (38).

$$
\operatorname{Rot}(z, \theta)=\left[\begin{array}{ccc}
\cos \theta & -\operatorname{sen} \theta & 0 \\
\operatorname{sen} \theta & \cos \theta & 0 \\
0 & 0 & 1
\end{array}\right]
$$

Por exemplo, a forma de determinar a nova posição $\left(A^{\prime}\right)$ de um ponto genérico $(A)$, é demonstrada na Equação (39).

$$
A_{\left(x^{\prime}, y^{\prime}, z^{\prime}\right)}^{\prime}=\operatorname{Rot}(z, \theta) \times A_{(x, y, z)}
$$




\section{MATERIAIS E MÉTODOS}

A pesquisa iniciou-se analisando dois equipamentos destinados ao ensaio de fluência. Um de propriedade do DCTA e o outro da Universidade Presbiteriana Mackenzie (UPM). Para desenvolver o conjunto de modernização, utilizou-se a estrutura da máquina de ensaio de fluência da marca The Electronic and Mechanical Engineering Co. Ltd. (EMEC), de propriedade do IPEN. A modernização do equipamento foi dividida em etapas, conforme mostrado no fluxograma da Figura 12.

Figura 12 - Fluxograma de ações para a modernização do equipamento EMEC.

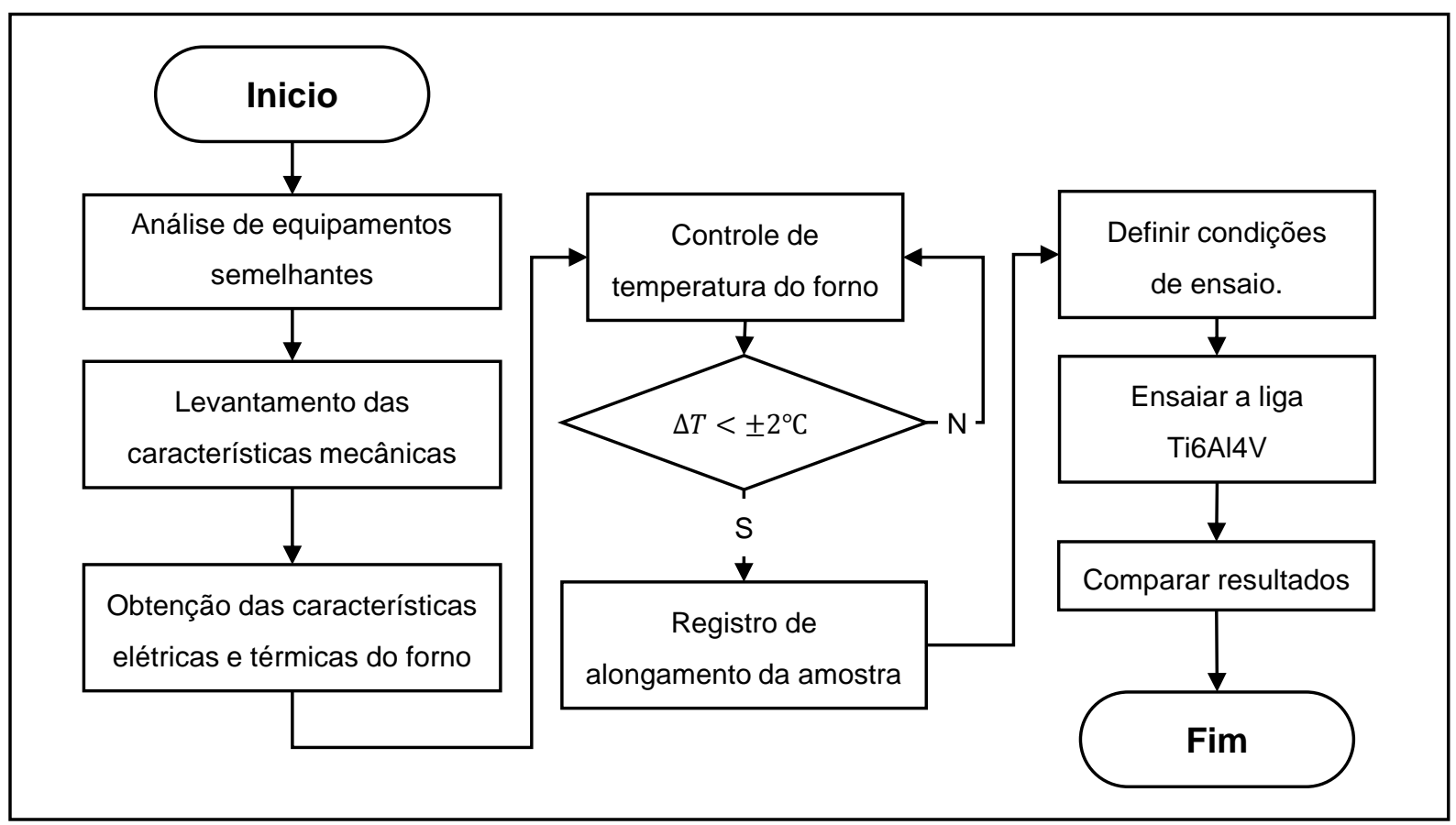

Fonte: autor da dissertação

\subsection{Características mecânicas}

Foi executado o levantamento das características mecânicas. Inicialmente utilizou-se um paquímetro analógico, da marca Mitutoyo ${ }^{\circledR}$, de $150 \pm 0,05 \mathrm{~mm}$. Para medir as dimensões maiores, utilizou-se uma trena de $5 \mathrm{~m} \pm 1 \mathrm{~mm}$, da marca Starret $^{\circledR}$. Foram elaborados desenhos esquemáticos com as medidas do equipamento. 


\subsubsection{Análise numérica do braço de alavanca}

Com a finalidade de determinar o comportamento da tração em função da variação do alongamento. Pequenas variações com um número finito de passos foram aplicados ao conjunto de equações para produzir uma série do par ordenado de interesse. Neste caso, formado por $\delta$ em função de $\sigma$. Na Figura 13 é apresentado o algoritmo, que foi fundamentado na modelagem do braço de alavanca. No qual, após o usuário inserir as variáveis, um bloco de processamento calcula os parâmetros da análise. Em seguida, outro bloco computa repetidas vezes os valores do par de interesse. Finalmente, o algoritmo plota os resultados de $\sigma$ em função de $\delta$, em um gráfico de duas dimensões.

Figura 13 - Algoritmo de análise do braço de alavanca.

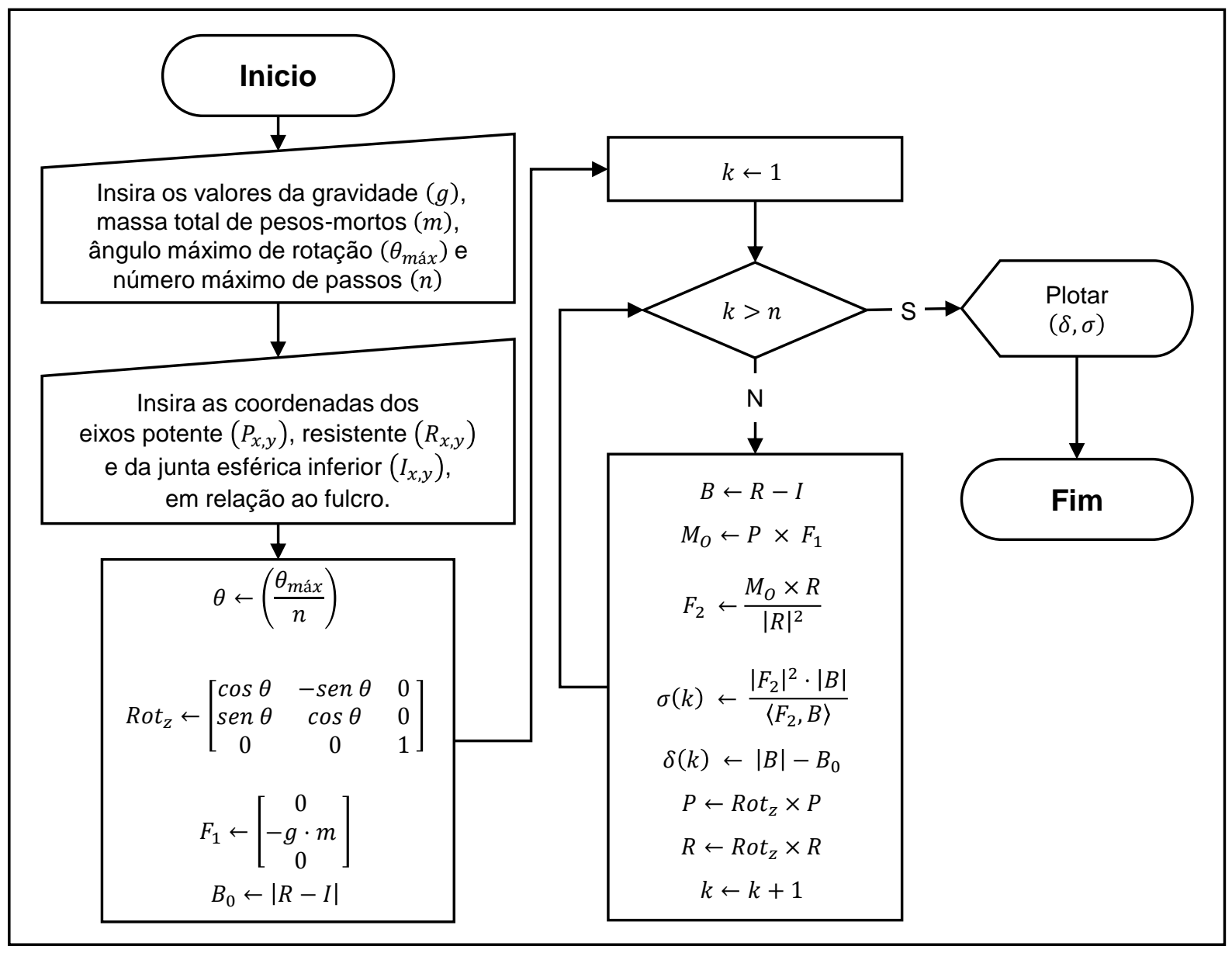

Fonte: autor da dissertação

Os valores das distâncias dos elos e juntas da cadeia cinemática foram referenciadas em relação ao fulcro da alavanca. Lançou mão da análise vetorial a fim de levantar as características dinâmicas da tração aplicada ao corpo de prova. Para 
tanto, utilizou-se a rotina, apresentada abaixo, especialmente desenvolvida para o software SciLab. Os valores da simulação computacional por análise numérica foram simplificados em uma equação linear através do método dos mínimos quadrados.

Figura 14 - Rotina produzida no SciLab para análise do braço de alavanca.

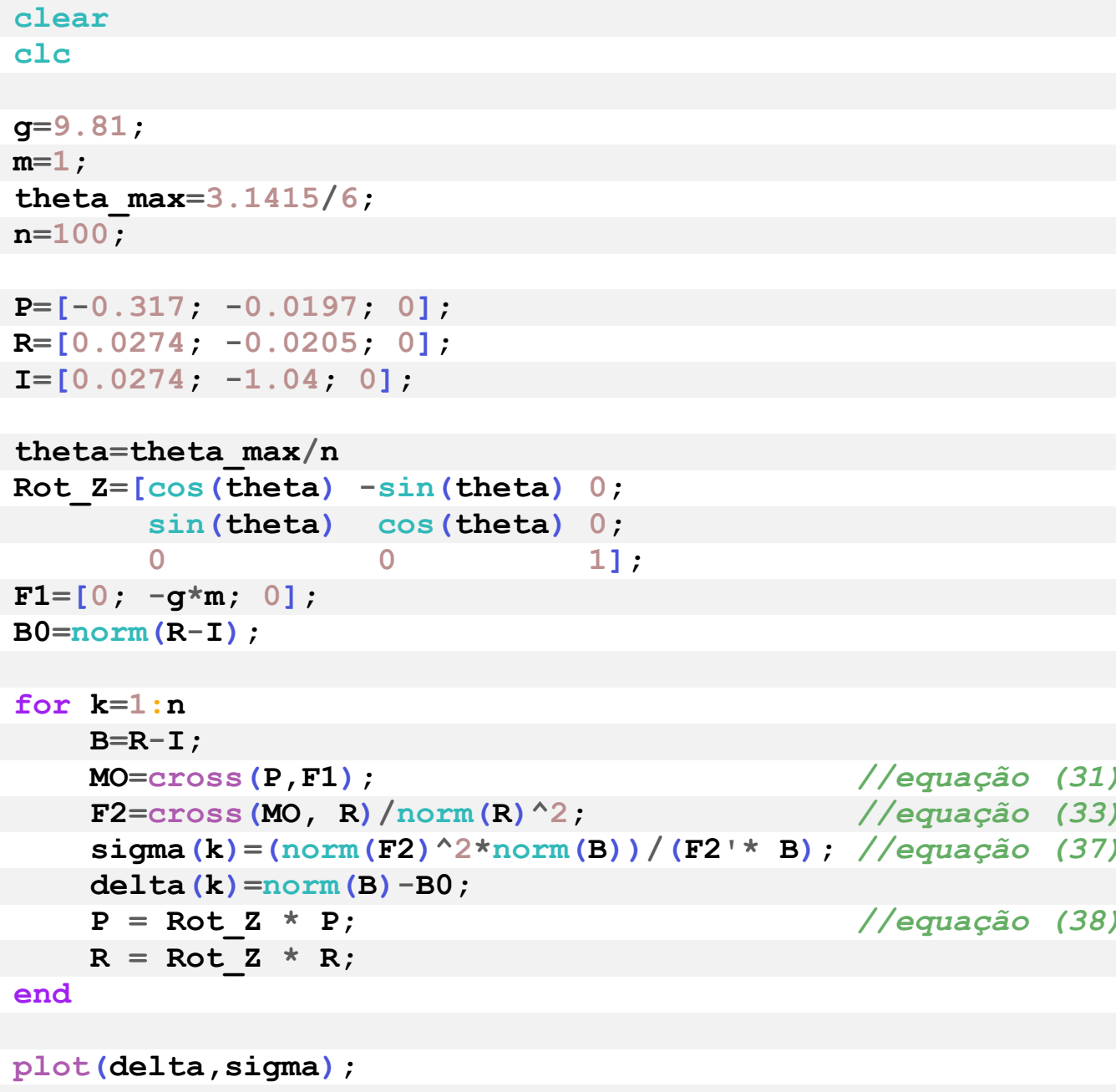

Fonte: autor da dissertação

\subsection{Características elétricas e térmicas}

A fim de determinar as características elétricas do forno, utilizou-se um alicate amperímetro digital TRUE-RMS AC/DC, modelo POL-08, fabricado pela Politerm, com precisão $\pm 1,0 \%$ para medição de corrente e $\pm 0,8 \%$ para medição de resistência ou tensão. Para determinar as características térmicas do forno, empregou-se três relés de estado sólido (SSR - Solid State Relay), como mostrado na Figura 15, com o objetivo controlar o acionamento dos aquecedores. Os SSR da marca JNG Materiais Elétricos possuem capacidade de condução de corrente de 25,0 A, tensão nominal de 
240,0 Vac e tolerância a picos na saída de até 800,0 V. Termopares do tipo K, AWG 24, fabricados pela Salcas Indústria e Comércio LTDA., coletaram a temperatura instantânea no centro de cada zona (TPS - Termopar da zona superior, TPC - central e TPI - inferior).

Figura 15 - Relé de estado sólido.

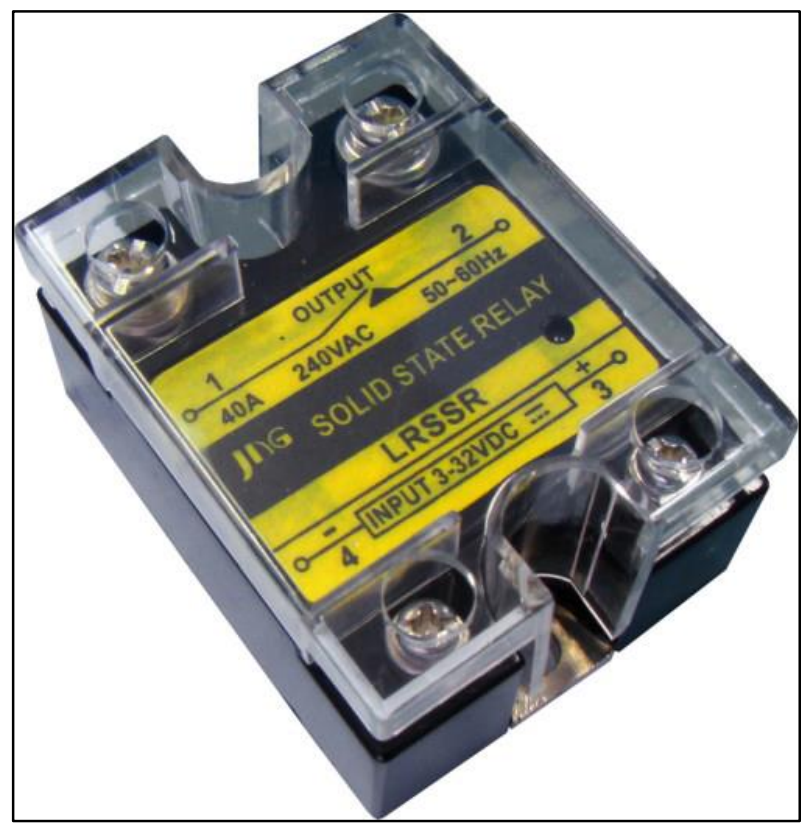

Fonte: JNG Materiais Elétricos (2017)

Adicionalmente, placas ADC transformaram os sinais elétricos dos termopares em informação digital. Estas placas são baseadas no circuito integrado (CI) Maxim MAX6675 e possuem um ADC de 12 bits, capaz de ler temperaturas entre $273 \mathrm{~K}$ e 1296,75 K, com resolução de 0,25 K e que possui, internamente, um segundo sensor de temperatura para fazer a compensação de junção fria. Este $\mathrm{Cl}$ possui interface de comunicação em série síncrona (SPI - Serial Peripheral Interface).

Figura 16 - Placa ADC para termopar tipo K.

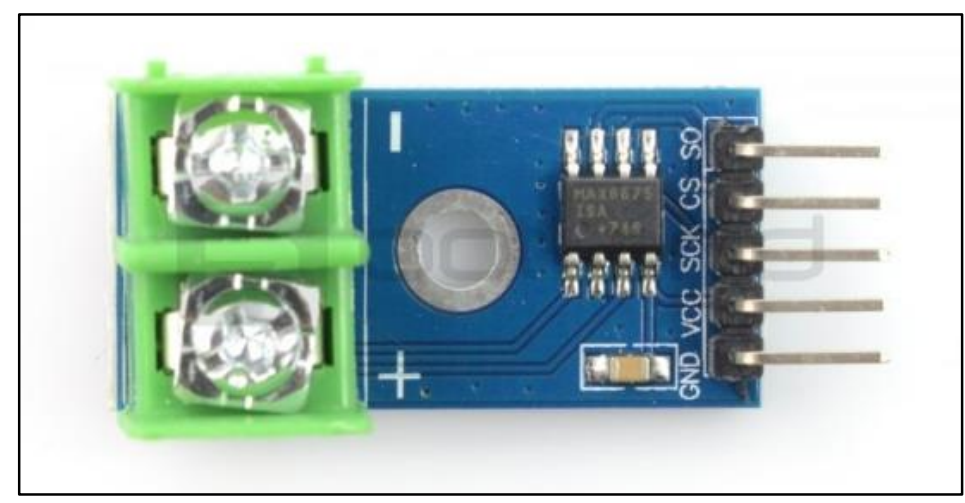

Fonte: Botland (2018) 
Uma plataforma de desenvolvimento Arduino, modelo Nano, reuniu a leitura das três zonas em um pacote de dados formado por um conjunto de números representados por ponto flutuante de 32 bits. Este pacote foi enviado para um computador pessoal (PC), que transformou os números de ponto flutuante para ASCII e armazenou as leituras em formato de texto separado por vírgulas (CSV - Commaseparated values). O Arduino possui um $\mathrm{Cl}$ Microcontrolador modelo Atmega328p, fabricado pela Atmel, e foi programado a partir do Ambiente de Desenvolvimento Integrado (IDE - Integrated Development Environment) nativo da plataforma. O Microcontrolador também gerenciou o acionamento dos SSR, cada ciclo de trabalho tinha duração média de 351,0 ms.

Figura 17 - Placa Arduino Nano com conexão de bornes parafusados

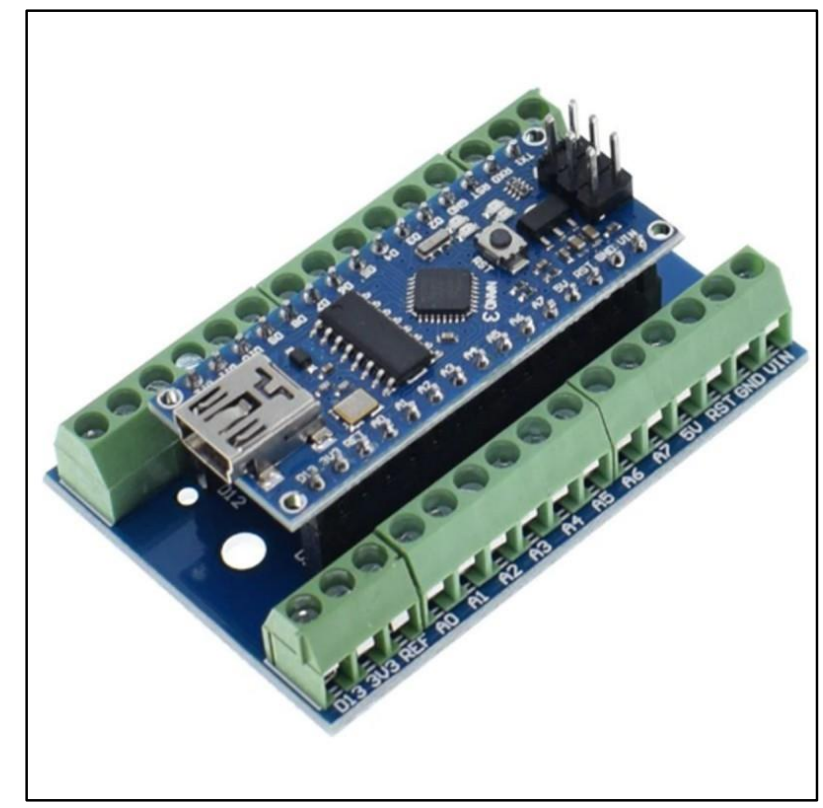

Fonte: By the way ([2019?])

A fim de obter as curvas de aquecimento e resfriamento executou-se a seguinte rotina:

- iniciar a coleta de dados,

- ligar os SSR, aguardar 5400 segundos,

- desligar os SSR, aguardar 8400 segundos e, finalmente,

- encerrar a coleta de dados.

Os tempos foram definidos pela observação da elevação de temperatura, dentro de níveis seguros (abaixo de $1000^{\circ} \mathrm{C}$ ). A partir dos dados coletados ajustou-se 
curvas exponenciais para o aquecimento e resfriamento utilizando os métodos dos mínimos quadrados.

Apesar de não comporem a estrutura do forno, os sensores de temperatura têm papel decisivo no controle, uma vez que é impossível dissociar completamente suas imperfeições e atrasos das características dinâmicas do forno. Com base na última coleta de dados obteve-se o ruído intrínseco dos sensores. Para tanto, aplicouse um alisamento (smoothing), utilizando um filtro digital de média móvel com janela de dados de 100 pontos. A partir do conjunto de dados brutos (RD - raw data) subtraiu-se os dados alisados (SD - smoothed data). Esta operação forneceu um conjunto de ruídos (ND - noise data) a que o sensor está sujeito.

\subsubsection{Controle de temperatura do forno}

A técnica utilizada no controle deste processo foi o Proporcional-IntegralDerivativo (PID). Determinou-se as constantes do controlador (Kp, Ti, Td) a partir das características dinâmicas e das curvas de aquecimento e resfriamento, para as temperaturas de $373 \mathrm{~K}, 573 \mathrm{~K}$ e $773 \mathrm{~K}$, utilizando-se a princípio o método da malha aberta de ZN e posteriormente com o método da malha fechada fez-se o ajuste fino.

O código embarcado no microcontrolador atuou no processo de aquecimento, a fim de manter a temperatura interna do forno em um intervalo de $\pm 2 \mathrm{~K}$ do SP para o ensaio. Para tanto, a leitura dos termopares realimentou o sistema de controle que atuou na variável controlada por intermédio da fração de tempo em que o aquecedor permaneceu ligado. Esta fração era atualizada em ciclos de 3s (aproximadamente $0,34 \mathrm{~Hz})$.

\subsection{Registro de alongamento da amostra}

Previamente ao registro da deformação da amostra, fez-se necessário conhecer as limitações do LVDT disponível. O modelo TD 43 possui curso de 38,0 $\mathrm{mm}$ e foi produzido pelo Instituto de Pesquisas Tecnológicas (IPT). Este sensor foi fixado com seu curso total estendido, em uma prensa manual juntamente com um Relógio Comparador, da marca Digimess e modelo 121.322, com oexibido na Figura 18. O relógio comparador possuía faixa de medição de 0 a $50 \mathrm{~mm}$ e resolução de 0,01 $\mathrm{mm}$. Foram produzidos deslocamentos em intervalos de 0,2 $\mathrm{mm}$. Utilizou-se um 
indutímetro, marca Icel, modelo RLC- 410 , com precisão de $\pm 2 \%$, o qual mediu a indutância em cada um dos 3 indutores do LVDT, para cada nova posição.

Figura 18 - Configuração do ensaio de indutância do TD-43.

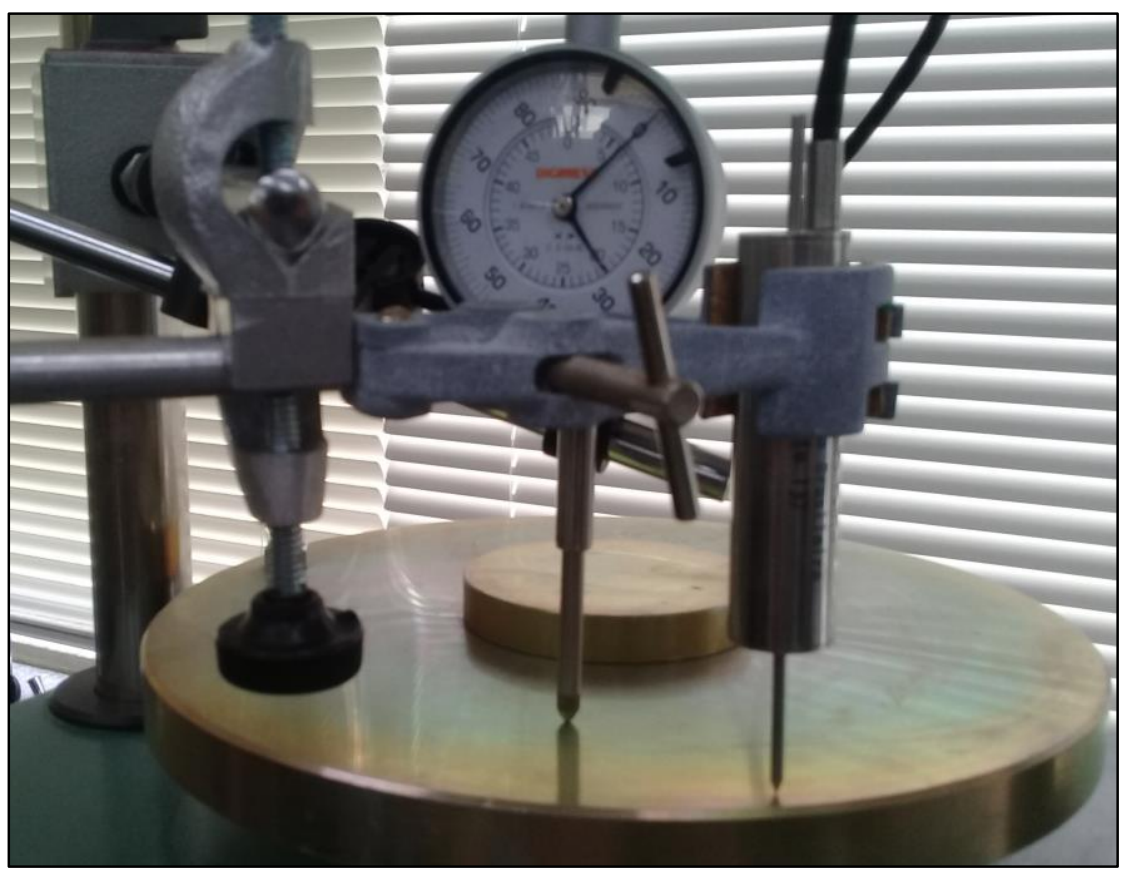

Fonte: autor da dissertação

Lançando mão de métodos numéricos, aplicou-se a equação do o princípio da indução mútua e de resposta em frequências para excitação com amplitude de $5 \mathrm{Vpp}$, entre $100 \mathrm{~Hz}$ e $100 \mathrm{kHz}$. A priori, o método de leitura baseado na indução demonstrou ótima repetibilidade e baixo ruído, porém impraticável para o momento, uma vez que não haveria tempo para desenvolver os circuitos eletrônicos necessários.

Desta maneira, optou-se em utilizar o condicionador de sinal para LVDT, modelo GSTD 43, produzido pelo IPT, que tem como saída uma diferença de potencial elétrico. A tensão é proporcional ao deslocamento do núcleo do sensor, variando na faixa de $\pm 8 \mathrm{Vdc}$. Na leitura da tensão de saída do condicionador de sinal, utilizou-se uma placa com Cl ADC modelo ADS1115, da marca Texas Instruments. Este conversor possui quatro entradas para medição de tensão elétrica. Há a possibilidade de utilizar cada canal independente ou na configuração de dois canais de medição diferencial, escolheu-se a segunda. A resolução deste ADC é de 16 bits, o que permite subdividir a faixa de tensão lida em mais de 65 mil valores discretos. A interface de comunicação é o Circuito Inter-integrado ( ${ }^{2} \mathrm{C}$ - Inter-Integrated Circuit). Também, operacionalizou-se a detecção de ruídos neste processo de digitalização. Através da 
comunicação $\mathrm{I}^{2} \mathrm{C}$, o Arduino coletou a informação do $\mathrm{ADC}$, aplicou-se um smoothing, utilizando o filtro digital EMA $\operatorname{com} \alpha=0,01$, o dado filtrado foi enviado ao PC em formato de ponto flutuante de 32 bits. O PC, por sua vez, converteu os dados de ponto flutuante para ASCII e armazenou o conjunto em formato CSV. A taxa de amostragem média foi de $\sim 2,19$ leituras por segundos.

\subsubsection{Calibração do LVDT}

A montagem para calibração foi executada utilizando-se um micrômetro com faixa de medição de 0 a $25 \mathrm{~mm}$ e resolução de $0,01 \mathrm{~mm}$. $O$ arco do micrômetro foi removido para que ambos pudessem ser fixados concêntricos em eixo longitudinal, de forma que a movimentação do encosto móvel variasse o núcleo do LVDT.

A fim de determinar o null point, estendeu-se o curso do LVDT e foram produzidos deslocamentos. Com o indutímetro buscou-se a posição em que a indutância dos dois secundários fossem idênticas. Nesse momento o sensor foi conectado ao condicionador de sinal, modelo GSTD 43, também produzido pelo IPT, especifico para este LVDT, e ajustou-se a saída do condicionador para 0V.

O condicionador de sinal foi conectado ao ADS1115 e este conectado ao microcontrolador que registrou os deslocamentos em intervalos de $0,5 \mathrm{~mm}$. Dentro da faixa mais linear, $\pm 7,5 \mathrm{~mm}$, a partir do null-point, ajustou-se uma equação linear pelo método dos mínimos quadrados.

\subsection{Ensaio de Fluência}

Para realização dos ensaios de fluência foram confeccionados corpos de prova, conforme dimensões exibidas na Figura 19. O material ensaiado, a liga de titânio Ti-6Al-4V, foi adquirida na empresa Multialloy Metais e Ligas Especiais Ltda., na forma de barras cilíndricas de 12,7 mm de diâmetro e foram usinados por comando numérico computadorizado (CNC) pela empresa Fautec Ferramentaria Automação e Usinagem Ltda. 
Figura 19 - Dimensões e formato do corpos de prova.

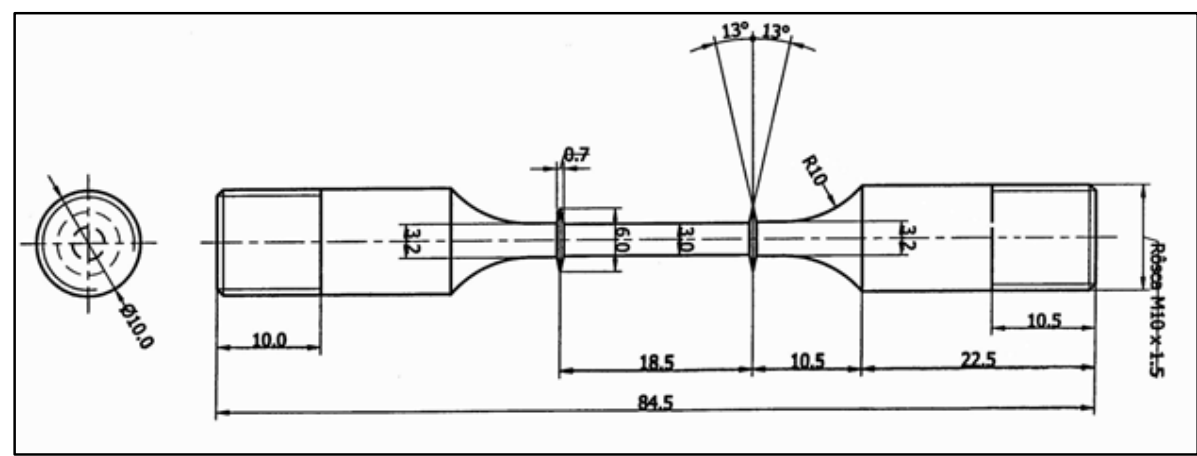

Fonte: Dos Reis (2014)

As condições dos ensaios foram determinadas para que os ensaios fossem menores que uma hora (3600 segundos), com base nos estudos de Briguente (2011). Nesse sentido optou-se pela tensão $319 \mathrm{MPa}$, temperatura de $873 \mathrm{~K}$; na modalidade de carga constante. As curvas de deformação, em milímetros por milímetro, foram plotadas em função do tempo, em segundos. Os parâmetros: tempo de fluência primária $\left(t_{p}\right)$, taxa de fluência secundária $\left(\dot{\varepsilon}_{s}\right)$, tempo final de fratura $\left(t_{f}\right)$ e a deformação de fratura $\left(\varepsilon_{f}\right)$ foram comparados nos ensaios realizados no equipamento do DCTA (Mayes) e do Mackenzie (Zwick).

\subsubsection{Instalação do conjunto de modernização no equipamento EMEC}

A equação do LVDT foi adicionada ao código embarcado no microcontrolador e forneceu o deslocamento com precisão $1 \mu \mathrm{m}$. Além de três temperaturas instantâneas para as zonas e uma para a amostra. Os dados foram recebidos em um PC pelo software livre Processing, que plotou gráficos e salvou as informações em um arquivo com a extensão CSV, com atualizações a cada 588ms. O código embarcado aplicou cum filtro EMA com $\alpha=0,01$ na temperatura da amostra e nos deslocamentos do LVDT.

Os dados foram transmitidos em pacotes de 256 bits, formado por 8 valores de ponto flutuante simples (32 bits), com o seguinte leiaute:

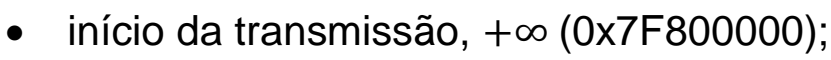

- temperatura da zona inferior;

- temperatura da zona central;

- temperatura da zona superior;

- temperatura da amostra; 
- valor do LVDT1;

- valor do LVDT2 (alternativo); e

- fim da transmissão, $-\infty$ (0xFF800000).

A aplicação, com interface exibida na Figura 20, recebeu os dados através da porta serial selecionada, eliminou as marcações inicial e final, converteu os valores para caracteres alfanuméricos, adicionou ponto-e-vírgula entre os valores, adicionou um recuo de linha para cada novo pacote e salvou continuamente em um arquivo CSV. O arquivo foi salvo com nome padrão, no qual era formado pelo texto "data" seguido de ano, mês, dia, hora, minuto e segundo do início do teste (aaaammddhhmmss.csv). Para exemplificar o ensaio foi salvo com o nome "data20190717171130.csv".

Figura 20 - Tela da interface

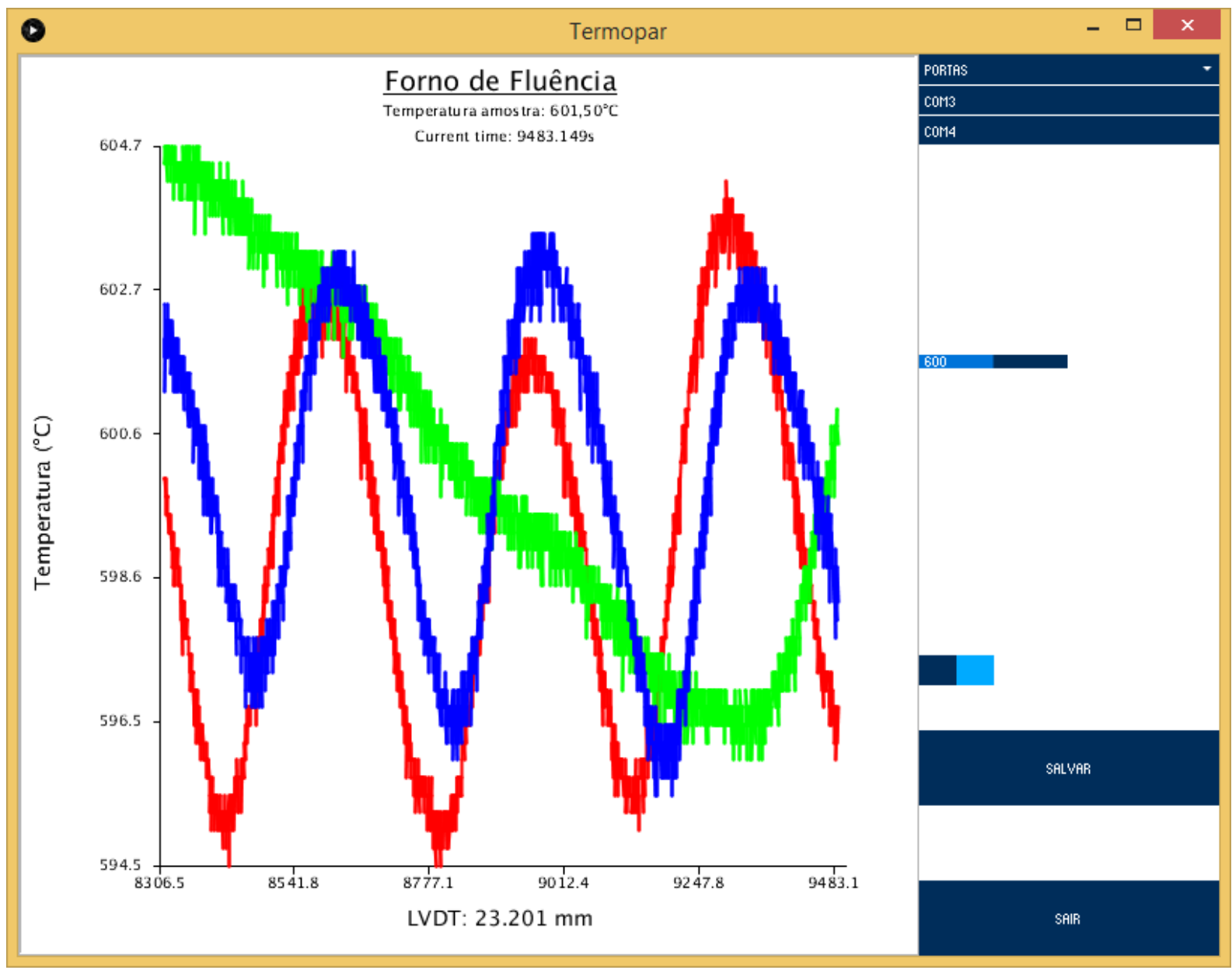

Fonte: autor da dissertação

A amostra foi fixada no extensômetro com, com um termopar do tipo $\mathrm{K}$ amarrado na altura do centro do corpo de prova. O LVDT, modelo TD-43 foi fixado em 
local próprio das hastes extensométricas. Três termopares, também do tipo $\mathrm{K}$, coletaram a temperatura no centro longitudinal de cada zona. A disposição axial dos sensores de temperatura foi definida para que ficassem o mais próximo possível da parede, para tanto, foram amarrados em uma haste de Inconel, que foi, por sua vez, amarrada na parede do forno. As aberturas foram isoladas termicamente com uma manta cerâmica, de maneira que permitiam o deslocamento das hastes sem comprometer o ensaio.

No braço de alavanca, foi adicionado um nível laser, que projetou sua inclinação na parede. Foram feitas marcações, acima e abaixo com o objetivo de não haver erro maior que $1 \%$ na aplicação da carga.

A temperatura foi definida em $873 \mathrm{~K}$ e iniciou-se o aquecimento. Após o forno atingir o SP e estabilizar a temperatura em $\pm 2 \mathrm{~K}$, iniciou-se uma pré-carga de 31,9 $\mathrm{MPa}$ (10\% da tensão definida para o ensaio). Em seguida, aguardou-se $3600 \mathrm{~s}$ e a carga total foi aplicada, com um total de $23,5 \mathrm{~kg}$ de peso morto. Na interface, um botão de "salvar" marcou o instante inicial $(t=0)$ do ensaio.

Durante o ensaio, girou-se o tambor de ajuste sempre que a marcação do nível laser se deslocava do ponto central. Garantiu-se que em momento algum a projeção fugisse da tolerância de $1 \%$. No instante da ruptura, o botão "salvar", na interface, foi pressionado novamente, com o objetivo de marcar o final do ensaio.

Os dados coletados foram importados para o software OriginLab, versão 9, no qual foram produzidas as curvas de deformação e taxa de fluência, ambas em função do tempo.

Definiu-se o início da fluência estacionária a partir da menor taxa de fluência. Esta taxa foi utilizada como coeficiente angular de uma reta tangente que definiu o início da fluência terciária quando a fluência instantânea deixou de ser descrita com o coeficiente $R^{2}<99,9 \%$. 


\section{RESULTADOS E DISCUSSÕES}

\subsection{Processo de modernização do equipamento EMEC (IPEN)}

O objeto principal deste estudo é composto por dois dispositivos:

i) o G35 é um mecanismo de aplicação de carga de tração uniaxial constante em uma amostra. Basicamente, é um braço de alavanca que amplifica a força empregada por peso-morto;

ii) o G28 é um forno cilíndrico com três zonas distintas de aquecimento, distribuídas conforme apresentado na Figura 21. O invólucro do forno é, na parte interna, de material refratário e, por fora, revestido com uma chapa metálica. No entanto, conforme mostrado na Figura 22, foi recebido por doação e estava sem medidor de deformação e sem controlador de temperatura.

Figura 21 - Distribuição das zonas de aquecimento do forno.

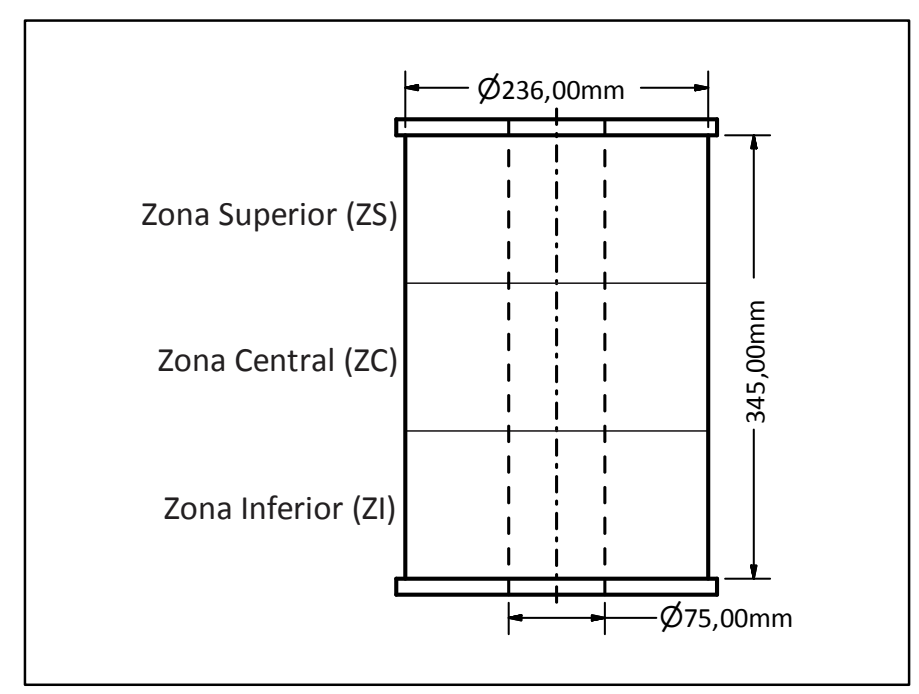

Fonte: autor da dissertação

Este equipamento possuía em seu projeto inicial controle manual de temperatura, através de potenciômetros, com mostradores analógicos. O alongamento da amostra era registrado através de um relógio comparador e 
necessitava que um operador registrasse o valor exibido manualmente em intervalos de tempo pré-estabelecidos. Havia ainda um item opcional para registro de alongamento da amostra em função do tempo, que consistia em um registrador $X Y$ para plotar as informações de alongamento da amostra em papel milimetrado.

Figura 22 - Vistas frontal e lateral do equipamento EMEC, pertencente ao IPEN.

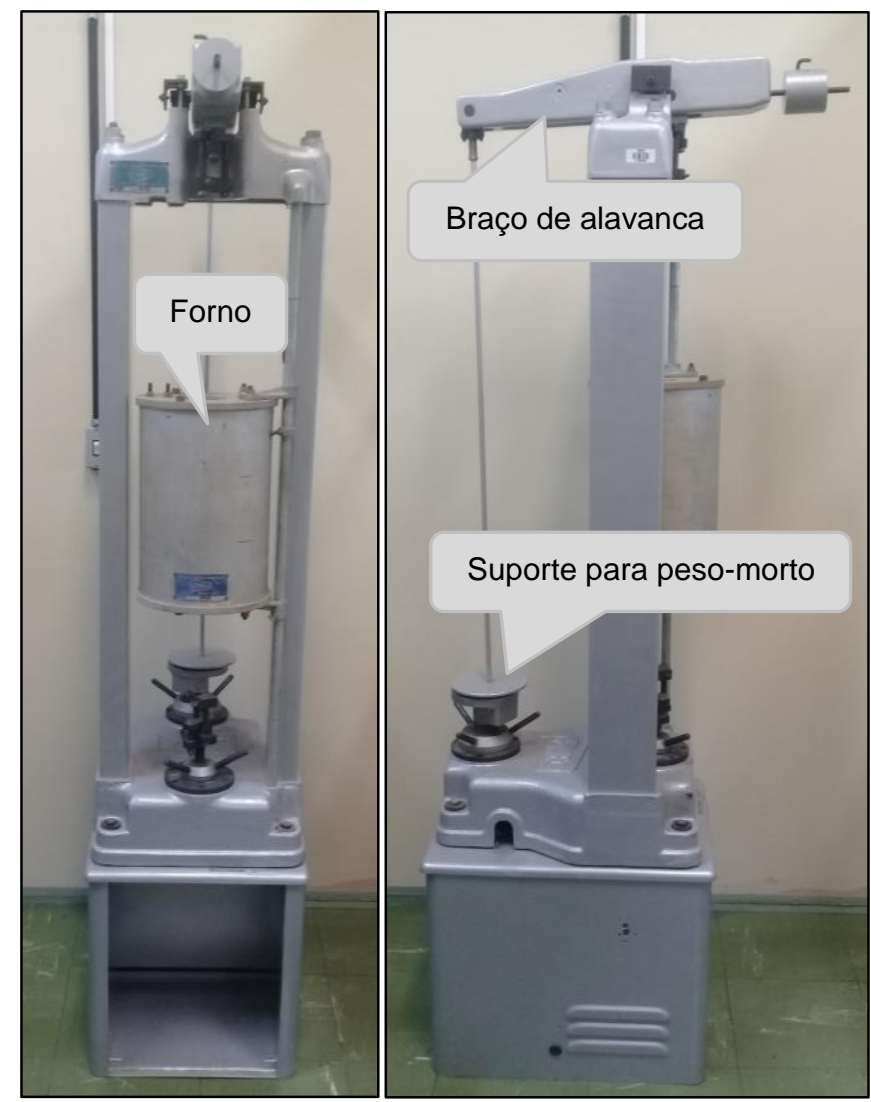

Fonte: autor da dissertação

\subsubsection{Aspectos mecânicos}

No dispositivo de aplicação de carga G35, no braço de alavanca, mais especificamente no ponto de contato do fulcro, possui um corte em "V" com abertura de $120^{\circ}$, enquanto o eixo de rotação possui um ângulo de $90^{\circ}$. Este formato de encaixe impõe uma restrição de rotação de $30^{\circ}$. No desenho esquemático da Figura 23 é exibido o centro de rotação e os pontos de força. Ainda, é possível visualizar o suporte de peso-morto, as barras de tração e as garras que pendem a amostra. Observa-se que o braço de alavanca é complexo porque o eixo do fulcro não está alinhado com os eixos de forças potente e resistente. As coordenadas $(x ; y)$, em relação ao fulcro, 
medidas em metros, obtidas pela medição foram:

$P_{x y}=(-0,317 ;-0,0197), R_{x y}=(0.0274 ;-0.0205), I_{x y}=(0.0274 ;-1.04)$.

Figura 23 - Esquemático do mecanismo de força

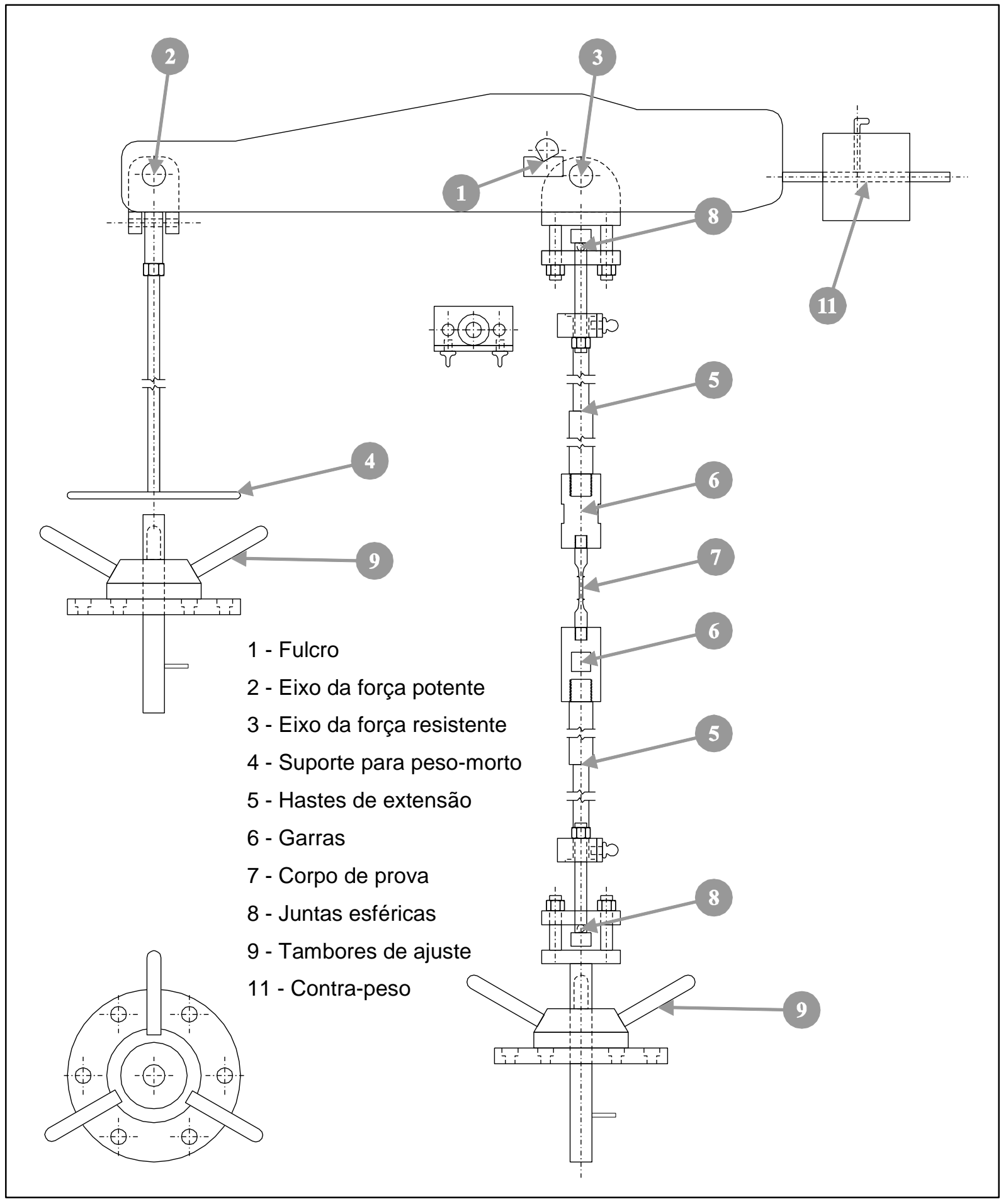

Fonte: autor da dissertação

A análise numérica das caraterísticas dinâmicas expôs o comportamento da tração na amostra, caso a inclinação do braço seja ignorada durante o ensaio. $\mathrm{Na}$ 
Figura 24 é exibido um gráfico da simulação do comportamento da tração na amostra $(\sigma)$ em função do alongamento $(\delta)$, sem a correção no ângulo do braço, para cada $1,0 \mathrm{~kg}$ de massa $(m)$ no suporte de peso-morto. A regressão linear, dos dados da simulação, forneceu a equação (40), que pode ser utilizada para estimar a variação da carga.

$$
\sigma=m \cdot(98,15879-2389,41749 \cdot \delta)[N]
$$

Figura 24 - Tração na amostra, em função do alongamento.

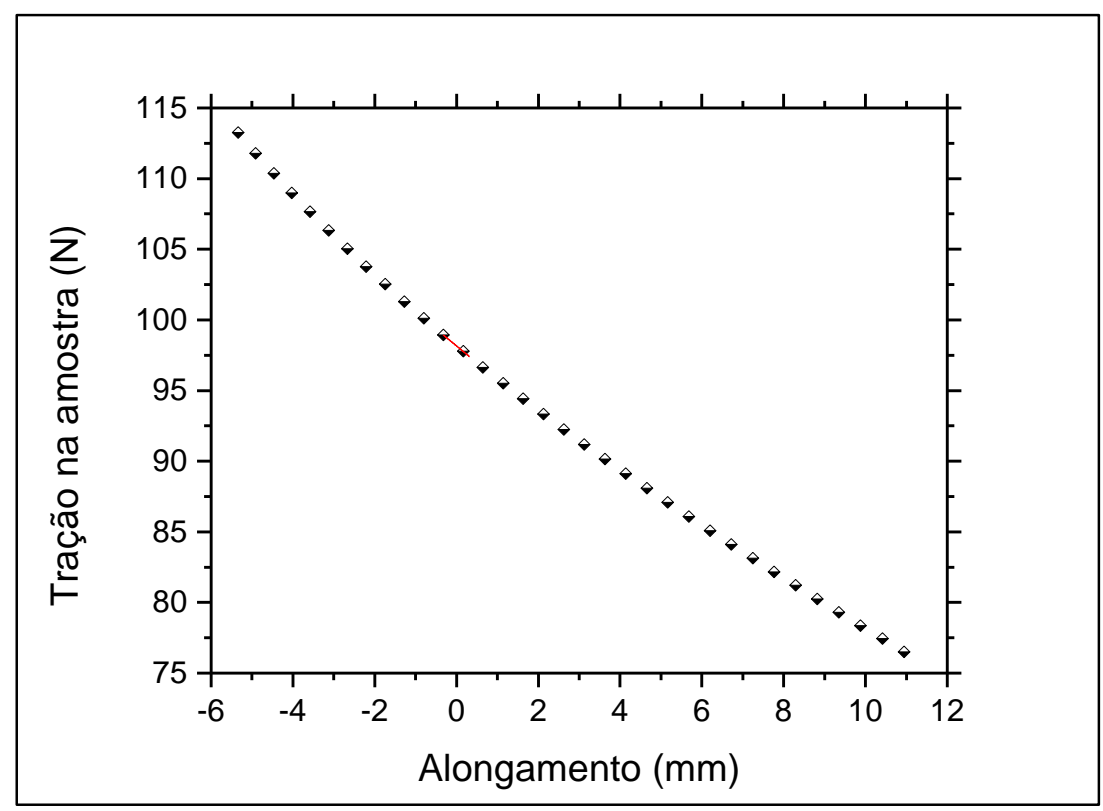

Fonte: autor da dissertação

Desta maneira, é possível inferir que o desalinhamento entre os eixos potente, resistente e o fulcro foram propositais. Provavelmente o projetista previu a compensação para as mudanças na área da seção transversal da amostra. O que leva a crer que o equipamento foi desenvolvido para o estudo de uma liga específica.

\subsubsection{Aspectos elétricos}

Os aquecedores do forno, modelo G28, nas zonas superior (ZS) e inferior (ZI) possuem $63,5 \Omega$, na central (ZC), 63,8 $\Omega$. Quando alimentado com sua tensão elétrica nominal $(220,0 \mathrm{~V})$ fornece uma potência térmica de $2283,0 \pm 18,5 \mathrm{~W}$. Ao considerar a margem de erro do instrumento de medida, é possível inferir que a potência nominal é de $2300 \mathrm{~W}$. Entretanto, o fato de ZC ter a resistência elétrica ligeiramente superior 
as demais é a informação que mais chama a atenção neste aspecto. Esta diferença poderia ser apenas uma imperfeição construtiva não fosse o fato das zonas mais externas serem idênticas. Ora, a resistência maior fornece potência ligeiramente menor $(0,47 \%)$. Provavelmente, o projetista buscou maior estabilidade térmica no centro do forno.

\subsubsection{Aspectos térmicos}

Após manter o forno ligado por 5400 s (90 min.) plotou-se os dados de temperatura em função do tempo que apresentaram-se como curvas exponenciais, conforme demostrado na Figura 25. Nota-se que a zona inferior tem dificuldade de perder calor, se comparado com a zona superior, que tem facilidade. Durante os ensaios para modelar o forno, houve a tentativa de evitar a convecção com uma vedação improvisada, utilizou-se uma chapa de $15 \mathrm{~mm}$ de aço-carbono. Mesmo assim, observou-se que este fenômeno tem influência significativa no processo de manutenção da temperatura. Uma solução empregada durante o ensaio com a amostra foi a vedação com manta cerâmica. Porém, por praticidade, a utilização de um material refratário, poroso, para evitar perdas por condução, e com desenho que permita o encaixe, tanto na abertura superior, quanto na inferior, encaixado nas aberturas a fim de conter o fluxo de ar no interior do forno, resolveria o problema.

A regressão exponencial, inicialmente, utilizando o método de mínimos quadrados e, a posteriori, com ajuste manual forneceu o conjunto de equações apresentados em (41) e (42), para aquecimento e resfriamento, respectivamente. As quais fornecem a temperatura teórica máxima do forno $\left(T_{\max }=1143\right)$, que é um diferencial entre as temperaturas interna e ambiente $(300 \mathrm{~K})$, e as constantes de tempo para aquecimento e resfriamento $\left(\tau_{a}=3100 \mathrm{~s}, \tau_{r}=9000 \mathrm{~s}\right)$. Destacou-se as características da ZC, uma vez que é a zona mais estável e, portanto, a região onde deve permanecer a amostra para o ensaio de fluência.

$$
\left\{\begin{array}{l}
T_{s}(\mathrm{t})=1085\left(1-e^{-t / 3100}\right)+300 \\
T_{c}(\mathrm{t})=1143\left(1-e^{-t / 3100}\right)+300 \\
T_{i}(\mathrm{t})=1075\left(1-e^{-t / 3100}\right)+300
\end{array}\right.
$$




$$
\left\{\begin{array}{l}
T_{s}(\mathrm{t})=885 e^{-t / 9000}+300 \\
T_{c}(\mathrm{t})=933 e^{-t / 9000}+300 \\
T_{i}(\mathrm{t})=876 e^{-t / 9000}+300
\end{array}\right.
$$

Figura 25 - Curva de aquecimento e resfriamento nas três zonas do forno.

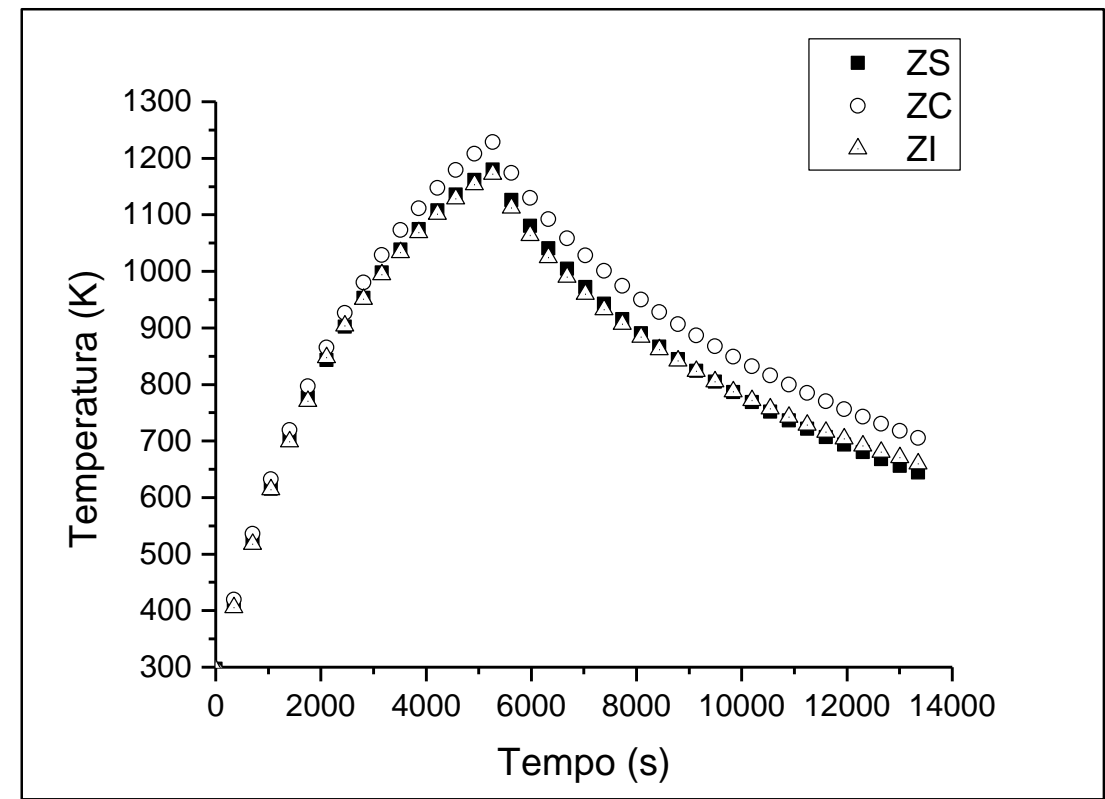

Fonte: autor da dissertação

Este estudo não analisou a composição dos resistores elétricos. É possível que tenham sido produzidos com fios de ligas de excelência a base de FeCrAl $\left(\right.$ Kanthal $\left.^{\circledR}\right)$. Porém, o estudo considerou que os aquecedores foram confeccionados com liga de $\mathrm{NiCr}$, a mais econômica para este fim. E, neste último caso, teria ponto de fusão de $1618 \mathrm{~K}$. Todavia, a temperatura crítica está acima da máxima teórica, para a potência de 2300 W. E, nada obstante, a alimentação elétrica de $220 \mathrm{~V}$ não provoca danos agudos. Enquanto a composição dos resistores for desconhecida, recomenda-se utilizar o forno em temperaturas abaixo de $1153 \mathrm{~K}$, com a finalidade de evitar efeitos tardios, justamente pela acentuação do efeito de fluência nos aquecedores. Este patamar representa $70 \%$ da temperatura absoluta de fusão do $\mathrm{NiCr}$ e pode ser utilizado para os ensaios na liga Ti-6Al-4V. 


\subsubsection{Controle da temperatura}

A análise pelo método de Ziegler e Nichols de malha aberta produziu a função de transferência (característica dinâmica) do forno exposta na Equação (43).

$$
G(s)=\frac{425,7 e^{-(88637) s}}{181832 s+1}
$$

Os parâmetros do PID, calculados a partir dos valores apresentados na Equação (43) são apresentados na Tabela 4.

Tabela 4 - Resultado dos parâmetros do PID

\begin{tabular}{c|ccc}
\hline Tipo de controlador & \multicolumn{3}{c}{ Parâmetro } \\
& $K_{c}$ & $T_{i}$ & $T_{d}$ \\
\hline P & 20,51 & $\infty$ & 0 \\
PI & 18,46 & 295457 & 0 \\
PID & 24,61 & 177274 & 44319 \\
\hline
\end{tabular}

A implementação dos parâmetros de controle proporcional-integral obteve ótima estabilidade na resposta, os dados foram plotados na Figura 26 e detalhados na Figura 27.

Porém não foi observada a mesma estabilidade no controlador PID. Provavelmente, os ruídos causaram provocaram a instabilidade do controlador com ação derivativa.

Para a realização do ensaio de fluência, houve a necessidade de mover os termopares da posição inicial para que fosse possível instalar as hastes extensométricas e esta alteração interferiu na dinâmica do aquecimento do forno, ou pelo menos em sua representação. Na Figura 28 é possível verificar a variação da temperatura em torno de $\pm 1,5 \mathrm{~K}$, porém com desvio do SP de $873 \mathrm{~K}$. 
Figura 26 - Aquecimento da ZC para SP de $773 \mathrm{~K}$.

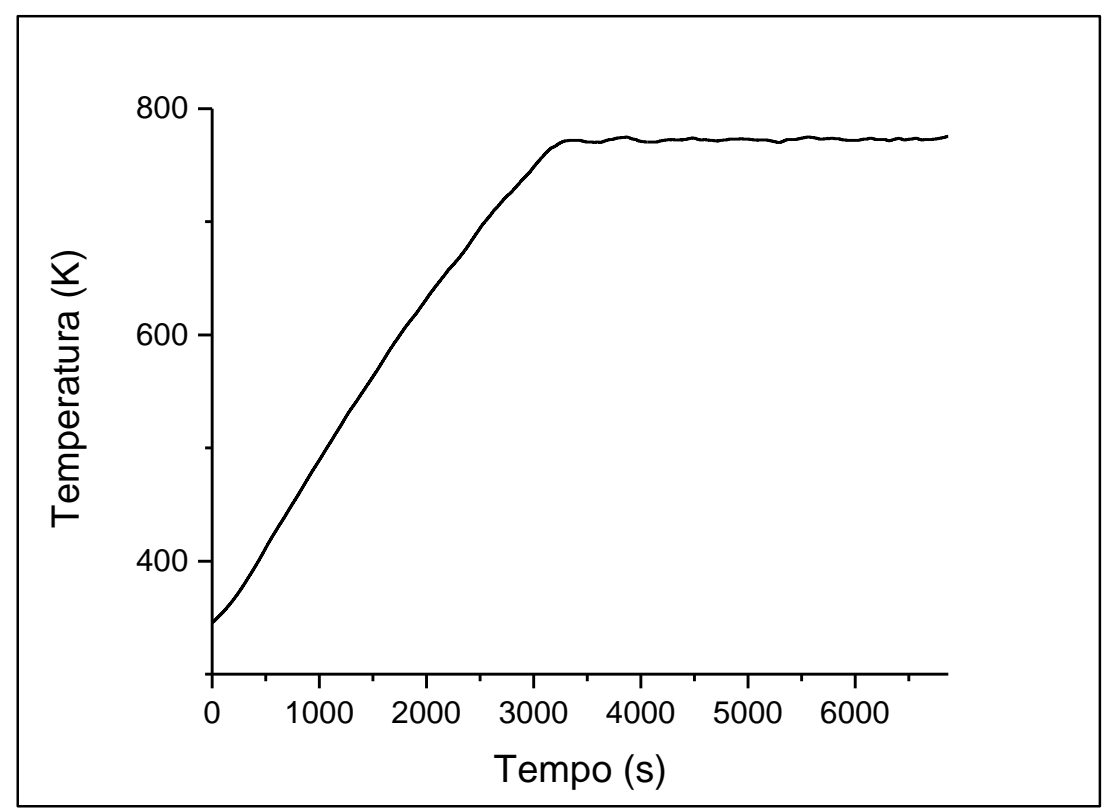

Fonte: autor da dissertação

Figura 27 - Recorte de 500s no aquecimento da ZC para SP de $773 \mathrm{~K}$.

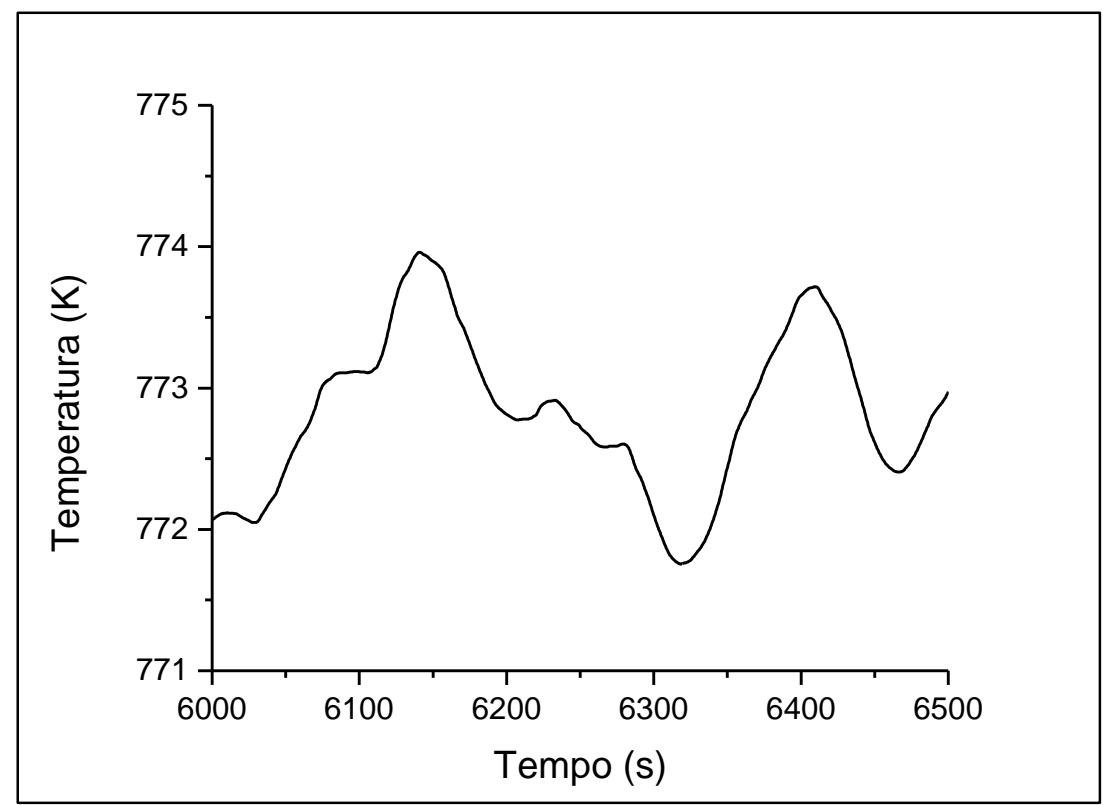

Fonte: autor da dissertação

\subsubsection{Sensor de deslocamento}

O deslocamento do núcleo, no interior do TD-43, provocou variações nas autoindutâncias e na Figura 29 é exibido um gráfico dos valores obtidos em função do deslocamento do núcleo. Observa-se, porém, que no ponto $21.83 \mathrm{~mm}$ os valores são 
coincidentes para ambos os secundários. Desta maneira, é nesta posição que encontra-se o null-point.

Figura 28 - Curva de aquecimento durante ensaio de fluência com SP de $873 \mathrm{~K}$

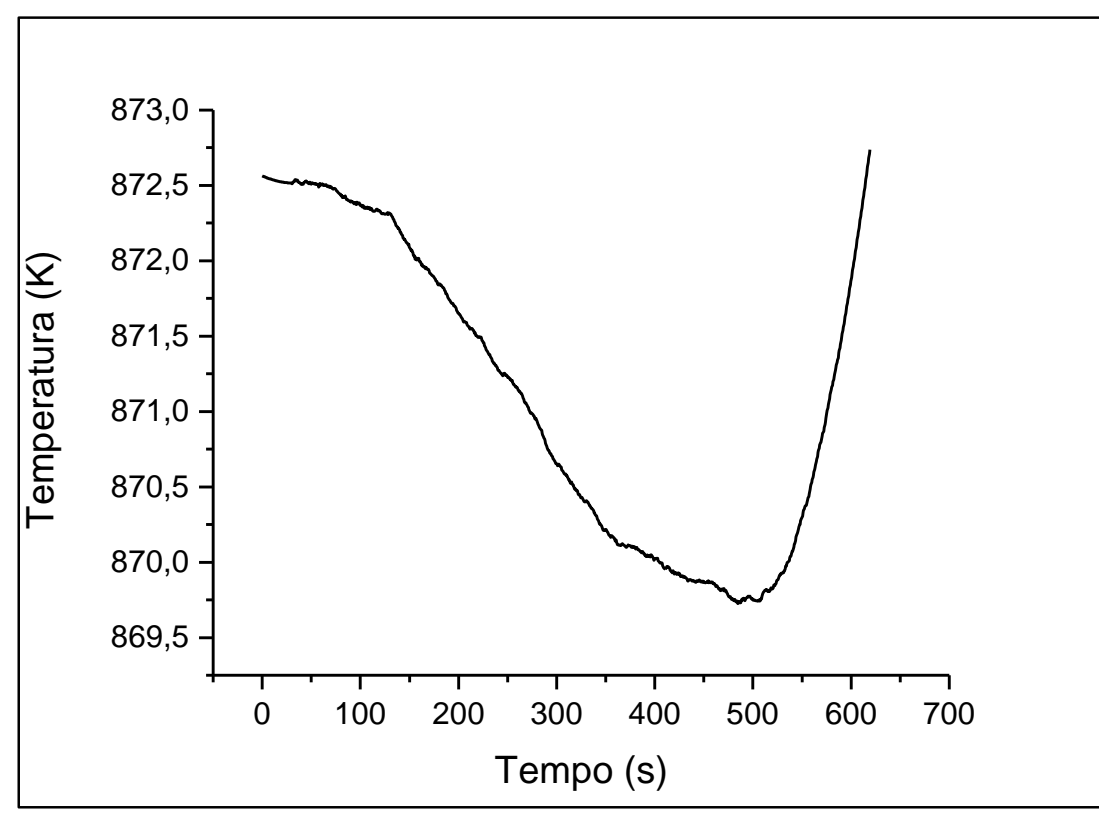

Fonte: autor da dissertação

Figura 29 - Indutâncias do TD-43 em função do deslocamento do núcleo.

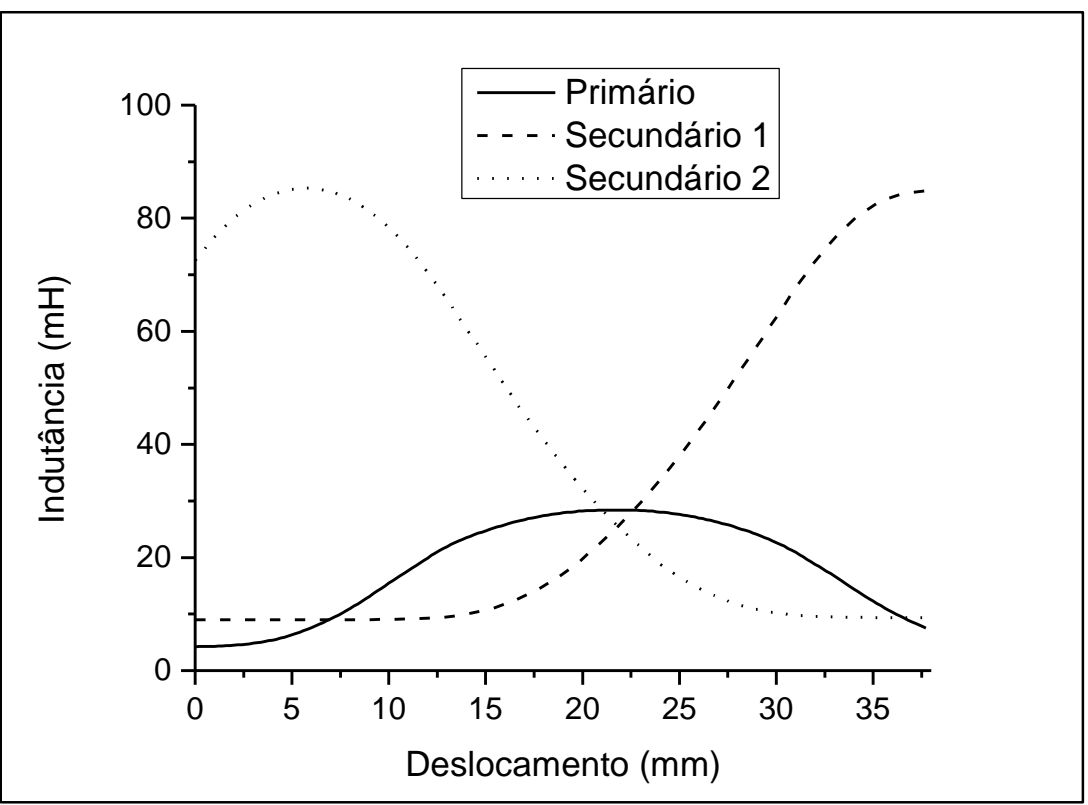

Fonte: autor da dissertação

A simulação da resposta do sensor, para tensão de excitação com amplitude de $5 \mathrm{Vpp}$ e uma frequência de $1 \mathrm{kHz}$ resultou na resposta do sensor em função do 
deslocamento. No entanto, os valores à esquerda do null-point foram definidos como negativos e os valores à direita, positivos. Um gráfico desta resposta é exibido na Figura 30. Na qual, é possível observar que há relativa linearidade entre a faixa de \pm 8 $\mathrm{mm}$. A regressão linear neste intervalo forneceu o parâmetro de sensibilidade de $30 \mathrm{mV} / \mathrm{V} / \mathrm{mm}$.

Figura 30 - Simulação da resposta em função do deslocamento.

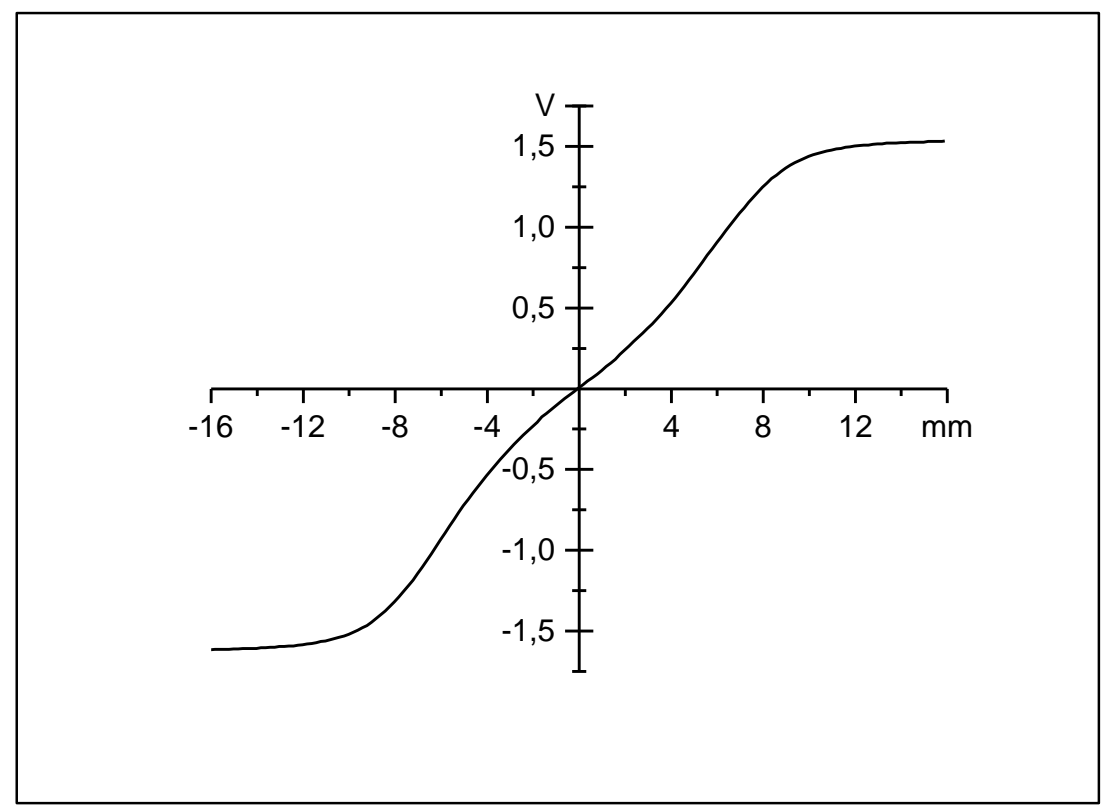

Fonte: autor da dissertação

Com o conjunto formado pelo GSTD-43, ADC e microcontrolador, foram registrados valores digitais a cada $0,5 \mathrm{~mm}$ de deslocamento As leitura do ADC plotadas em função do deslocamento $(x)$ produziram o gráfico mostrado na Figura 31 . A regressão linear pelo método dos mínimos quadrados forneceu a equação do deslocamento a partir da leitura do ADC conforme exibida na Equação (44).

$$
x=A D C\left(7,564 \times 10^{-4}\right)-4,392 \times 10^{-3}[\mathrm{~mm}]
$$

\subsubsection{Ensaio de fluência}

Após a implantação do conjunto de modernização no equipamento do IPEN, também foi ensaiada a liga Ti-6Al-4V a $873 \mathrm{~K}$ e $319 \mathrm{MPa}$. A curva da deformação em função do tempo foi plotada na Figura 32. 
Figura 31 - Leitura do ADC em função do deslocamento real

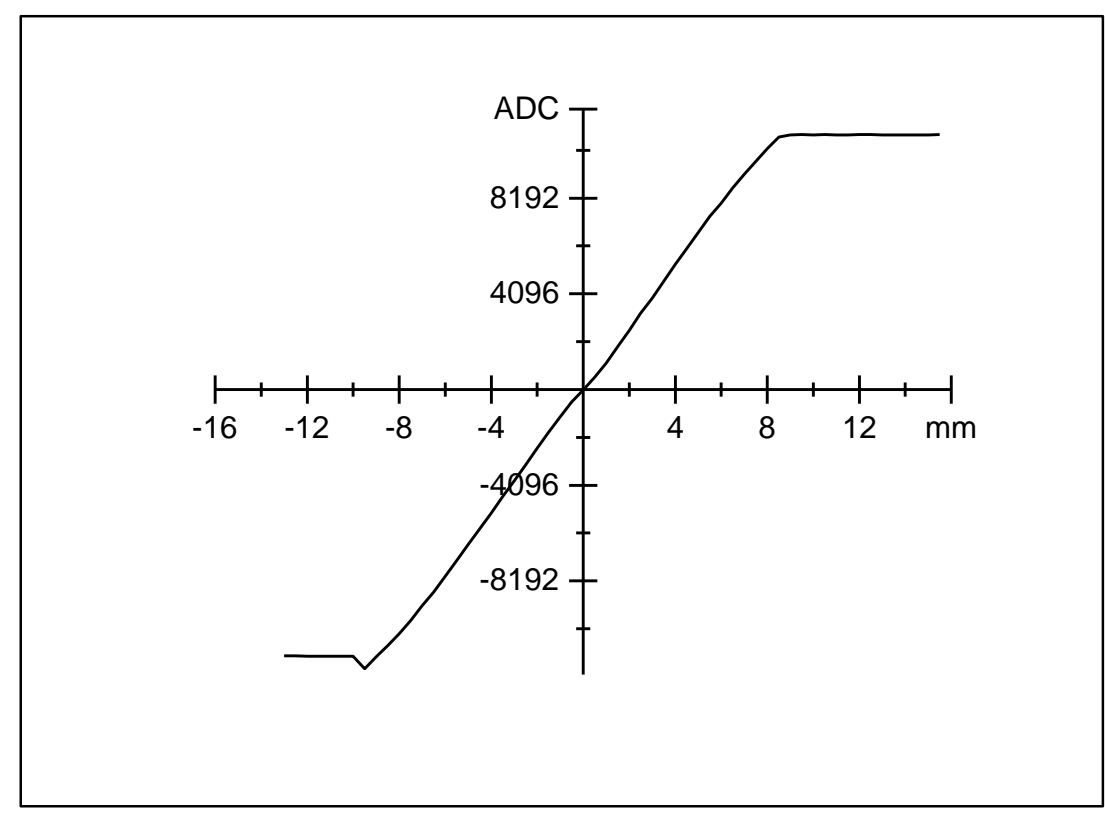

Fonte: autor da dissertação

Figura 32 - Curva da deformação em função do tempo (EMEC)

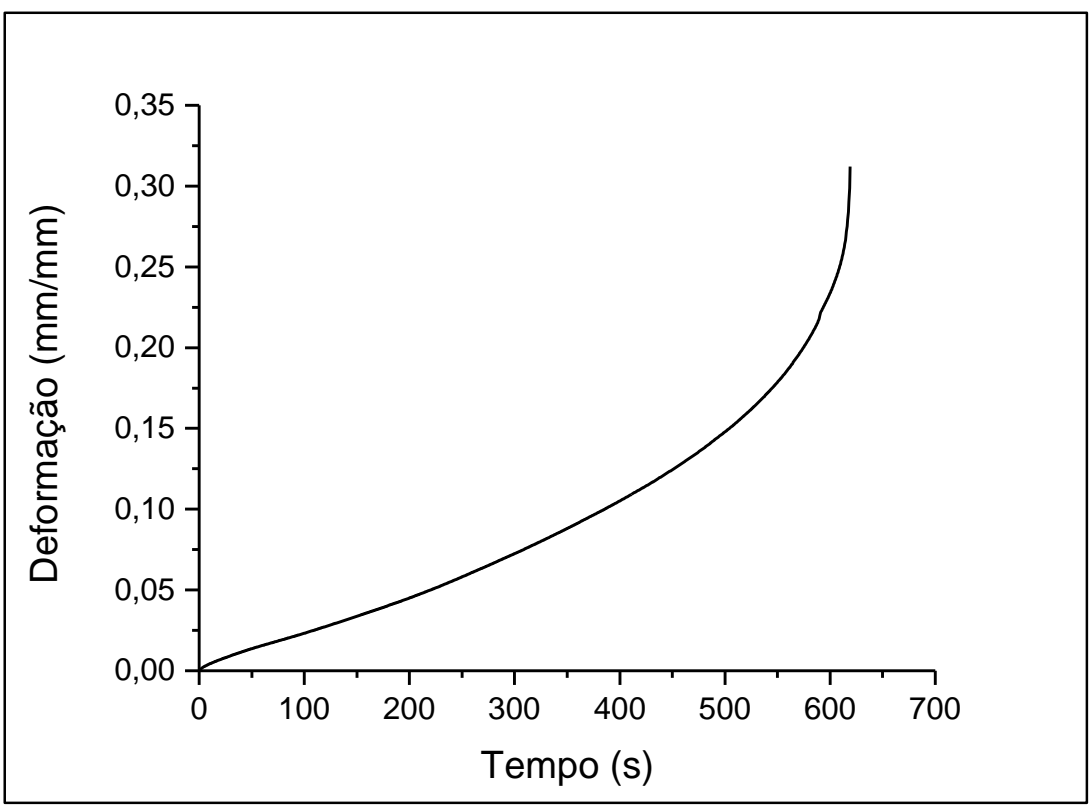

Fonte: autor da dissertação 


\subsection{Análise do equipamento Zwick (UPM)}

O equipamento, exibido na Figura 33 foi fabricado em 2015 pela empresa alemã Zwick-Roell. Esta solução foi adquirida pela Universidade Presbiteriana Mackenzie, na empresa Zwick Roell do Brasil Comércio de Máquinas e Equipamentos Ltda. Este, possui componentes de outros fabricantes, a saber:

- controlador de temperatura, da marca Eurotherm e modelo 2604, para controle independente de três zonas;

- LVDT, da marca HBM e modelo 1-WA/50MM-T, com curso de 50,0mm e sensibilidade de $80 \mathrm{mV} / \mathrm{V}$ em seu curso nominal; e

- servomotor, da marca Stegmaier-Haupt e modelo RX330CR1, com encoder IGD26H-2500-V05-0, com tensão de alimentação de $58 \mathrm{~V}$, corrente elétrica de 9,4 $\mathrm{A}$, pode fornecer torque de 1,54 $\mathrm{Nm}$, com a finalidade de aplicar a carga à amostra.

Demais partes e componentes possuem a marca Zwick-Roell, a saber:

forno bipartido, com três zonas de aquecimento e potência elétrica total de $3500 \mathrm{~W}$;

- termopares do tipo R para controlar a temperatura de cada zona;

- termopares do tipo N, para registro da temperatura na amostra;

- célula de carga, modelo Xforce K, com capacidade nominal de $10 \mathrm{kN}$ e sensibilidade de $2 \mathrm{mV} / \mathrm{V}$; e

- um software proprietário denominado "testXpert II".

O dispositivo de aplicação de carga é uma mesa móvel, conectada a uma barra com junta de três graus de liberdade. A transmissão da força é realizada por dois fusos, com castanhas de esfera fixadas na mesa e, na outra ponta do fuso, um motor de passo com redutor de 1:100 e encoder absoluto. O fuso tem passo de 6,0 $\mathrm{mm}$ e o conjunto servomotor-redutor tem uma resolução de 20 mil passos por revolução, o que confere uma resolução de $3,0 \times 10^{-4} \mathrm{~mm}$ ao movimento da mesa. 
Figura 33 - Imagem do equipamento Zwick, pertencente à UPM.

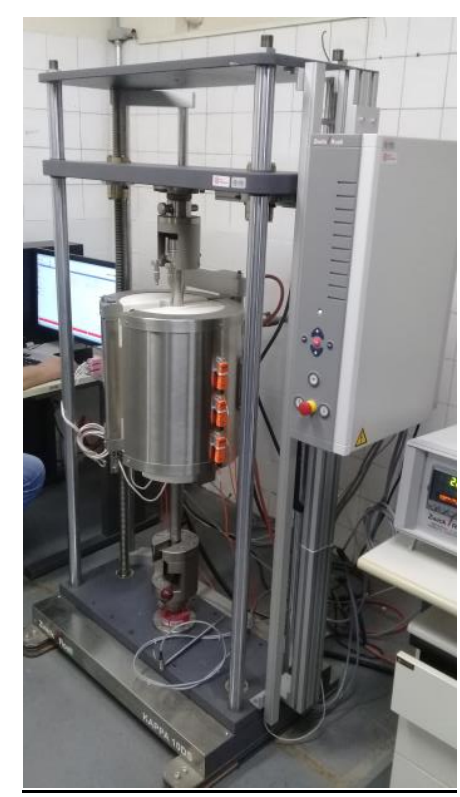

Fonte: autor da dissertação

A construção robusta do forno, aliado a 3 tomadas de temperatura próximo aos resistores, com termopares do tipo $\mathrm{R}$, conferem ótimo controle. Durante o ensaio a maior temperatura registrada na amostra foi de $873,66 \mathrm{~K}$ e a menor $872,54 \mathrm{~K}$, que são oscilações bem inferiores aos $\pm 2 \mathrm{~K}$, exigido pela ASTM E139. Outro aspecto que confere qualidade a este equipamento foi a sensibilidade do LVDT que leu variações de $0,1 \mu \mathrm{m}$, isto representa erro inferior a $10^{-5}$. Porém a carga, aplicada no ensaio, oscilou como demonstrada na Figura 34.

Figura 34 - Oscilação da força provocado pelo equipamento Zwick

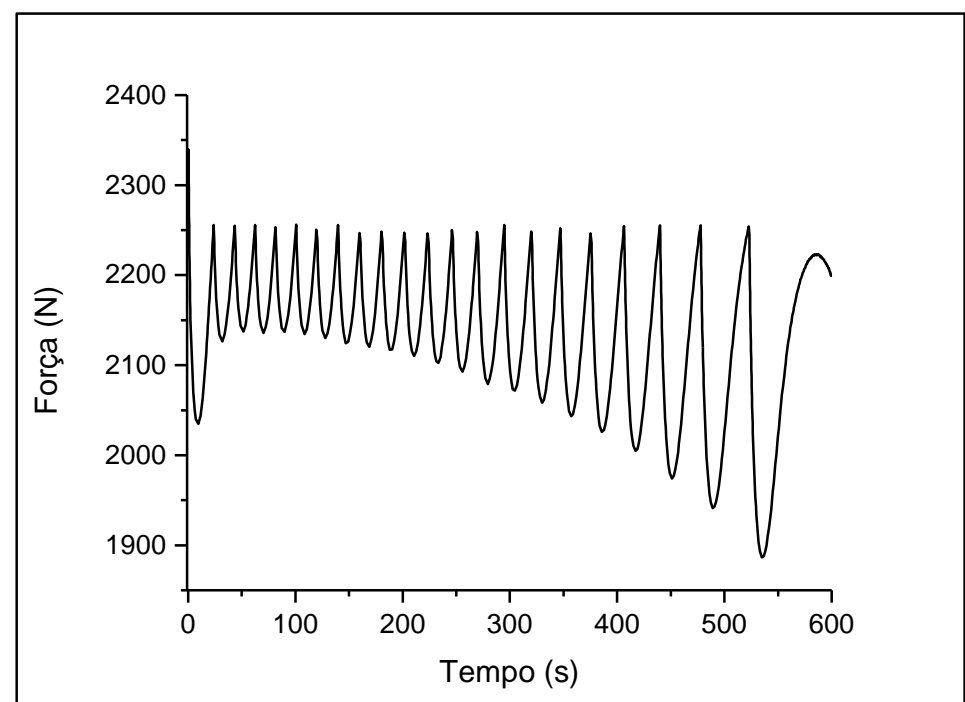

. Fonte: autor da dissertação 
Esta incapacidade que o dispositivo de aplicação de carga apresenta para manter a força constante durante o ensaio é provocada pela rotação do fuso, que armazena energia no coeficiente elástico do conjunto como um todo. Como são peças rígidas o coeficiente é baixo. A adição de uma mola, possivelmente na barra, reduziria substancialmente as oscilações.

Figura 35 - Curva da deformação em função do tempo (Zwick)

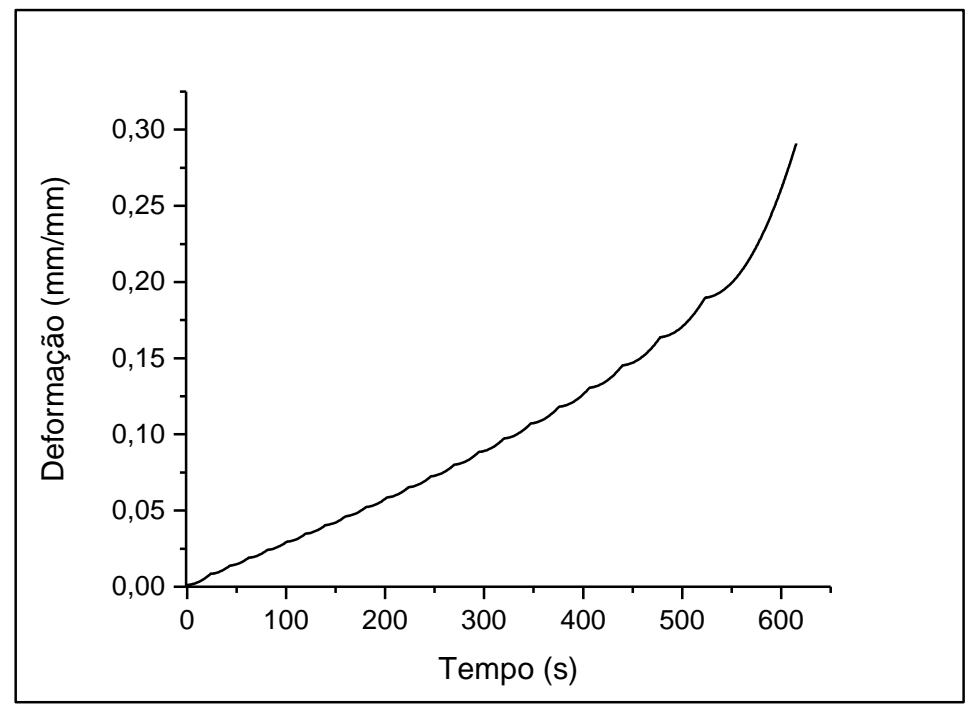

Fonte: autor da dissertação

Quando exibido resultado do ensaio da liga Ti-6Al-4V a $873 \mathrm{~K}$ e $319 \mathrm{MPa}$, a variação é perceptível durante a deformação da amostra, como exibido na Figura 35. Nesse ensaio o rompimento ocorreu com $615 \mathrm{~s}$, pouco mais de $10 \mathrm{~min}$.

\subsection{Análise do equipamento Mayes (DCTA)}

$O$ equipamento demonstrado na Figura 36 pertence ao LEME/AMR/IAE/DCTA, localizado em São José dos Campos, SP. O aparato foi fabricado pela empresa Denison Mayes Group e há pouca informação disponível.

O retrofit foi realizado pela empresa BSW Tecnologia, Industrial e Comércio Ltda., que no processo de modernização inseriu um conjunto de atualização e um controlador de processos térmicos, da marca Coel e modelo HW 4200. O conjunto ainda é composto por uma placa eletrônica e um software chamado de Antares, capaz de gerenciar diversos equipamentos em um único computador. 
Figura 36 - Imagem do equipamento Mayes, pertencente ao DCTA.

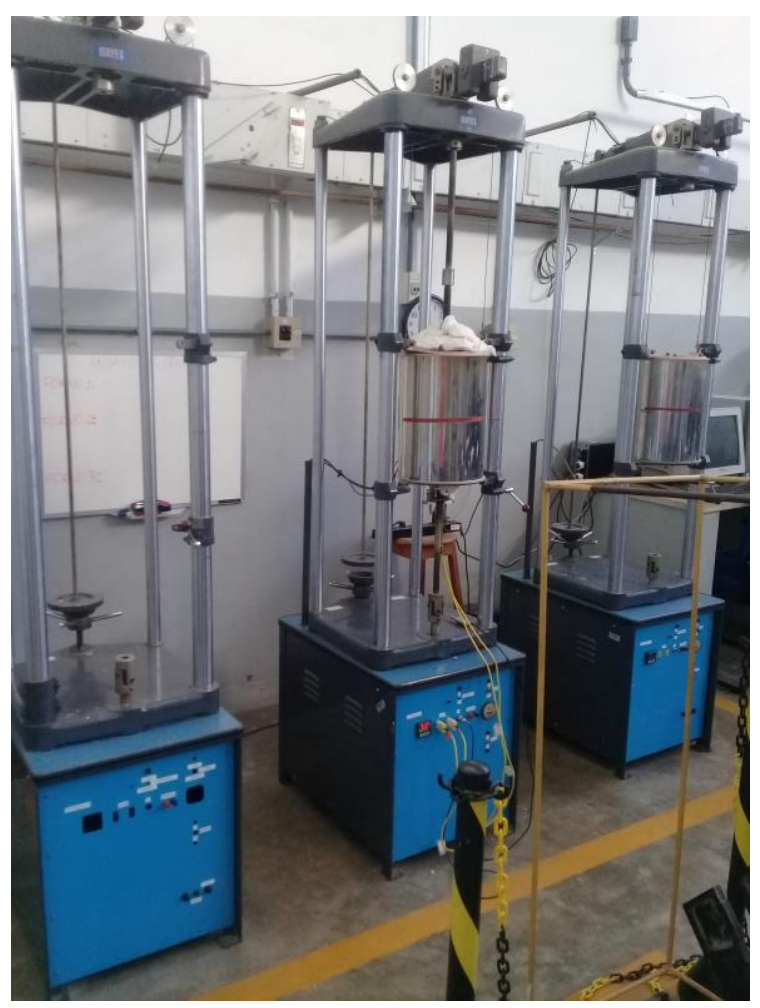

Fonte: autor da dissertação.

Com base em um termopar e um LVDT, instalados na amostra, a placa eletrônica captura e o software registra a temperatura interna do forno e o alongamento do corpo de prova. A temperatura interna do forno é regulada pelo controlador de processos, a partir da realimentação (feedback) de um segundo termopar, Todos os termopares são do tipo $\mathrm{K}$ e ficam instalados próximos à amostra, mas sem tocá-la.

Dado que o controle e o registro de temperatura são feitos por termopares distintos, é possível que haja divergência entre a temperatura real e a temperatura armazenada pelo software, com erro sistemático de $12,11 \mathrm{~K}$, como exibido na Figura 37. O desvio padrão da temperatura foi de 0,0434 K. Nesse caso entendeu-se que circuito de leitura na placa eletrônica não foi calibrado ou pode haver falha na compensação de junção fria.

Outro aspecto observado foi que, apesar do forno ter 3 zonas de aquecimento independes, o controlador utiliza apenas um SSR e um termopar na realimentação do parâmetro. Ao replicar a mesma informação para acionamento das zonas de aquecimento, com ligação elétrica em paralelo, não é possível detectar gradiente de temperatura. Desta maneira, o registro da temperatura central pode não refletir as da 
parte superior e da inferior. É possível que haja diferença e, consequente, gradiente de temperatura. Uma vez que há uma tendência natural da convecção aumentar a temperatura da região superior em relação às demais.

Figura 37 - Temperatura durante o ensaio em função do tempo

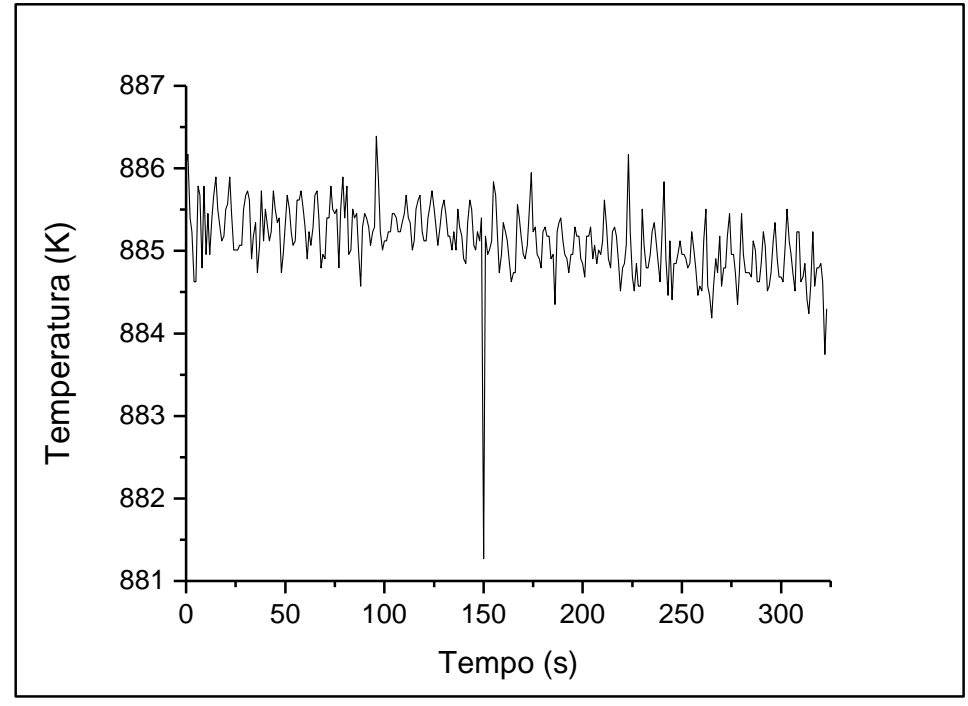

. Fonte: autor da dissertação.

O transdutor utilizado nesta máquina é, também, do tipo LVDT, da marca Schlumberger e modelo D 6,50, com sensibilidade na saída de 53,18 mV/V/mm. Em termos de deslocamento, a resolução apresentada pelo software Antares é de $4,32051 \times 10^{-4} \mathrm{~mm}$, conforme demostrado pelos degraus na Figura 38.

A fim de garantir a constância na aplicação de carga na amostra, foram instalados níveis de bolha nos braços de alavanca e a correção da inclinação é feita constantemente durante o ensaio. As manivelas para esta correção possuem alto relação de transformação (que não foi apurado) mas que conferem movimentos sutis. No ensaio com a liga Ti-6Al-4V a $873 \mathrm{~K}$ e $319 \mathrm{MPa}$, o rompimento da amostra ocorreu com $323 \mathrm{~s}$, pouco mais de 6 min. A Figura 39 apresenta a curva da deformação da amostra em função do tempo. 
Figura 38 - Recorte de um registro de alongamento

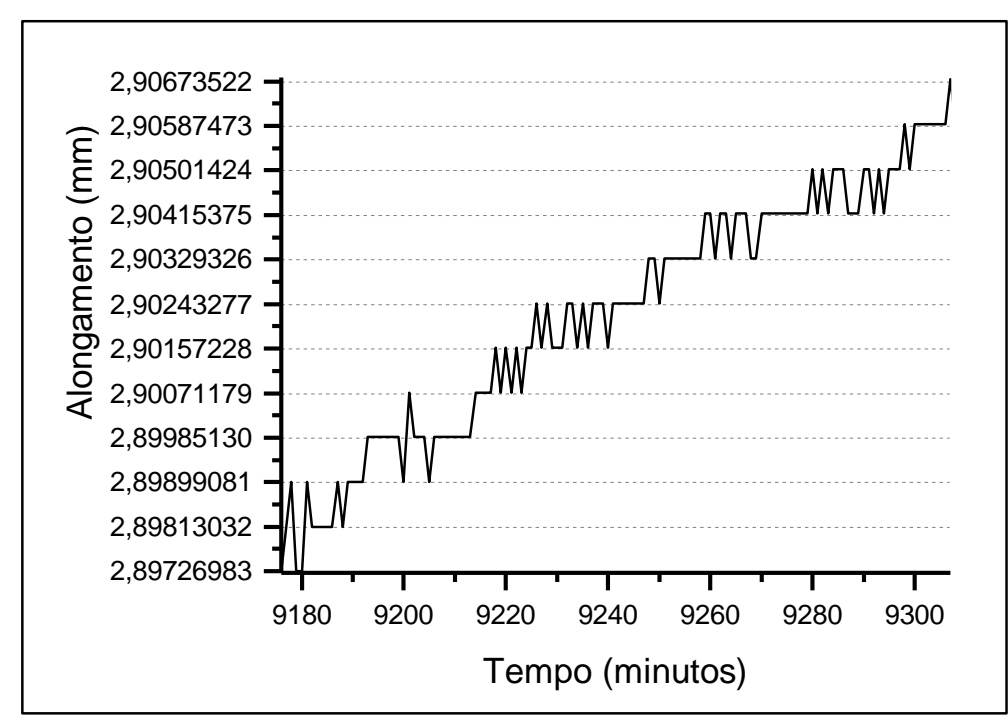

. Fonte: autor da dissertação

Figura 39 - Curva da deformação em função do tempo (Mayes)

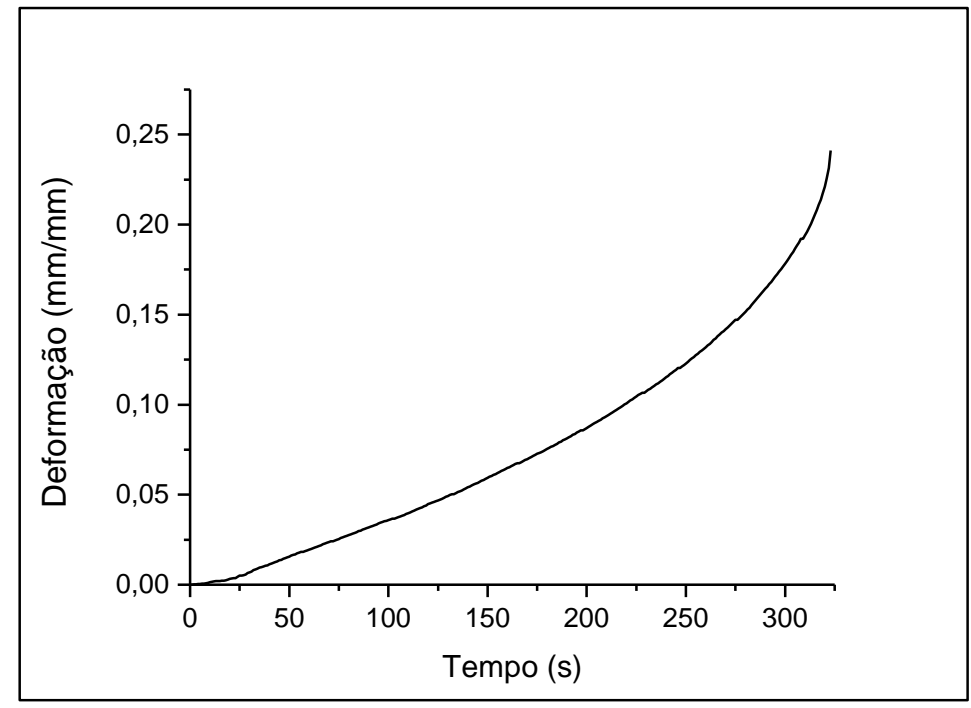

. Fonte: autor da dissertação

\subsection{Comparação entre os resultados dos ensaios}

Os resultados dos ensaios nos três equipamentos para corpos de prova com microestrutura equiaxial foram reunidos na Tabela 5 em que são mostrados os tempos de fluência primária $\left(t_{p}\right)$, a taxa de fluência secundária $\left(\dot{\varepsilon}_{s}\right)$, o tempo final de fratura $\left(t_{f}\right)$ e a deformação de fratura $\left(\varepsilon_{f}\right)$. As curvas de deformação em função do tempo foram plotadas sobrepostas na Figura 40. 
Tabela 5 - Parâmetros obtidos com os ensaios nos diferentes equipamentos

\begin{tabular}{ccccc}
\hline & \multicolumn{4}{c}{ Parâmetros } \\
Local do ensaio & $t_{p}(s)$ & $\dot{\varepsilon}_{s}\left(s^{-1}\right)$ & $t_{f}(s)$ & $\varepsilon_{f}(\mathrm{~mm} / \mathrm{mm})$ \\
\hline $\begin{array}{l}\text { Mayes } \\
(\text { DCTA })\end{array}$ & 39 & $5,04 \times 10^{-4}$ & 321 & 0,2412 \\
$\begin{array}{l}\text { Zwick } \\
(\text { UPM })\end{array}$ & - & $2,85 \times 10^{-4}$ & 615 & 0,2808 \\
$\begin{array}{l}\text { EMEC } \\
(\text { IPEN) }\end{array}$ & 52 & $2,71 \times 10^{-4}$ & 619 & 0,2986 \\
\hline
\end{tabular}

Fonte: própria

Figura 40 - Sobreposição das curvas de deformação em função do tempo

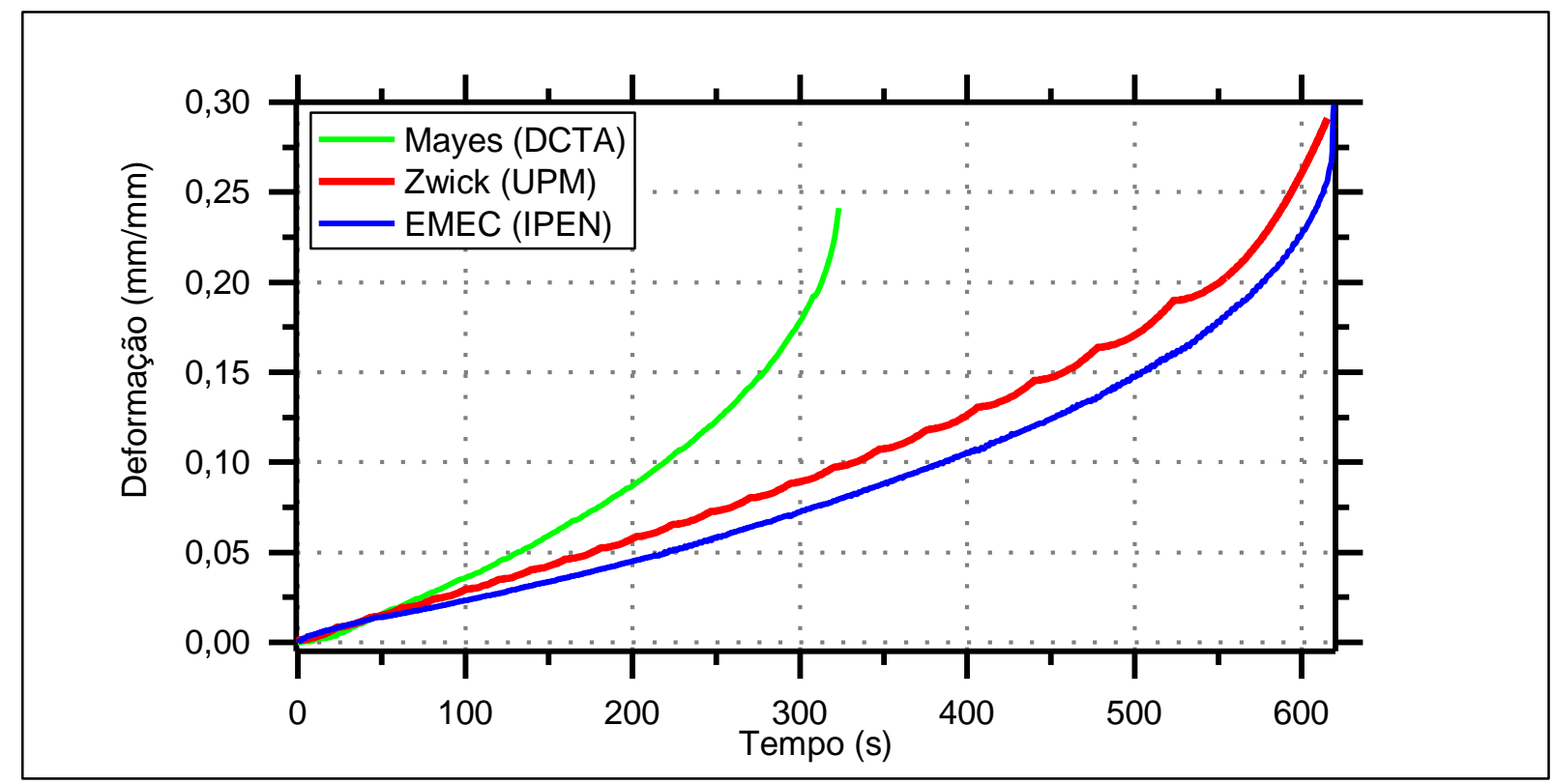

Fonte: autor da dissertação

Observa-se que os valores entre os resultados do equipamento modernizado neste estudo e o Zwick Roell/Kappa 10 DS são bastante semelhantes. Por outro lado, há uma divergência nos tempos de ruptura e taxa de fluência estacionária com o equipamento Mayes com conjunto de modernização BSW/Antares, na ordem de $60 \%$. Porém o fato de estarem na mesma ordem de grandeza $\left(10^{-4}\right)$ demonstra que, apesar 
de incipiente, os resultados do processo de modernização é promissor. Há de considerar que foi realizado apenas um ensaio para cada equipamento.

Outro aspecto a ser observado é que o dispositivo de aplicação de carga da Zwick oscilou e manteve-se abaixo dos $2350 \mathrm{~N}$ necessários para provocar uma tração de $319 \mathrm{MPa}$ na amostra. Por outro lado a temperatura no forno da EMEC esteve cerca de $2 \mathrm{~K}$ abaixo do SP. Nesse sentido, pode-se afirmar que a redução na carga em uma máquina e a redução na temperatura da outra pode ter estendido o tempo para a ruptura.

Ademais, há a necessidade de que sejam realizados maior número de ensaios em cada uma das máquinas, para cada condição de ensaio e com várias condições. 


\section{CONCLUSÕES}

Com base no que foi apresentado, as características mecânicas, elétricas e térmicas do equipamento EMEC G28/G35 permitem afirmar que este foi um projeto de excelência. Principalmente, se comparado às análises das máquinas da UPM e do DCTA. Por outro lado, a defasagem pôde ser contornada readequando-o ao uso com a adição de instrumentação de baixo custo. Além disso, o uso de dispositivos eletrônicos integrados para a leitura da deformação e controle de temperatura permitiu o registro de todos os dados em um único meio digital. Esta reunião das variáveis facilitou a análise posterior. De forma mais ampla, os resultados dos testes, na mesma ordem de grandeza, demonstraram que esta proposta, mesmo incipiente, é promissora. Outro aspecto relevante é que em todo processo foram utilizados tecnologias royalty-free, permitindo a reprodução sem custos adicionais. Ademais, o controlador é atualizável, permitindo otimizações sem mudanças de hardware.

A respeito da manutenção de temperatura, cabe ressaltar que os fornos utilizados nos equipamentos de fluência são complexos por possuírem múltiplas zonas de aquecimento e serem distribuídos verticalmente, de modo que a variação de temperatura em uma zona influencia na outra pelo processo de convecção. A modelagem deste sistema de múltiplas entradas com múltiplas saídas (MIMO) carece de maior atenção. Apesar da necessidade de ajustes finos, a fim de aumentar o rigor no controle de temperatura e registro de alongamento da amostra, este estudo foi capaz de desenvolver o conjunto de modernização do equipamento estudado. $E$ foi suficiente para estudar o comportamento em fluência da liga Ti6Al4V, além de obter resultado muito semelhante a um equipamento considerado de excelência.

Outrossim, a proposta de melhoramentos futuros no controle de temperatura do forno e novas facilidades podem ser adicionadas. Para exemplificar, métodos numéricos podem ser aplicados à análise, fornecendo os parâmetro do ensaio de forma automática e em tempo de execução. De forma que este equipamento não está limitado ao estudo de apenas uma liga e outros materiais com fluência perceptível abaixo da temperatura de $1173 \mathrm{~K}$ podem ser estudados. 
No que diz respeito aos mecanismos, atuadores lineares podem ser adicionados ao conjunto, corrigindo a inclinação do braço e minimizando os erros do ensaio. Outra proposta possível é acrescentar uma célula de carga, a fim de que haja rigor no controle da tensão aplicada ao corpo de prova. 


\section{REFERÊNCIAS BIBLIOGRÁFICAS}

ABDELAZIZ, Y. A. Precise Temperature Measurement Using Noble Metal Thermocouples. In: SU, Y.-H. Noble Metals. Rijeka: Intech, 2012. Cap. 10, p. 207222.

AL-SHARIF, L. et al. Linear Variable Differential Transformer Design and Verification Using MATLAB and Finite Element Analysis. In: PERUTKA, K. MATLAB for Engineers: Applications in Control, Electrical Engineering, IT and Robotics. [S.I.]: [s.n.], 2011. Cap. 4, p. 75-94.

AMERICAN SOCIETY FOR TESTING AND MATERIALS. Surface Engineering. Philadelphia: ASTM, v. 5, 1996.

AMERICAN SOCIETY FOR TESTING AND MATERIALS. ASTM E139-11: Standard practice for conducting creep, creep-rupture and stress-rupture tests of metallic materials. West Conshohocken: ASTM International, 2011.

ÅSTRÖM, K. J.; HÄGGLUND, T. Advanced PID Control. Research Triangle Park: ISA - The Instrumentation, Systems, and Automation Society, 2006.

BARBOZA, M. J. R. Estudo e Modelagem sob Condições de Fluência da Liga Ti6Al4V. 2001. 196 f. Tese (Doutorado em Engenharia Aeronáutica e Mecânica) Instituto Tecnológico de Aeronáutica, São José dos Campos.

BARBOZA., M. J. R.; MOURA NETO, C. D.; SILVA, C. R. M. D. Creep mechanisms and physical modeling and physical modeling for Ti-6Al-4V. Materials Science and Engineering A, v.369, 25 March 2004. p. 201-209.

BEIFEI, Y. X. D. Z. M. Fuzzy PID temperature control system's design based on LPC2368. Electronic Measurement Technology, 2009.

BOTLAND. MAX6675 thermocouple - SPI temperature senso. Electronics, 2018. Disponivel em: https://botland.com.pl/en/temperature-sensors-analog-anddigital/12504-max6675-thermocouple-spi-temperature-sensor.html. Acesso em: 27 abr. 2019.

BOYLESTAD, R. L. Introdução à análise de circuitos. 12ª . ed. São Paulo: Pearson Prentice Hall, 2012.

BRIGUENTE, L. A. N. D. S. Estudo de tratamento térmico e recobrimento como forma de barreira térmica sobre o comportamento em fluência da liga Ti-6Al4V. 2011. 185 f. Dissertação (Mestrado em Engenharia Aeronáutica e Mecânica) Instituto Tecnológico de Aeronáutica, São José dos Campos.

BY THE WAY. Productos. Base Adaptador Arduino Nano V.3 con Borneras, [2019?]. Disponivel em: https://www.bytheway.com.co/otros/145-base-adaptadorarduino-nano-v3-con-borneras.html. Acesso em: 25 jul. 2019. 
CALLISTER, W. D. Materials Science and Engineering: An Introduction. 7th. ed. New York: Wiley, 2007.

DIETER JR, G. E. Mechanical metallurgy. New York: McGraw-Hill, 1961.

DORF, R. C.; BISHOP, R. H. Sistemas de Controle Modernos. 8ª . ed. Rio de Janeiro: LTC, 2001.

DOS REIS, A. G. et al. Creep Properties Evaluation at $600^{\circ} \mathrm{C}$ of Maraging 300 Steel Solution Treated. Tecnologia em Metalurgia, Materiais e Mineracao, 11(1), Mar 2014. 22-26.

DRUMEA, A. et al. System on Chip Signal Conditioner for LVDT Sensors.

Electronics System-Integration Technology Conference (ESTC), Dresden, 07 September 2006. 629-634.

EREN, H. Inductive Displacement Sensors. In: WEBSTER, J. G. Measurement, instrumentation, and sensors handbook. Boca Raton: CRC Press LLC, 1999. Cap. 6.2, p. $79-100$.

FROST, H. J.; ASHBY, M. F. Deformation mechanism maps: the plasticity and creep of metals and ceramics. Oxford: Pergamon Press, 1982.

GARCIA, A.; SPIN, J. A.; SANTOS, C. A. D. Ensaio dos materiais. 2.․․ ed. Rio de Janeiro: LTC, 2012.

GRAY, R. M.; NEUHOFF, D. L. Quantization. IEEE Transactions on information theory, IT-44, n. 6, October 1998. 2325-2383.

GWAK, K.-W.; MASADA, G. Y. Nonlinear Optimal Control of an Input-Constrained and Enclosed Thermal Processing System. International Journal of Control, Automation, and Systems, v. 6, p. 160-170, 2008.

IEEE COMPUTER SOCIETY. IEEE 754-08: Standard for Floating-Point Arithmetic. 2008. $58 \mathrm{f}$. The Institute of Electrical and Electronics Engineers, Inc, New York.

JNG MATERIAIS ELÉTRICOS. Relés de estado sólido SSR. 2017. 1 f. São Paulo. Disponivel em: http://www.jng.com.br/upload/download/\%7B6226598F-3A41-49FA83B0-93F5DEE91BB3\%7D_43\%20-\%20\%20Catalogo\%202016\%20\%20Rel\%C3\%A9s\%20Est\%20Solido\%20Auxiliares\%20\%20-\%20BR.pdf. Acesso em: 20 mai. 2018.

JUVINALL, R. C.; MARSHEK, K. M. Fundamentals of machine component design. Nova Jersey: Wiley, 2012.

KASSNER, M. E. Fundamentals of Creep in Metals and Alloys. 2nd. ed. Oxford,: Elsevier, 2009.

KIM, G. J. Case-based design for assembly. Computer-Aided Design, London, 29, n. 7, 1997. 497-506. 
KUMAR, Y. V. P. et al. Cascaded PID Controller Design for Heating Furnace. IOSR Journal of Electronics and Communication Engineering, v. 5, n. 3, p. 76-83, 2013.

LARSON, R.; FARBER, B. Estatística aplicada. 4. ‥ ed. São Paulo: Pearson Prentice Hall, 2010.

LIYING, Z.; GUOSHU, Z. Application of fuzzy-PID control algorithm in uniform velocity temperature control system of resistance furnace. Chinese Journal of Scientific Instrument, 2008.

MELLO, C. H. P.; SILVA, C. E. S. D.; SOUZA, J. F. D. Desenvolvimento de produtos aplicando técnicas de projeto para montabilidade em uma abordagem de engenharia reversa. In: XIII Simpósio de Engenharia de Produção. Bauru: UNESP. Novembro 2006.

MELO, L. F. Sensores de temperatura: Termopares. 2010. Notas de aula Universidade Estadual de Londrina, Londrina.

NATIONAL INSTITUTE OF STANDARDS AND TECHNOLOGY. Tables of Thermoelectric Voltages and Coefficients for Download. NIST ITS-90 Thermocouple Database, 2008. Disponivel em: https://srdata.nist.gov/its90/download/all.tab. Acesso em: 07 out. 2019.

NAYAK, R.; KUMAR, A.; MISHRA, A. Furnace Temperature Control \& Calibration of Thermocouple Using Digital Temperature Controller. Industrial Engineering Letters, v. 2, n. 6, p. 16-24, 2012.

NORTON, R. L. Cinemática e dinâmica dos mecanismos. Porto Alegre: AMGH, 2010. $812 \mathrm{p}$.

OGATA, K. Modern Control Engineering. 5th. ed. New Jersey: Pearson, 2010.

OMEGA ENGINEERING. Thermocouple types. Resources, Norwalk, 2019.

Disponivel em: https://www.omega.com/en-us/resources/thermocouple-types.

Acesso em: 07 out. 2019.

OPPENHEIM, A. V.; WILLSKY, A. S.; NAWAB, S. H. Sinais e sistemas. 2ª ed. São Paulo: Pearson Prentice Hall, 2010.

POWELL, J. M. LVDT's. Mike's Flight Deck, 2013. Disponivel em:

http://www.mikesflightdeck.com/lvdts/lvdts.html. Acesso em: 24 abr. 2018.

REIS, D. A. P. Efeito do recobrimento cerâmico e da atmosfera de ensaio na fluência de liga metálica refratária de titânio. 2005. 199 f. Teste (Doutorado em Engenharia e Tecnologia Espaciais) - Instituto Nacional de Pesquisas Espaciais, São José dos Campos.

SCANDELARI, L. Filtros Digitais. Introdução a Filtros Digitais e Filtros Medianos, 2013. Disponivel em: http://paginapessoal.utfpr.edu.br/scandelari/laboratorio-depds/Filtros_digitais_1.pdf/view. Acesso em: 12 mai. 2019. 
SPONG, M. W.; HUTCHINSON, S.; VIDYASAGAR, M. Robot Modeling and Control. 1st. ed. [S.I.]: John Wiley \& Sons, 2006.

TEIXEIRA, B. O. S.; JOTA, F. G. Modelagem, controle e otimização do processo dos fornos de reaquecimento de placas. Controle \& Automação, v. 18, p. 67-93, 2007.

TICIANELLI, É. A.; GONZALEZ, E. R. Eletroquímica: princípios e aplicações. São Paulo: EDUSP, 1998. 224 p.

TOCCI, R. J.; WIDMER, N. S.; MOSS, G. L. Sistemas digitais: princípios e aplicações. 11a․ ed. São Paulo: Pearson Prentice Hall, 2011.

UNITED STATES ARMY TEST AND EVALUATION COMMAND. MTP 5-2-599: Creep Test Procedures. 1968. 22 f. National Technical Information Service, Washington.

XIE, X.-L.; LONG, Z. Fuzzy PID Temperature Control System Design Based on Single Chip Microcomputer. Online Engineering Innovations based on Intelligent Information Processing, 11, n. 8, 2015. 29-33.

ZIEGLER, J. G.; NICHOLS, N. B. Optimum settings for automatic controllers. Transactions of the ASME, 1942. 759-768. 
INSTITUTO DE PESQUISAS ENERGÉTICAS E NUCLEARES

Diretoria de Pesquisa, Desenvolvimento e Ensino

Av. Prof. Lineu Prestes, 2242 - Cidade Universitária CEP: 05508-000 Fone/Fax(0XX11) 3133-8908

SÃO PAULO - São Paulo - Brasil

http://www.ipen.br

O IPEN é uma Autarquia vinculada à Secretaria de Desenvolvimento, associada à Universidade de São Paulo e gerida técnica e administrativamente pela Comissão Nacional de Energia Nuclear, órgão do

Ministério da Ciência, Tecnologia, Inovações e Comunicações. 